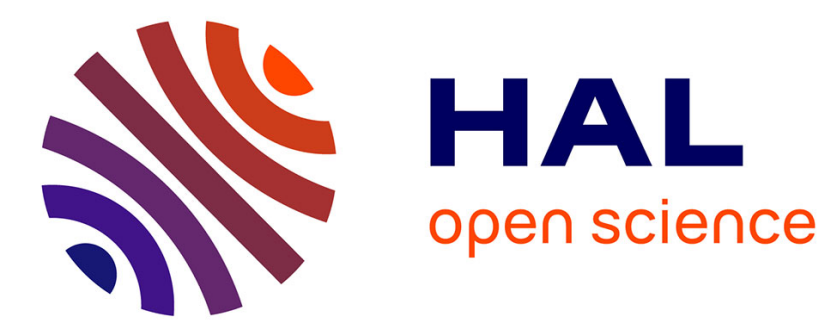

\title{
Self-foaming polymers: Opportunities for the next generation of personal protective equipment
}

Florent Monie, Thomas Vidil, Bruno Grignard, Henri Cramail, Christophe Detrembleur

\section{- To cite this version:}

Florent Monie, Thomas Vidil, Bruno Grignard, Henri Cramail, Christophe Detrembleur. Self-foaming polymers: Opportunities for the next generation of personal protective equipment. Materials Science and Engineering: R: Reports, 2021, 145, pp.100628. 10.1016/j.mser.2021.100628 . hal-03454352

\section{HAL Id: hal-03454352 \\ https://hal.science/hal-03454352}

Submitted on 29 Nov 2021

HAL is a multi-disciplinary open access archive for the deposit and dissemination of scientific research documents, whether they are published or not. The documents may come from teaching and research institutions in France or abroad, or from public or private research centers.
L'archive ouverte pluridisciplinaire HAL, est destinée au dépôt et à la diffusion de documents scientifiques de niveau recherche, publiés ou non, émanant des établissements d'enseignement et de recherche français ou étrangers, des laboratoires publics ou privés.

\section{(1)(1) 8 (2)}

Distributed under a Creative Commons Attribution - NonCommercial - ShareAlikel 4.0 


\title{
Self-foaming polymers: opportunities for the next generation of Personal Protective Equipment
}

\author{
Florent Monie $^{\mathrm{a} \dagger}$, Thomas Vidil ${ }^{\mathrm{b}{ }^{*}}$, Bruno Grignard ${ }^{\mathrm{a}}$, Henri Cramail ${ }^{\mathrm{b}}$, Christophe \\ Detrembleur $^{\mathrm{a}^{*}}$
}

${ }^{\text {a }}$ Center for Education and Research on Macromolecules (CERM), CESAM Research Unit, University of Liège, Department of Chemistry, Sart-Tilman, B6A, 4000, Liège, Belgium ${ }^{\mathrm{b}}$ University Bordeaux, CNRS, Bordeaux INP, LCPO, UMR 5629, F-33600, Pessac, France $\dagger$ These authors have equally contributed to the work.

\section{Thermolysis}

- Carbamic acid derivatives

- Carbonates

- Esters

- Carboxylic acids

- Meldrum's acids

- Nadimides

$\checkmark$ Water/air filtration

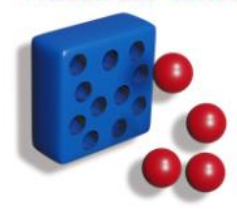

$\checkmark$ Electromagnetic interference shielding

$\checkmark$ Thermal or sound insulation

\section{Electric discharge protection}

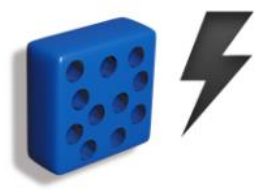

\section{Self-foaming Polymers}
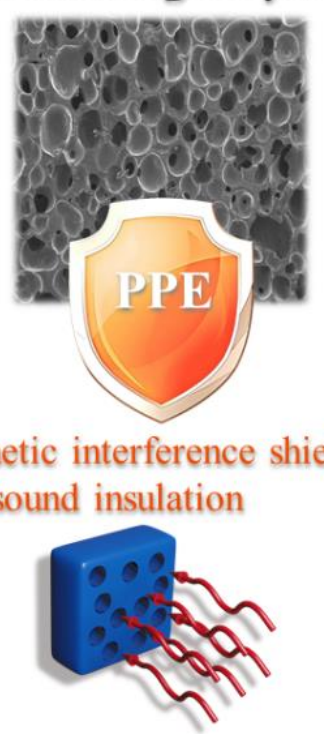

\section{Condensation}

- Phenol-formaldehyde

- Carboxylic acids-alcohols

- Imine formation

- Poly-(amid acid) and -(amid ester)

- Siloxane/silazane-amine

- Cyclic carbonates

Shock absorption

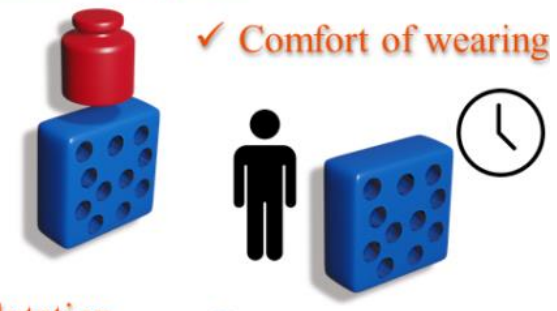

Flotation

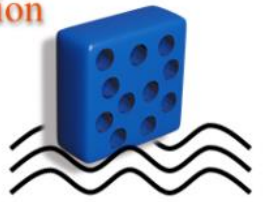




\section{Abstract}

Polymeric foams merge the intrinsic lightness of porous materials with low thermal and electrical conductivity as well as good energy adsorption capabilities and filtration abilities, depending on their morphology. Such combinations explain their widespread use in many applications, including in the domain of personal protective equipment (PPE). Indeed, foams are the materials of choice to fulfill a series of essential protective functions, including: (i) insulation, (ii) dissipation, (iii) adsorption, (iv) filtration, (v) flotation and, of course, (vi) cushioning. Historically, foams were developed by iterative formulation works aiming at nucleating and stabilizing bubbles of gas in a polymer matrix. The foaming of polyurethanes is among the earliest - and today most mature - methodologies. Indeed, polyurethanes are obtained from isocyanate precursors that have the ability to partially decompose in gaseous $\mathrm{CO}_{2}$ in the presence of water. The gas, also referred to as the blowing agent (BA), is released concomitantly with the polymerization reaction to initiate the expansion of the growing polymer. Because the BA is primarily embedded in the molecular structure of the precursors of the polymer, this system is usually labelled as self-foaming. With the growing health and environmental awareness regarding the toxicity of isocyanates, a burgeoning number of selffoaming polymers and their precursors that circumvent the use of isocyanates are reported in the literature. They combine an interesting range of assets - from the typical ease of use of onepack systems to the relative innocuity of their blowing gas (e.g., $\mathrm{CO}_{2}, \mathrm{H}_{2} \mathrm{O}$, halogen-free alkanes) - that are very well suited to the large-scale production of foams in compliance with strict safety and environmental specifications.

In this context, the present review is showcasing both historical and emerging self-foaming (pre)polymers that represent opportunities for the production of the next generation of safer and environmentally benign PPE. A special attention is dedicated to the self-foaming mechanisms - i.e., the chemical transformations of the (pre)polymers that result in the release of the blowing agent - and its interplay with the physicochemical processes resulting in the hardening of the (pre)polymers (e.g., sol-gel or rubber-glass transitions). A classification of those mechanisms - (i) thermolysis and (ii) condensation - is proposed for the first time. The properties of the resulting foams are also briefly discussed in terms of densities, cell morphology and mechanical response with the intention to guide the reader in selecting the best foaming process for the targeted polymer matrix and with a special emphasize on the PPE application domains.

Keywords: self-foaming; polymer foams; polyimide; polyurethane; polybenzoxazine; polyester 


\section{Table of content}

ABSTRACT …….....................................................................................................................................................................2

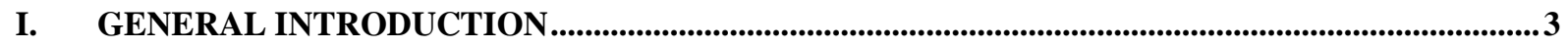

II. FOAMING VERSUS SELF-FOAMING ........................................................................................6

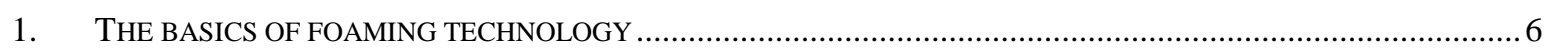

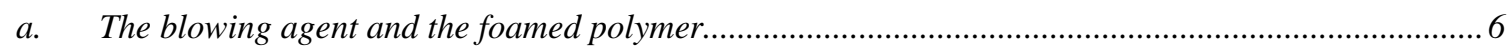

b. Chronology of a foaming process - The foaming window …………………................................. 8

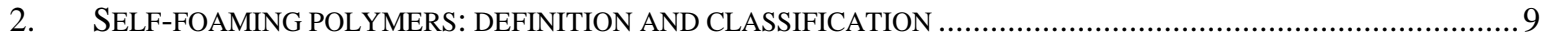

III. SELF-FOAMING POLYMERS BY THERMOLYSIS......................................................................10

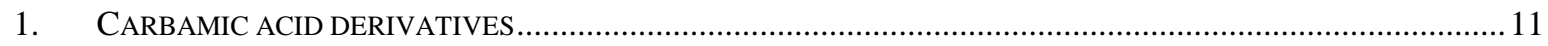

a. Thermal degradation of in-situ generated carbamic acid derivatives ..............................................11

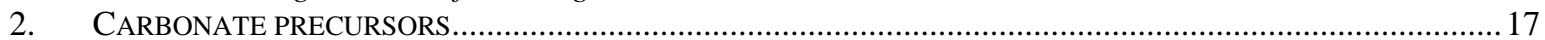

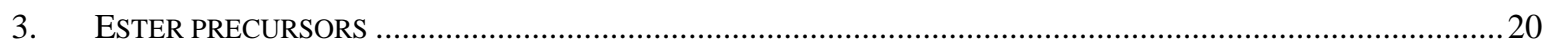

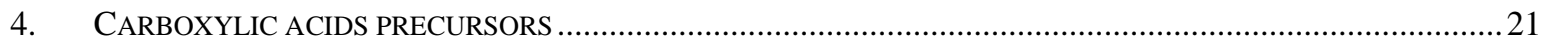

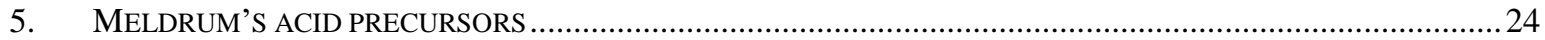

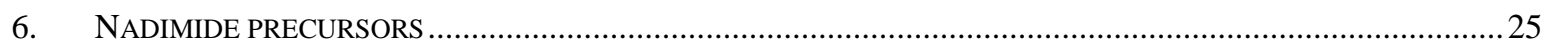

IV. SELF-FOAMING POLYMERS OBTAINED VIA CONDENSATION AND

POLYCONDENSATION REACTIONS............................................................................................................26

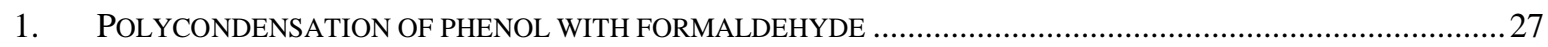

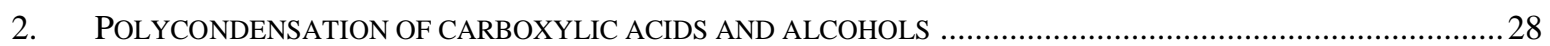

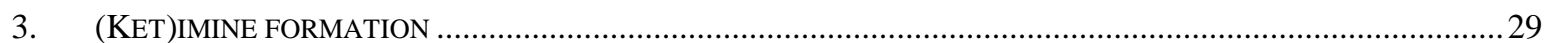

4. INTRAMOLECULAR CONDENSATION OF POLY(AMIDE ACID)S AND POLY(AMIDE ESTER)S .......................30

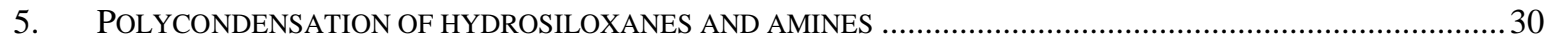

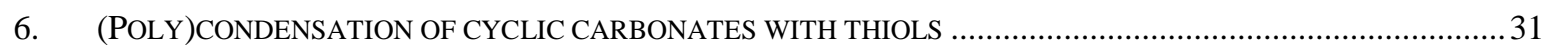

V. DISCUSSION, CONCLUSION AND PERSPECTIVES ................................................................................32

VI. REFERENCES................................................................................................................................................... 40

\section{General introduction}

Polymeric foams are obtained by nucleation of bubbles of gas - also referred as cells or cavities - in a polymer melt or a mixture of monomers, followed by a phase transition that stabilizes the resulting porous structure, e.g. rubber-glass or sol-gel transition, to give a $3 \mathrm{D}$ expanded material. The resulting material combines two phases that are both recognize for their intrinsic lightness, low thermal and electrical conductivity as well as good energy adsorption capabilities.[1-4] The polymeric phase ensures the mechanical strength of the material while the gaseous phase guarantees the exceptional lightness and low conductivity. At equal strength to weight ratio, there is no other material that can compete with the properties of polymeric foams. For all these reasons, they are now irreplaceable in a wide range of applications including packaging, electronics, transportation, furnishing, clothing, aerospace, or construction materials.[1,4] Among this broad scope of applications, the recent outbreak of COVID19 sheds light on the important role of polymeric foams in the application domain of personal protective equipment (PPE).[5] Many masks, respirators and visors used since the beginning of the pandemic comprise one or several foamed parts.[6-8] They usually fulfill breathing, filtration, sealing or protective functions.[9-12] For instance, the nose seal of several models of face mask is made of a closed cell foam[7]. Another example is the foam strip of face shields that ensures a tight adhesion to the forehead and guarantees wearing comfort.[13,14] In those examples, the foam is contributing to the improvement of the wearability of PPE, a decisive role to ensure the consistent use and thus, the efficacy of the 
equipment according to physicians.[15] As an indicator of the importance of PPE in the foam market, in a recent survey from Foam Expo Europe,[16] most foam producers are declaring new businesses dedicated to the development of components for medical devices - and in particular for PPE - in order to compensate the decreasing demand in other sectors affected by the economic crisis that comes along the pandemic.

Beyond the healthcare sectors and the ongoing sanitary crisis, polymeric foams are used in many other PPE. Foam earplugs, used as hearing protective device, are the prime example of mainstream PPE.[17,18] One can also mention the energy-absorbing foams used to prevent mechanical impact hazards in safety footwear and helmets.[19] Moreover, with the growing awareness about the impact of human activities on public health, the sector of PPE heads toward the latest innovations of material science. Original protecting devices using foams as key materials are described in the recent literature and represent new opportunities for the foam industry. For instance, melamine foams were recently used as a breathable support of metalorganic framework to develop new filters of particulate matter, the major source of air pollution.[20,21] These innovative materials will be increasingly needed to address what has become the most concerning environmental issue in developing countries. Composite foams are also used to develop lightweight electromagnetic interference (EMI) shielding materials.[22-27] With the raise of electromagnetic pollution resulting from the development of gigahertz electronic systems and telecommunication devices, these new materials will be part of the next generation of PPE.

The development of these novel advanced foamed materials coincides with the ongoing mutation of the foam industry. Indeed, a transition towards sustainable polymeric matrices (e.g., biosourced and non-toxic polymer precursors) and environmentally benign foaming methodologies (e.g., "non-ozone depleting" and "non-greenhouse" blowing gases) is under way. To date, the foam industry is largely dominated by polyurethane (PU) foams. They represent $50 \%$ of the annual global foam production.[1] One reason of their success is their convenient self-foaming (or self-blowing) ability. Indeed, PUs are made by polyaddition of dior polyols onto di- or polyisocyanates. The partial hydrolysis of the later during the polymerization reaction results in the formation of unstable carbamic acids, which spontaneously decomposes into an amine and carbon dioxide, $\mathrm{CO}_{2}$.[28] The amine reacts with additional isocyanate to give a urea, and the in-situ generated $\mathrm{CO}_{2}$ serves as the blowing agent (BA). These PU foams are considered "self-foamed" in the sense that the BA is held latent in the molecular structure of the polymer precursors. Thus, the BA can be referred as "endogenous" to the polymer precursors (Figure 1B). It is released concomitantly with the main polyaddition reaction, with no other residue. This unique ability allows very simple batch foaming processes and gives access to easy lab-scale development as well as industrial implementation.[29,30]

Unfortunately, isocyanates are toxic.[31,32] The health concerns and regulation changes associated with their use are forcing scientists and $R \& D$ researchers to prepare the future of the foaming industry by exploring novel routes to design isocyanate-free foams. Especially for healthcare sectors where the regulations are usually more drastic, as well as for all application domains implying a close contact of the foam with the end-user (like PPE).[33]

Other polymeric matrices are commonly used in the foam industry. Polyethylene, polystyrene, epoxy resin or rubbers are among representative examples.[1,4] However, none of them exhibit the same intrinsic foaming ability than PU foams. The growth of porous cells inside those matrices requires the use of external precursors of $\mathrm{BA}$, i.e., compounds that are distinct from the polymer precursors. They can be referred as "exogenous". In general, they are low boiling point liquid, like short alkanes (e.g., pentane) or halogeno-alkanes and -alkenes. They are directly mixed with the polymer precursors and evaporate when the temperature is increased to initiate the polymerization or the phase transition associated with the processing of the pre- 
formed polymer. The transformation experienced by these BA during the foaming process is a phase transition (liquid to gas). For this reason, they are usually designated as physical blowing agent (PBA). Historically, chlorofluorocarbons (CFCs) were extensively used as PBA because of their high chemical and thermal stability.[34] These ozone depleting substances are however responsible for the major environmental crises of the last century: the ozone hole.[35] The Montreal protocol (1987) has banned the use of CFCs[36] and the latter have been replaced by hydrofluorocarbons (HFCs) that do not harm the ozone layer as much as CFCs. With thousands of times the global warming potential of $\mathrm{CO}_{2}$, they will be gradually phased-out over the next 20 years by amendment of the Montreal protocol.[37,38]

Under the pressure of these new regulations, industrial and academic scientists are relentlessly looking for new versatile and ecofriendly blowing methods. $\mathrm{CO}_{2}$ turns out to be the most viable alternative because it is renewable, innocuous and cheap. It is now incorporated as a super- or subcritical fluid inside polymer melts, before a sudden pressure drop that initiates the growth of the bubbles.[39-42] In the field of PPE devices, it was for instance used for preparing EMI absorbing materials by foaming many polymer matrices loaded by conductive fillers (e.g. carbon nanotubes,[43-48] graphene[49-51]). It was also exploited for designing nonisocyanate polyurethanes (NIPUs) foams as promising alternatives to conventional PU foams for thermal insulation. [52] Despite the numerous advantages of this method used for foaming many polymer matrices, $[39,40,53,54]$ it does require intricate equipment to maintain $\mathrm{CO}_{2-}$ polymer melt under pressure. Moreover, the method is hardly transferrable to crosslinked polymers, i.e., thermosetting polymers. The same issues are encountered for the use of pressurized $\mathrm{N}_{2}$.

Other alternatives to harmful or unstable PBA are solid compounds that can be dispersed in the polymeric matrix under ambient conditions and that decompose upon heating to release a gas. Because the process behind the release of the blowing gas is a chemical reaction, these BA are referred as chemical blowing agent (CBA).[3] Like PBA, they are distinct from the polymer precursors and are thus considered as exogenous BA (Figure 1A). Advantageously, their use does not require any complex equipment and their thermal latency is predictable and well controlled. Typical examples include azodicarbonamide or mineral carbonates. For instance, Altuna et al. recently used sodium bicarbonate to blow biobased thermosetting epoxy foams cured with anhydrides.[55] The thermal decomposition of sodium bicarbonate yields $\mathrm{CO}_{2}$, water and sodium carbonate. Other CBA, like azodicarbonamide, are toxic and decompose into dangerous gases, like carbon monoxide or ammonia.

With no system - neither PBA, nor exogenous CBA - being able to compete with the versatility and simplicity of isocyanate-based formulations, researchers are looking for solutions that could mimic self-blowing PUs, while circumventing the toxicity of isocyanates, and be implemented to various polymer matrices. Over the last decades, a limited but growing number of works were dedicated to the development of self-blowing systems that would obey the following points: $(i) \mathrm{BA}$ is held latent inside the molecular structure of polymer precursors, $(\mathrm{ii})$ the blowing gas released during BA's decomposition is ideally environmentally benign, and (iii) no chemical residue (i.e., unanchored byproduct) is remaining inside the final polymer matrix. In order to respect those principles, authors are ingeniously revisiting basic concepts of organic chemistry, including selective decarboxylation, condensation reactions or sacrificial protecting groups. Methodologies were first proposed for isocyanate-free commodity polymers, such as epoxy resins[56] or high- $T_{g}$ phenolic resins.[57] In a recent example, Monie et al. introduced a process for the simple construction of self-blown PUs obtained from isocyanatefree precursors. $[58,59]$ This system that will be discussed later can operate with an impressive range of innocuous and readily accessible precursors, offering materials that have the potential to compete with the broad diversity of existing isocyanate-based PU foams. This tour de force, together with other precedents of the literature, demonstrates that realistic self-blowing 
alternatives to the traditional isocyanate route are no longer a distant dream. Advantageously, many of these new systems can be used for the synthesis of advanced foamed materials and with a high degree of safety for the end-user. They are promising for the production of the next generation of PPE, in accordance with the latest regulations for health and environment, although most of these processes have still to be improved for large scale production.

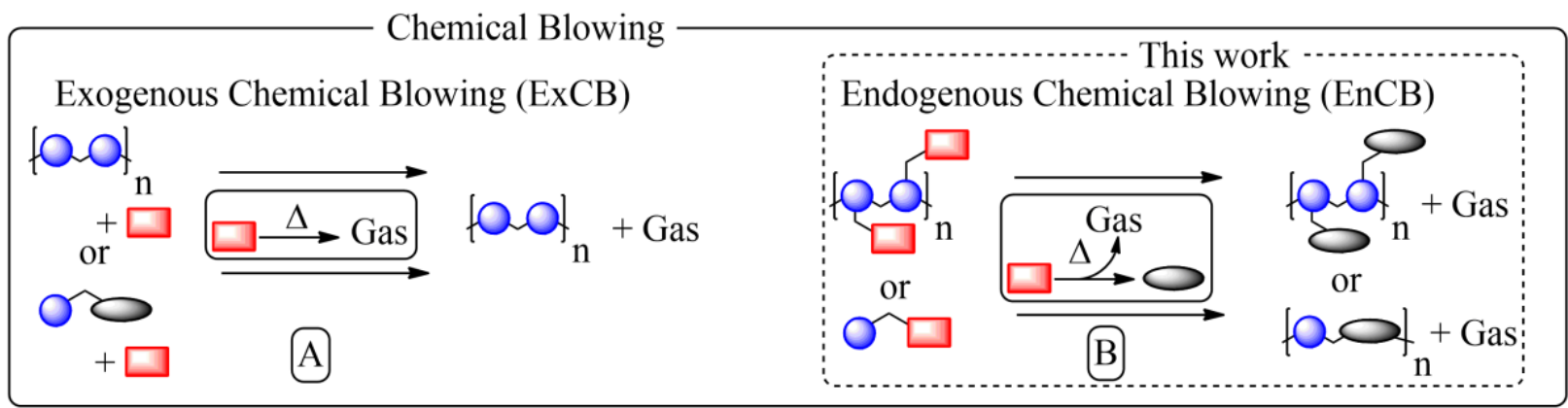

Figure 1: Comparison between exogenous $(A)$ and endogenous $(B)$ chemical blowing.

The aim of this paper is to review for the first time the current state of the art of self-foaming polymers. Foaming processes using exogeneous BA are out of scope of this review and interested readers are directed to recent reviews in the field. [3,4,60] After a brief reminder of the fundamentals of the foaming technology, self-blowing polymers are discussed based on the mechanism responsible for the formation of the blowing agent. For sake of consistency, we will not detail all works done in the field, however we have selected some of the most relevant examples illustrating the main concepts and reactions involved for constructing the foams. In the last section of this review, we critically discuss pros and cons of the self-foaming polymers, as well as their potential exploitation for designing the next generation of PPEs. We also draw some trends whenever possible with the intention to guide the reader in selecting the best foaming process for the target polymer matrix or application.

\section{Foaming versus Self-Foaming}

\section{The basics of foaming technology}

In this section, the fundamentals of foaming polymers are addressed in order to understand some of the main constraints associated to the different foaming approaches that will be exposed later. Other concepts such as homogeneous and heterogeneous nucleations, cells growth, foams stabilization, etc. are however not discussed in order to focus the review to the chemistry involved for the foam formation, rather than its physics. The reader is however invited to read excellent reviews discussing the physics behind foaming.[40,61-63]

\section{a. The blowing agent and the foamed polymer}

Conventionally, a foaming process involves two protagonists: $(i)$ the blowing agent and (ii) the polymer or the precursors of the polymer.[4] Blowing agents are classified in two families: $(a)$ the physical blowing agents (PBA) and (b) the chemical blowing agents (CBA).[3] PBA $(a)$ are liquids or gases that are dissolved in the polymer matrix. They form the gaseous cellular phase by experiencing a phase transition, either by vaporization in the case of liquid PBA or by a sudden desorption resulting from a pressure drop in the case of gaseous PBA. CBA $(b)$ are usually solids that are dissolved or dispersed inside the polymeric matrix. They produce gas by thermal decomposition. The formation of the gaseous cellular phase can be instantaneous after the decomposition of the CBA, or it can be delayed as a function of the gas solubility in the 
polymer matrix. If this latter is high, a temperature increase and/or a pressure drop might be necessary to reach the supersaturation state and trigger the nucleation and the growth of the cavities. It is worth noting that, when considering CBA, the actual blowing agent is the gas produced by thermal decomposition of the solid CBA. By extension, the solid precursor is also called "blowing agent". During the foaming process, both PBA and CBA undergo a transformation resulting in an abrupt change of volume and an increase of the global entropy.

The foamed polymers, also called the polymer matrices, are classified in two families as well: (i) thermoplastic polymers[64] and (ii) thermosetting polymers.[65] These are the traditional families discerned in polymer science, independently of the foaming technology context. This distinction is of utmost pertinence when considering the foaming strategy to adopt and the endapplication of the foam.

Thermoplastic polymers are amorphous or semicrystalline polymers constituted of large macromolecules associated through intermolecular connections such as entanglements, hydrogen bonds and glassy domains. They are soluble in good solvent and they can reversibly undergo a transition from an elastic solid to a low viscosity melt. When heated above their glass transition temperature, $T_{g}$, they behave as a viscous liquid. In this state, they may be easily processed and reshaped. They harden in the form of an elastic solid upon cooling down the $T_{g}$. In the foam industry, their processes do not involve any polymerization reaction. The polymers are used as received, in the form of pellet of well-formed macromolecules.[66] The growth of the cellular porous structure is initiated when the polymer is behaved as a viscous liquid, i.e., when $\mathrm{T}>T_{g}$.

Thermosetting polymers are 3D-crosslinked network - theoretically a single giant macromolecule - that are obtained by reacting polyfunctional precursors, either small molecules or prepolymers, in the course of a polymerization reaction, also known as a crosslinking reaction. During the crosslinking reaction, the reactive system undergoes a sol-gel transition, i.e., a transition from a low viscosity solution of precursors to a crosslinked elastic solid, also called a gel.[67] This transition involves a gradual increase of the viscosity. It is irreversible. Once the gel is formed it will not relax stresses anymore, except if reprocessing/dynamic networks are involved.[68-70] The shape of the polymer is set and cannot be changed anymore. In the foam industry, their processes usually involve the solution of precursors that is crosslinked during the growth of the cellular porous structure.[71]

The end-properties of thermoplastic and thermosetting foams are also very different due to their distinctive molecular structure. The solubility of thermoplastic polymers and the reversibility of their hardening transition (i.e. glass transition) limit their use to applications involving mild conditions. They cannot be used at temperatures close to $T_{g}$ where they soften.[72] This would result in the general collapsing of the porous structure. On the other hand, they are very suited when considering the possibility to recycle the foam.[73] Thermosetting foams exhibit superior thermal and solvent resistance thanks to their covalent crosslinks.[74,75] Their porous structure can be preserved even after long exposure to harsh conditions such as high temperature and swelling in good solvent.[76] Contrarily to thermoplastic, they cannot be reprocessed, and their recycling is much more complicated.[77,78]

In the context of PPE applications, both families are relevant. Indeed, the choice between a thermoplastic or a thermosetting foam is very dependent on the hazard associated to the use of the PPE. When considering a protective equipment against heat exposure, it is of course preferable to use a thermosetting foam. However, when considering the nose seal of a disposable mask, a thermoplastic foam might be more adapted to anticipate the recycling of the foam after use. 


\section{b. Chronology of a foaming process - The foaming window}

Depending on both, the polymer - thermoplastic or thermosetting - and the blowing agent, the fabrication of a foam can proceed via very different processes - extrusion, pressure vessel, etc. - under various conditions of temperature and pressure - T, P. However, the same steps are always involved:

1- The blend of the blowing agent and the thermoplastic polymer, or the precursors of the thermosetting polymer, in a temperature and a pressure window $-\mathrm{T}_{\mathrm{mix}}, \mathrm{P}_{\mathrm{mix}}-$ where the viscosity of the system, $\eta$, is adapted to the mixing process, and the blowing agent is stable.

2- The blowing step resulting from the decomposition and/or vaporization of the blowing agent, triggered by applying new temperature and pressure conditions $-\mathrm{T}_{\text {blow }}, \mathrm{P}_{\text {blow }}-$ allowing to reach the supersaturation state, i.e. the limit of the generated gas solubility in the polymer, which causes the nucleation phenomenon. These new conditions are also coinciding with the viscosification of the polymeric phase, i.e. crosslinking of the thermoset or glass transition of the thermoplastic. $\eta$ must be adapted to the nucleation and the growth of the bubbles.

3- The stabilization of the porous structure via the hardening of the polymeric phase vitrification in the case of a thermoplastic and gelation in the case of a thermosetting polymer - triggered by specific temperature and pressure conditions $-\mathrm{T}_{\text {stab }}, \mathrm{P}_{\text {stab }}$.

The chronology of these three stages - blend, blowing, stabilization - is decisive to ensure the success of the foaming process. A critical point is the synchronization of the decomposition and/or vaporization of the blowing agent with the initiation of the viscosification of the polymer material.[56,71,79-90] It is indeed essential that the bubbles nucleate and grow in a certain viscosity window sometimes called the viscosity foaming window.[71,80] If the gas is released before the viscosity enter the foaming window, it will quickly diffuse through the polymer. The cavities will not grow, or they will collapse before stabilization.[86] If the gas is released once the viscosity exceeds the foaming window, no nucleation will occur due to the large elastic modulus of the polymer matrix that completely precludes any deformation.[89-91] No cavities will be formed.

In order to improve the foaming ability of a polymer-BA system, diverse additives can be added in various amounts to the formulation to facilitate nucleation and growth of the cavities.[92] The most widespread are heterogeneous nucleating agents, e.g. clays or carbon particles, and surfactants, e.g. siloxane or ethylene oxide oligomers. Nucleating agents will make the nucleation phenomenon more entropically favorable, allowing gas nucleus to appear homogeneously in the polymer volume.[93,94] Higher nucleation rate and lower critical nucleus radius usually lead to narrower cells-size distribution in the final material. However, it highly depends on the homogeneous dispersion of the nucleating agent in the polymer, as gas nuclei will appear at the surface of the heterogeneous particles. The surfactants are used to lower the surface tension around the gas nucleus, thus facilitating its growth in the viscous matrix. By facilitating the nuclei appearance and growth, these additives can provide foams with lower densities and better mechanical properties than additives-free analogues. Other additives can be added on foam formulation, e.g. to tune the decomposition temperature of the CBA. They will strongly depend on the chosen blowing system, i.e. polymer matrix to expand and the blowing method. 


\section{Self-foaming polymers: definition and classification}

Various systems defined in this review as "self-foaming" exist since decades (e.g. phenolic resins, polyurethanes, polyesters). However, the criteria to consider a polymer foam as "selffoamed" has never been clearly established.

In the frame of this review, self-foaming polymers are defined as expandable systems for which the blowing agent is embedded in the molecular structure of the macromolecules - or the precursors of the macromolecules. The latter become both the foamed material and the chemical blowing agent. There are no exogenous chemicals involved in the foaming process. In other words, the blowing agent is held latent by being covalently attached to the polymer, or the precursors of the polymer. It is released when the polymer is processed (e.g. extrusion of a thermoplastic polymer) or when the reaction of the precursors of the polymer is initiated (e.g. crosslinking of a thermosetting polymer). It is notew orthy that "self-blowing" or "self-foaming" have been used by others to name systems that are out of the scope of this review. For instance, systems where the phase transition of a physical blowing agent is initiated by the exotherm of the polymerization reaction.[95-97] To our viewpoint, they are just example of exogeneous physical foaming.

Self-foaming polymers can be classified into two main classes depending on their production mode as illustrated in Figure 2 and discussed below:
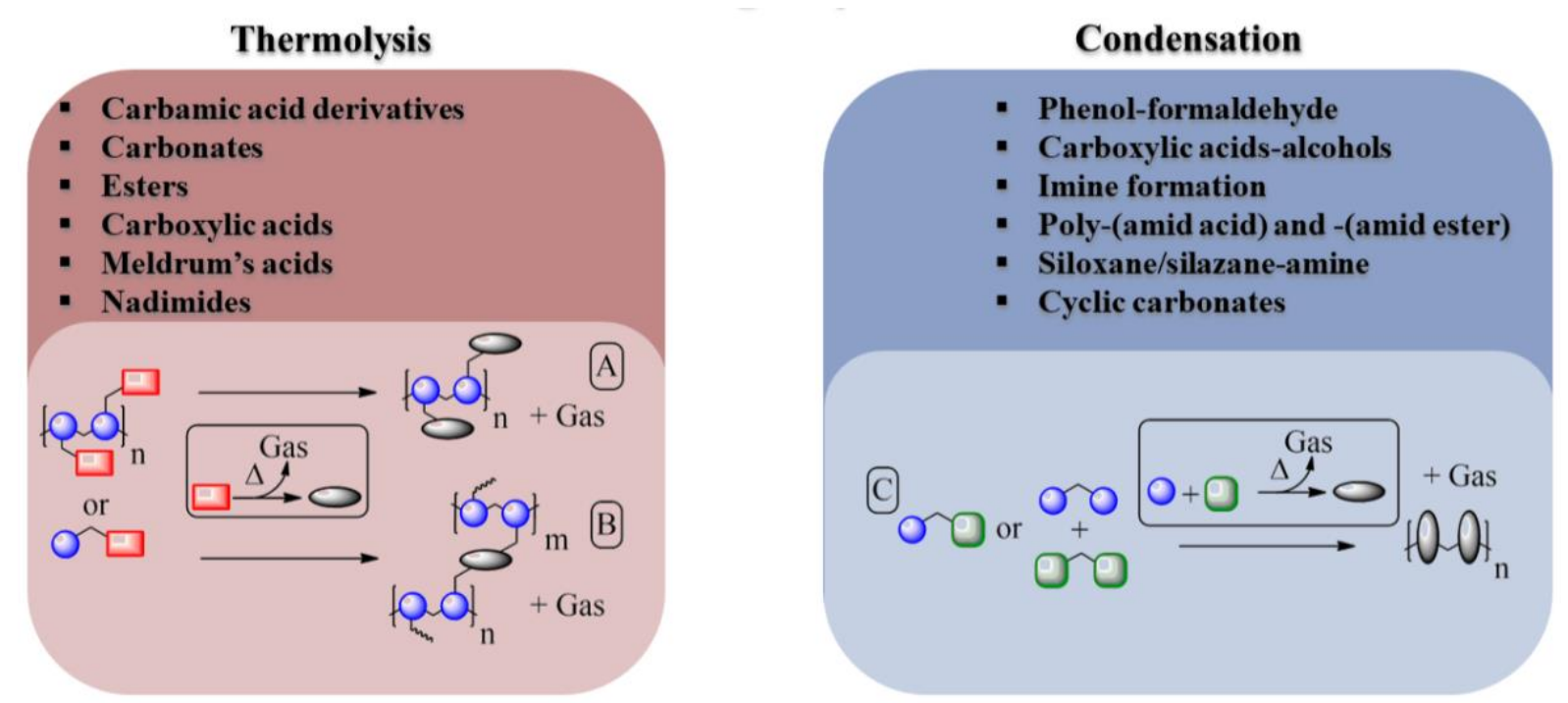

Figure 2: Classification of self-foaming polymers based on their production mode.

(i) Self-foaming polymers by thermolysis (Figure 2A,B)

They concern polymers or precursors of polymers bearing thermolabile groups. Their decomposition into small molecules (e.g. $\mathrm{CO}_{2}$, isobutene, $\mathrm{H}_{2} \mathrm{O}$, acetone) is thermally initiated and programmed to occur within the viscosity foaming window of the polymer. Interestingly, the formation of the blowing agent generates new functional groups anchored to the polymer chain. Two subfamilies can be discerned depending on the role played by these chemical functions :

(i.a) The chemical function is inert, i.e., unreactive (Figure 2A). In that case, the only role played by the thermolabile group is to release the blowing agent. Interestingly, the separation of the blowing agent from the thermoplastic or the growing 3D network, usually results in an increase of the $T_{g}$ of the polymer.[98] After the gas nucleation, the transition of the polymer from rubber to glass, and thus the stabilization of the porous structure, is triggered by the $T_{g}$ increase. 
(i.b) The chemical function is reactive and further contributes to a crosslinking reaction (Figure 2B). In other words, two moieties are held latent in the thermolabile groups: the blowing agent and the precursors of the crosslinking points of the thermosetting polymer. Advantageously, the in-situ release of the blowing agent and the sol-gel transition of the thermosetting polymer are programmed to take place simultaneously. The thermal latency of the curing reaction and the blowing process are synchronized, enabling the efficient stabilization of the porous structure.

(ii) Self-foaming polymers obtained via condensation and polycondensation.

In these self-foaming systems, the blowing agent is the small molecule (e.g. water, methanol, acetic acid, etc.) generated during the construction of the polymer by the condensation of two complementary functional groups of the polymers or their precursors (Figure 2C).[99,100] Thermosetting polymers obtained through polycondensation reactions are representative examples. Advantageously, in this case, the formation of the polymer network and the in-situ release of the blowing agent are concomitant. However, different scenarios can be discriminated depending on the role played by the condensation in the formation of the polymer:

(ii.a) The condensation can be the main polymerization reaction responsible for the formation of the polymer network (case of a classical polycondensation).

(ii.b) The condensation can be a side reaction that proceeds along the main polymerization reaction, and does participate in the formation of the polymer network.

(ii.c) The condensation can be a side reaction that does not contribute to the formation of the polymer network.

In the following sections, we depict the main trends in historical and emerging self-blowing polymers in the recent literature, emphasizing the motivations for their use in the scope of personal protection.

\section{Self-foaming polymers by thermolysis}

Herein, we describe the most relevant self-blowing polymer strategies by thermolysis and discuss their use or potential for PPE applications. Figure 3 illustrates the main blowing approaches resulting in the heat-induced release of volatiles by degradation of various chemical functions anchored to polymers or precursors of polymers. They are classified by the type of chemical group used as blowing agent precursor. 


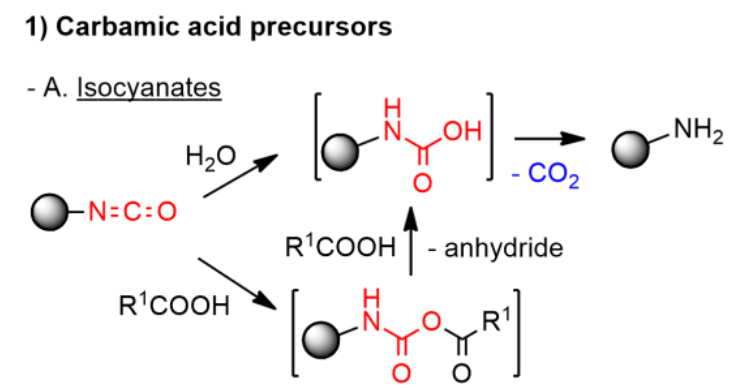

red: precursor of the blowing agent blue: blowing agent

: polymer or its precursor

- B. Covalent carbamates

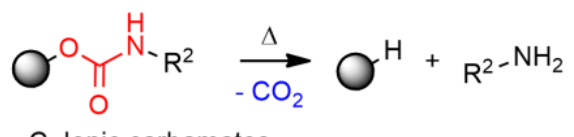

- C. lonic carbamates

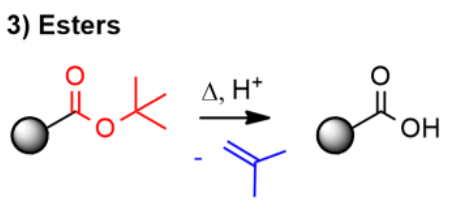

4) Carboxylic acids

$\mathrm{Q}_{\mathrm{H}}^{\stackrel{\mathrm{N}}{\mathrm{H}} \ominus} \underset{-\mathrm{CO}_{2}}{\stackrel{\Delta}{\longrightarrow}} \mathrm{Q}_{\mathrm{NH}_{2}}$

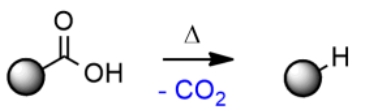

5) Meldrum's acid

2) Carbonates
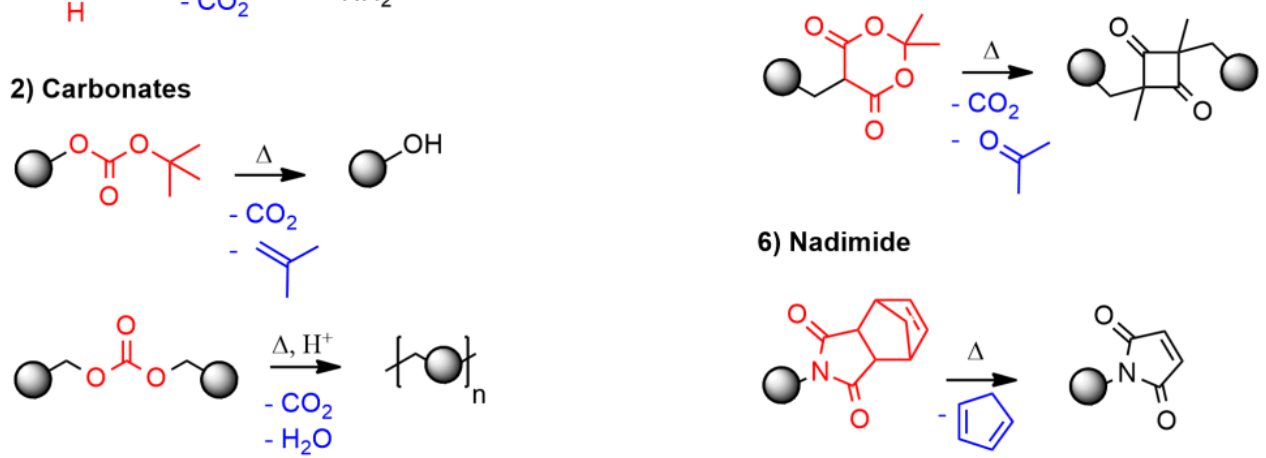

6) Nadimide

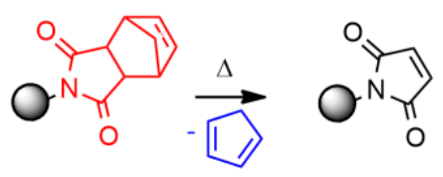

Figure 3: Main thermolabile groups and reactions involved in self-foaming polymers.

\section{Carbamic acid derivatives}

Carbamic acid and its derivatives (e.g., carbamates, carbamic anhydrides) are known for their ability to decompose thermally into an amine and $\mathrm{CO}_{2}$ (with an additional residue for carbamates and carbamic anhydrides). They are probably the most used thermolabile chemical functions in self-foaming technologies. Indeed, the self-foaming ability of isocyanate-based polyurethane formulations - the most commonly used self-foaming polymers - relies on the insitu formation of unstable carbamic acids by reaction of water with isocyanate functions, that subsequently decompose into $\mathrm{CO}_{2}$, the blowing agent, and an amine, the latter contributing to the growth of the polymer network.[101] Other self-foaming polymers using carbamic acid derivatives as $\mathrm{CO}_{2}$ generators have been described in the literature. Below, they are classified in two categories: (i) self-foaming polymers based on the thermal degradation of carbamic acids generated in-situ by reaction of isocyanate with a nucleophile (Figure 3A), and (ii) self-foaming polymers based on the thermal degradation of latent carbamic acids, i.e. carbamates (Figure 3B,C).

\section{a. Thermal degradation of in-situ generated carbamic acid derivatives}

\section{Formation of carbamic acid by reaction of isocyanates with water}

The polyaddition of polyisocyanates to polyols in the presence of water is historically a milestone in polyurethanes foams (PUF) preparation (Figure 4). In 2020, the PU-foam market was worth 37.8 billion USD [102] attesting for the importance of this production pathway. In this process, the isocyanate/alcohol reaction provides the urethane skeleton whereas the hydrolysis of isocyanates yields the carbamic acid that rapidly decomposes with the formation 
of an amine and $\mathrm{CO}_{2}$. The amine resulting from the carbamic acid degradation further reacts with isocyanates and contributes to the construction of the polymer network with the formation of urea linkages. PU materials which comprise significant amount of urea bonds are often referred to as poly(urethane-urea) (PUUR).[103,104]

The impressive diversity of accessible polyols at low cost, associated to various commercially available isocyanates, allow preparing PUFs of various properties, from flexible to rigid foams that meet the requirements for the target product. This is certainly the most mature and versatile technology for the preparation of self-foaming polymers.[92] Authors have reported comprehensive characterization of flexible and rigid foams obtained using conventional isocyanate precursors. Seo et al. have studied the effect of the initial water content on the mechanical, morphological, and thermal properties of rigid polyurethane foams prepared from polyisocyanates based on 4,4'-diphenylmethane diisocyanate (MDI) and polyether polyol.[105] Interestingly, the PUF density decreased from 173 to $40 \mathrm{~kg} \mathrm{~m}^{-3}$ by increasing the initial amount of distilled water from 0.5 to 3.0 parts per hundred polyol by weight (pphp), respectively, consequently increasing the cell size from 115 to $258 \mu \mathrm{m}$. In the meantime, the glass-transition temperatures were increased from 50 to $80{ }^{\circ} \mathrm{C}$ due to the increased fraction of urea linkages in the polymer matrix that reduced the overall chain mobility in the final network. Similarly, Gwon et al. reported a detailed study of flexible PUF obtained by reacting a mixture of oligomerized 4,4'-diphenylmethane diisocyanate (pMDI) and toluene diisocyanate (TDI) 75\% pMDI, 25\% TDI - with a glycerol based polyether polyol.[106] In that case, the density of the PUF can vary from 400 to $150 \mathrm{~kg} \mathrm{~m}^{-3}$ by increasing the initial amount of distilled water from 0.3 to $1.0 \mathrm{pphp}$. Interestingly, the authors demonstrated that catalysts specific to the alcohol-isocyanate reaction and to the water-isocyanate reaction - 1,4Diazabicyclo[2.2.2] octane (DABCO) and bis(2-dimethylaminoethyl) ether (BDMAE), respectively - can modulate the relative kinetics of the two reactions and, in return, the properties of the resulting foam. For instance, by increasing the catalyst ratio, [BDMAE]/[DABCO], from 0 to 1.2, the foam density can be decreased from 320 to $220 \mathrm{~kg} \mathrm{~m}^{-}$ ${ }^{3}$ (at constant water content, $0.5 \mathrm{pphp}$ ). This result illustrates the impact of an earlier release of the blowing gas in the foaming window of the thermosetting polymers.

It is however noteworthy that, despite the evident adaptability of self-blown PUF, physical blowing agents are also extensively used to obtain PUF. In particular, the use of low-boiling point chlorofluorocarbons (CFCs) has been preferred to water initiated self-blowing for a long time due to the lower thermal conductivity of CFCs as compared to $\mathrm{CO}_{2}$.[107] Moreover, $\mathrm{CO}_{2}$ is known for its high diffusivity through the cells walls that results in pressure drop and ultimately in dimensional instability of the foams.[108,109] With the hazardous environmental effects of CFCs (ozone depletion), and of the substitutes that have been proposed after the Montreal protocol (hydrofluorocarbon, HFC), there have been a regain of interest for waterblown PUFs over the past decades.[109] In particular, recent studies have investigated the possibility to improve their dimensional stability by using appropriate additives.[108] Moreover, a growing number of references are dedicated to self-blown "green" PUF, using biobased precursors of PU.[110,111] We recommend a recently published exhaustive and excellent review on the topic for more details.[92] In this context, there are new opportunities for the development of environmentally friendly and highly performant PUF in replacement of the foamy parts of PPE that are still based on physical blowing methods and petro-based precursors. In the case of PPE applications, PUFs are leaders with many products on the market,[1,112,113] e.g. shock protection/comfort materials (packaging, shoe soles, helmets, cushion, matrasses, ...),[19,114] electromagnetic interference absorbers, $[26,115,116]$ thermal or sound insulating panels, $[117,118]$ water or air filtration devices,[12] ear plugs, etc. $[119,120]$ 


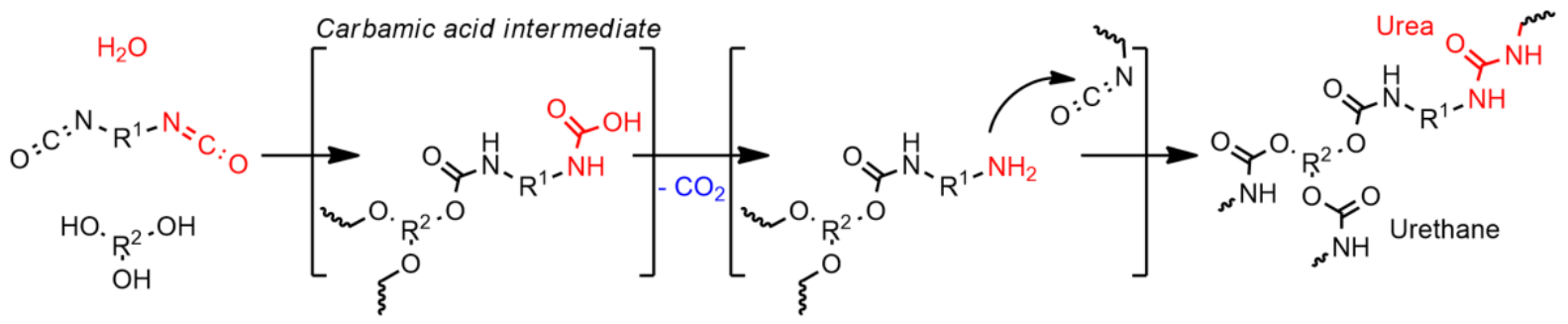

Figure 4: Formation of polyurethane foams by polyaddition of polyisocyanates to polyols in the presence of water.

\section{Formation of carbamic acid by reaction of isocyanates with carboxylic acids}

Carboxylic acids can add to isocyanates to form unstable carbamic anhydrides - also called $\mathrm{N}$ carboxylated anhydrides (NCA; Figure 3.1A) - that can spontaneously decarboxylate, yielding amides. These NCA are also reactive towards carboxylic acids to provide anhydrides and carbamic acids; the latter decomposing into $\mathrm{CO}_{2}$ and amines.[121] Therefore, when carboxylic acids are added to PU formulations composed of polyisocyanates and polyols, all these competitive reactions may occur in addition to the isocyanate/alcohol, isocyanate/amine and amine/anhydride ones. In the end, the formulations combining isocyanates and carboxylic acids results in the formation of hybrid networks with urethane, amide and urea linkages (Figure 5), self-blown by the $\mathrm{CO}_{2}$ released by degradation of $N$-carboxylated anhydrides.
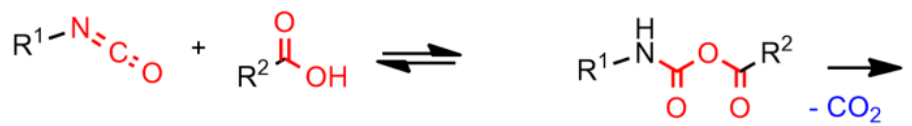
$N$-carboxylated anhydride

(ii)

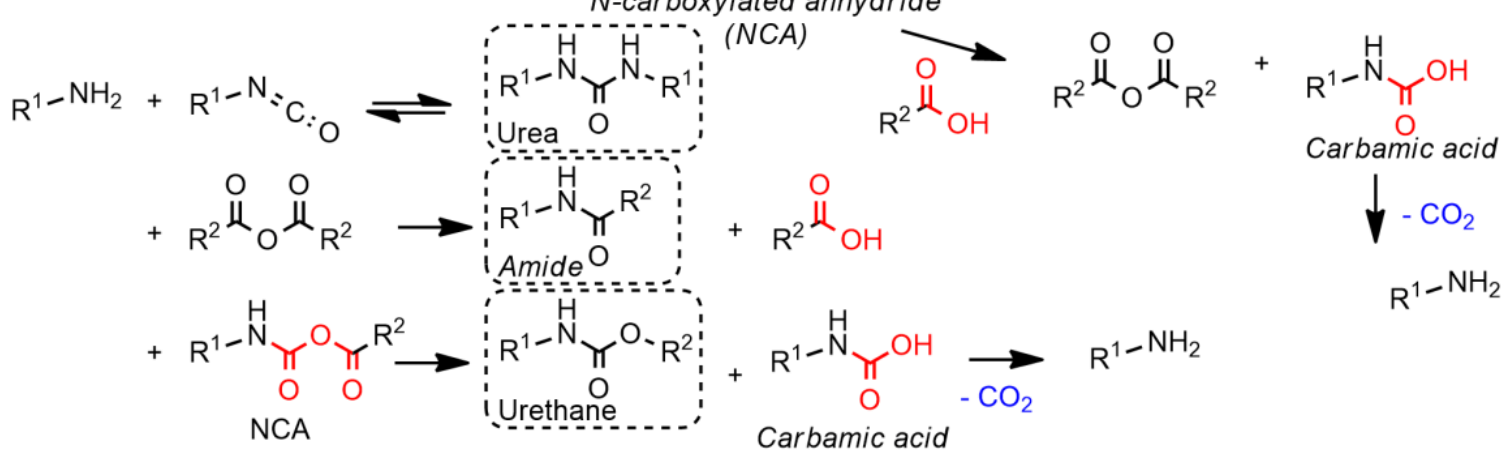

Figure 5: (i) Competitive reactions of isocyanates with carboxylic acids, and (ii) main reactions occurring when carboxylic acids are added to PU formulations composed of isocyanates and alcohols with the corresponding formed linkages. Adapted from [122], Copyright (2018) with permission from Elsevier.

Stanzione et al. reported such system for the preparation of expanded materials.[122,123] By adding bio-based polyesters with both $\mathrm{OH}$ and $\mathrm{COOH}$ chain ends - prepared by polycondensation of succinic acid and butanediol - to a PU formulation - composed of a commercial polyether polyol, methylene diphenyl diisocyanate, a catalyst and a surfactant hybrid polyurethane-polyamide materials (PUA) foams were obtained without adding water (Figure 6). The morphology and properties of the foams were dependent mainly on the weight fraction of bio-based polyester into the formulations and on the functionality of the bio-based polyester, i.e. the ratio of $\mathrm{COOH} v s \mathrm{OH}$ chain ends. Carboxylic acids being less reactive towards isocyanates than alcohols[124,125], slower cross-linking kinetics resulting in lower final expansions were observed as compared with similar $\mathrm{COOH}$-free formulations foamed by the addition of water. This lower expansion was the result of the blowing agent leaking out of the polymer matrix prior it was viscous enough to trap $\mathrm{CO}_{2}$ inside. In other words, the BA was release too soon in the foaming window. When polyesters with only $\mathrm{COOH}$ chain ends were used, collapsed foams were mainly collected. Flexible foams with densities between 61 and 76 
$\mathrm{kg} \mathrm{m}^{-3}$ were obtained when using polyesters with both $\mathrm{COOH}-$ and $\mathrm{OH}$ chain ends. Both open and closed cells morphologies were observed.

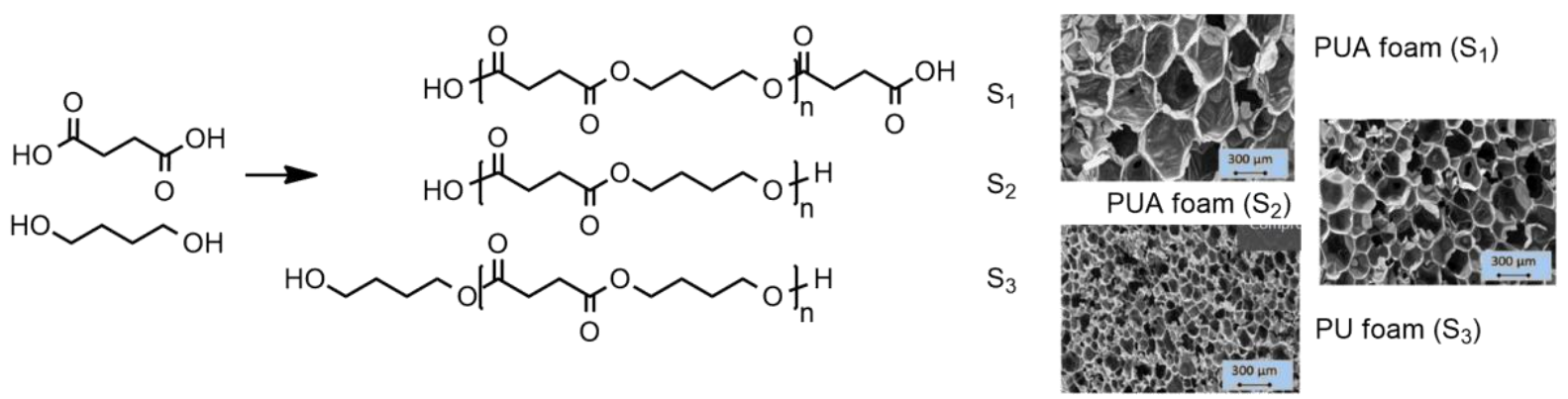

Figure 6: PU foams prepared from carboxylic acid (S1), alcohol (S3) and both functions (S2) terminated oligomers by reaction with MDI. " Adapted from [123], copyright (2018) with permission from Elsevier"

The reaction of isocyanates with carboxylic acids was also exploited to prepare self-foamed polyimides.[126-128] As an example, Liu et al. demonstrated that poly(amide ester) foams could be obtained from a partially hydrolyzed and methanolized dianhydride (PMDA) in the presence of a polyisocyanate, a PDMS-based surfactant and catalysts (Figure 7). Isocyanates were reacted with the carboxylic acids to provide the amide linkages along with $\mathrm{CO}_{2}$ generation. The obtained foam was post-cured under vacuum at $250{ }^{\circ} \mathrm{C}$ for the formation of the polyimide foam and for removing water and methanol by-products (without any change in the material volume expansion). After spraying silver(0) particles on the foams, the authors reported rigid low density foams $\left(<23 \mathrm{~kg} \mathrm{~m}^{-3}\right)$ with open-cell and high thermal stability $\left(\mathrm{T}_{\mathrm{g}} 5 \%=400{ }^{\circ} \mathrm{C}\right)$ that presented good EMI shielding efficiency (between 36 and $96 \mathrm{~dB}$ ) in the 200-7000 $\mathrm{MHz}$ frequency range.

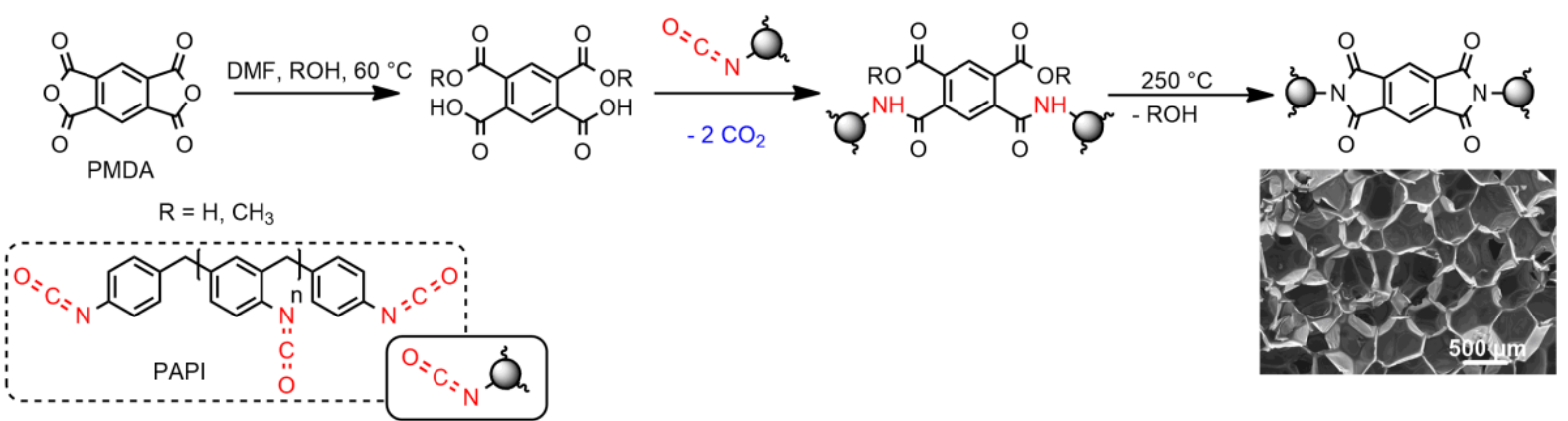

Figure 7: Preparation of self-blown polyimide foams from anhydride and isocyanate compounds. Adapted from [127] Copyright (2012) Wiley Periodicals, Inc.Thermal degradation of carbamates

Carbamates are much thermally stable compared to carbamic acids and can be used as latent blowing agents when a thermal curing is tolerated. Two main families of stable carbamates have been used for the preparation of epoxy-amine foams. They consist in covalent (Figure 3B) or ionic carbamates (Figure 3C).

Epoxide-amine formulations are commonly used to obtain high-performance thermosets[129] that find many applications in fields such as coatings, electronics, adhesives or as matrices in combination with reinforcing fibers for structural composites for instance. More particularly, epoxy foams are used for their superior resilience to thermomechanical stress as compared to other conventional polymer foams, including PU foams.[130,131] They are the best alternatives when low densities materials with good thermal insulation and excellent mechanical strength are required. For these reasons, epoxy foams are well adapted for shielding materials and are of potential interest in protective equipment against a wide range of hazards (e.g. chemical, thermal, electrical, electromagnetic). For instance, Fan et al. recently described thermally 
insulating epoxy-silver nanosheet composite foams with excellent electromagnetic interference (EMI) shielding performances.[132] Méjean et al. also reported the use of epoxy foam composites as alternatives to PU foams for anechoic chamber applications.[133] It is however well known that epoxy foams are not easily obtained through classical physical blowing methods, in particular because gas nucleation is restricted into the rapidly growing network. Indeed, a general limitation of epoxide systems is the high reactivity of the starting reactants. The addition of amines onto epoxides is usually very fast and is not always compatible with the technical use of the resin, e.g. foaming. Several authors addressed this issue by developing blocked hardeners in the form of polyamines functionalized with thermolabile protecting groups. By doing so, the one-pot formulation of blocked-amine and epoxy is unreactive until the appropriate temperature - usually well above room temperature - is applied to release the reactive primary amines. In particular, it has been proposed to block the amines in the form of thermo-cleavable carbamates. The cleavage of the carbamate results in the concomitant release of an amine and $\mathrm{CO}_{2}$. The latter remains trapped within the growing network and nucleates in the form of bubbles to provide a foam. Carbamates can then be used as both latent curing and blowing agent precursors. By using appropriate reaction temperatures and formulations, an adequate timing between both gas generation and cross-linking of the material can be obtained, providing properly expanded foams.

Below are described some examples of self-foaming epoxy resins based on covalent carbamates obtained through a classical isocyanate-alcohol reaction[134,135] or ionic carbamates (e.g., ammonium carbamate salts) resulting from the fixation of $\mathrm{CO}_{2}$ onto amines.[136] To our knowledge, they have not been used in the perspective of PPE applications yet. However due to the importance of epoxy resins for these applications, self-blown epoxies are of great promise for fabricating highly resilient protective equipment's.

\section{Covalent carbamates}

Fréchet et al. proposed the first self-blowing epoxy-amine system in which the amine functions are held latent in the form of covalent carbamates (Figure 3.1B).[137] Interestingly, they developed single-component precursors that enclose all the reactants of the formulation in the same molecule, i.e. the epoxy resin and the amines blocked under the form of carbamate (Figure 8 ). In practice, these precursors were obtained by end-capping diisocyanates with a monoalcohol bearing two epoxy functions. The resulting tetrafunctional bis-carbamates bearing epoxide groups decomposed at high temperature $\left(>150{ }^{\circ} \mathrm{C}\right)$ into 2 eq. of difunctional epoxy resin, 1 eq. of primary diamine and 2 eq. of $\mathrm{CO}_{2}$. These systems are designed to release the epoxy resin and the amine hardener in a ratio corresponding to the exact stoichiometry between the oxirane and the $\mathrm{NH}$ groups, i.e., the ratio to obtain the highest crosslinking density and thus the optimal thermomechanical properties of the epoxy material. The precursors were cured at various curing temperature, $T_{c}$, with $T_{c}$ being superior to the decomposition temperature of the carbamate, $T_{d}$. For all $T_{c}$ values, the difunctional epoxy resin and the primary diamine immediately reacted after their release to form the epoxy-amine network. For all curing conditions, $\mathrm{CO}_{2}$ effectively nucleated within the growing network, resulting in the formation of stable spherical bubbles with a radius, $R$, that is an increasing function of $T_{c}(10 \mu \mathrm{m}<R<$ $400 \mu \mathrm{m}$ for $160{ }^{\circ} \mathrm{C}<T_{c}<200{ }^{\circ} \mathrm{C}$ ). This single component formulation was a robust system to obtain highly crosslinked rigid foams with controllable pore size. In particular these closed-cell foams might be used as insulators for the prevention of thermal hazard or as impact resistance protection. 


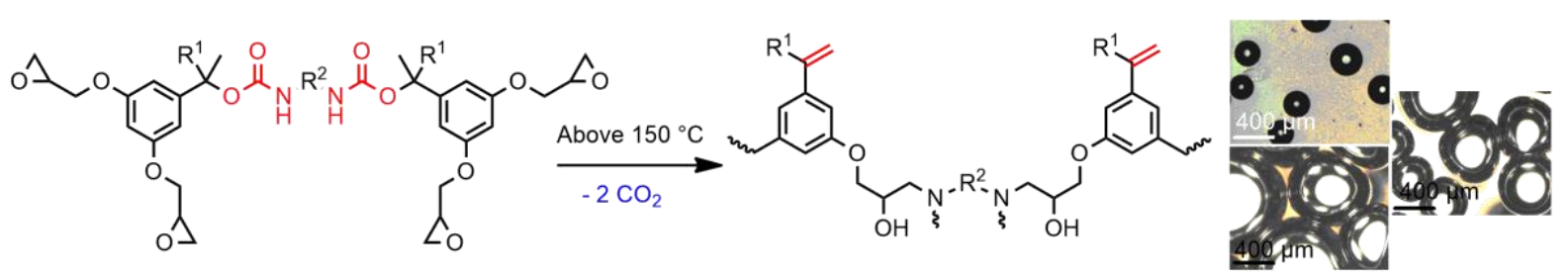

Figure 8: Thermolabile single-molecule self-blowing epoxy foam precursor Adapted with permission from [137]. Copyright (2011) American Chemical Society.

In order to bypass the multistep procedure for the synthesis of this single-component system, the same strategy might be applied to simpler multicomponent systems, i.e. where blocked amines in the form of carbamates would be mixed with regular epoxy resins to provide a selffoaming and thermolatent two-components system.

It is worth noting that several systems using amine hardener held latent under the form of photosensitive carbamates were described for the photocuring of epoxy resin [138-140]. In particular, amines protected with the well-known photo-sensitive o-nitrobenzyloxycarbonyl group[141] are commonly used in photo-curable epoxy-amine resins. In those cases, the photodeprotection of the amine was also concomitant with the release of $\mathrm{CO}_{2}$. When the thermosetting materials were processed in the form of film in an open environment, $\mathrm{CO}_{2}$ diffused out of the materials before the formulation was fully cured, leading to non-porous films. However, Arimitsu et al. observed the nucleation of bubbles during the photo-curing of a similar formulation in a sealed environment, proving that these systems might be exploited for preparing thin porous films[140].

\section{Ionic carbamates}

The reversible addition of $\mathrm{CO}_{2}$ to amines yields ionic carbamate salts. These salts can be seen as dormant amines that can undergo the reversible reaction upon heating and therefore release the amine and $\mathrm{CO}_{2}$ (Figure 3.1C). For instance, the use of $\mathrm{CO}_{2}$ as a mean to trap reactive amine prior heat-induced activation has been used in switchable tertiary-amine based catalysts, which is of high interest in polymer science[142,143].

Several authors proposed to use polyamines blocked with $\mathrm{CO}_{2}-$ i.e. poly(ionic carbamate)s as both the latent blowing agent and the curing agent of epoxy resins. [56,144,145] In particular, Ren et al. proposed to use a commercially available amine, $N$-aminoethylpiperazine, AEP, (Figure 9a), that was reacted with $\mathrm{CO}_{2}$ to block the amine moieties. The resulting solid poly(ionic carbamates), $B$-AEP ( $B$ for blocked) presented a melting point, $\mathrm{T}_{\mathrm{m}}$, that corresponded to its decomposition temperature, $T_{d}\left(T_{m}=T_{d}\right)$. It was dispersed in diglycidyl ether of bisphenol A (DGEBA) to provide epoxy-amine formulations with a shelf-life superior to 6 months. These formulations were crosslinked at a curing temperature, $T_{c}$, well above $T_{d}$, a temperature range where the unblocked amine, AEP, is known for reacting quickly with DGEBA. As expected, closed-cell rigid foams with densities of about $300 \mathrm{~kg} \mathrm{~m}^{-3}$ were obtained. These performances were competitive with those of other epoxy foams reported in the literature. Other poly(ionic carbamate)s and epoxides mixtures were also successfully evaluated in this work. 
(a)

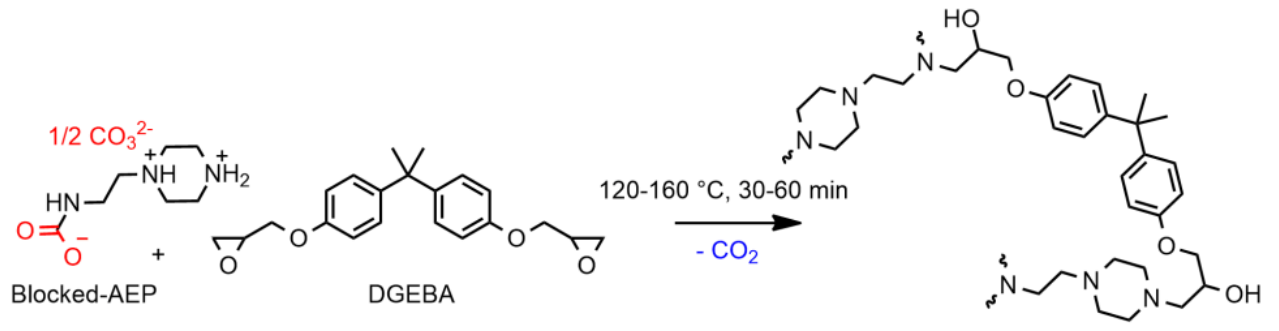

(b)

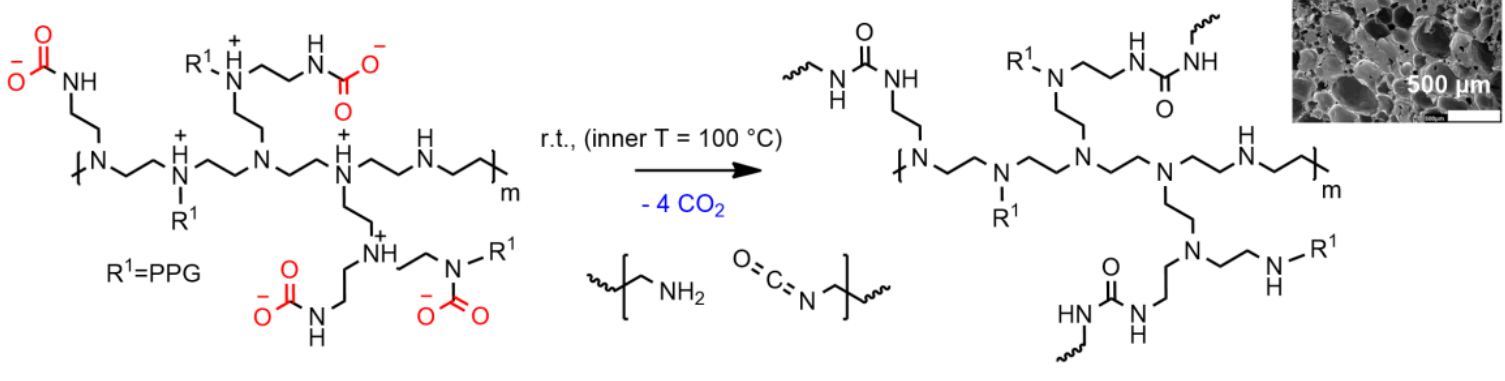

Figure 9: Ionic carbamate salts for the preparation of (a) epoxy (Adapted with permission from [56]. Copyright (2015), American Chemical Society) and (b) PU foams (Adapted with permission from [146] Copyright (2019) Wiley Periodicals, Inc).

As emphasized by the authors, the pore size distribution of the foams was very broad, probably due to inhomogeneities of the system before curing. Indeed, contrarily to the single component system described by Fréchet et al., the thermolatent systems based on carbamate salts are heterogeneous before curing as the tested carbamate salts were not miscible within the epoxy resins. The porosity of the foam was also expected to depend on the granulometry of these salts. Although there is a clear advantage of using such bicomponent system for the long-pot life of the formulation, there is a risk of sedimentation of the carbamate salt that might compromise the homogeneous curing of the resin.

Despite this drawback, carbamate salts are excellent alternatives to covalent carbamates for two main reasons: (i) their synthesis is a very cost-effective and environment-benign process based on the straightforward exposure of commercially available amines to $\mathrm{CO}_{2}$, and (ii) the thermal decomposition of the carbamate salt is VOC free, solely resulting in the release of the amine (i.e. the hardener) and harmless $\mathrm{CO}_{2}$ (i.e. the blowing gas). On the contrary, covalent carbamates are usually obtained from toxic isocyanates and their decomposition results in the release of the amine, gaseous $\mathrm{CO}_{2}$ and an alkene, the latter being a potentially harmful VOC. It is worth noting that carbamate salts have been successfully used for the latent curing-blowing of different epoxy resins including epoxy Novolac resins, which are known for providing materials with outstanding thermal stability, mechanical rigidity and electrical insulation.[145] These environmentally friendly foams are thus promising materials for a wide range of protective equipment.

Carbamate salts were also exploited for blowing other polymer matrices, such as polyurethanes. For instance, Xie et al. used the carbamate salt of an amine-reach compound, polyethyleneimine (PEI), in isocyanate-polyol formulations[146-148]( Figure 9b). They studied the influence of the quality of dispersion of the carbamate salts within the formulations on the properties of the resulting closed-cell foams. They observed that a better dispersion resulted in a smaller pore size dispersity and an improved mechanical strength.

\section{Carbonate precursors}

Organic carbonates - simply referred to as "carbonates" in this review - are known for their ability to thermally decompose into $\mathrm{CO}_{2}$, as well as an alkene and an alcohol whose structures are dependent on the alkyl substituents of the carbonate (Figure 3.2).[149] For instance, di-tert- 
butyldicarbonate, $\mathrm{Boc}_{2} \mathrm{O}$, is known as an exogeneous chemical blowing agent that is thermally decomposed into $\mathrm{CO}_{2}$, isobutene and tert-butanol [150]. However, its vaporization is sometimes observed before its thermolysis causing a serious safety issue because gaseous $\mathrm{Boc}_{2} \mathrm{O}$ is highly toxic. Alternatively, the carbonate group can be endogenous to the blowingsystem, i.e. grafted onto the (pre)polymer. In particular, the well-known tert-butoxycarbonyl $(t$-Boc) group is easily installed onto polymer backbones - or polymer precursors - given its widespread use as a protecting group in organic synthesis. Moreover, its decomposition into $\mathrm{CO}_{2}$ and gaseous isobutene - along with the corresponding deprotected (macro)molecule usually occurs in a temperature window $\left(150{ }^{\circ} \mathrm{C}-250{ }^{\circ} \mathrm{C}\right)$ that is compatible with the processing temperatures of many commodity polymers.

For these reasons, self-blowing high $T_{g}$ polymers were developed by grafting $t$-Boc groups onto phenol-containing poly(phenylquinoxaline)s[151] (PPQs) and polybenzoxazole (PBOs). PPQs and PBOs are considered as alternatives for the replacement of inorganic matrices in nanostructured films preparation, e.g. as insulators with low relative dielectric constant for microelectronics applications (low- $\kappa$ materials)[152]. Their good thermal stability[153-155] and the ability to introduce porosity are critical parameters for designing low $-\kappa$ materials.[156] For blowing thermoplastic PPQs, Merlet et al. functionnalized the phenolic hydroxyl groups of PPQ with $t$-Boc functions[157] prior to expansion[98,158] (Figure 10a). The authors showed that full decomposition of $t$-Boc groups occurred within 2 minutes at $160{ }^{\circ} \mathrm{C}$, which is far below the $\mathrm{T}_{\mathrm{g}}$ of the material $\left(\mathrm{T}_{g}=370^{\circ} \mathrm{C}\right.$ for ungrafted PPQ). For preparing porous samples, the casted polymer films were heated at various blowing temperature, $200{ }^{\circ} \mathrm{C}<\mathrm{T}_{\mathrm{b}}<300{ }^{\circ} \mathrm{C}$, under nitrogen atmosphere. No porosity was observed for $\mathrm{T}_{\mathrm{b}}<210^{\circ} \mathrm{C}$, i.e. for $\mathrm{T}_{\mathrm{b}}$ well below the $\mathrm{T}_{\mathrm{g}}$ of ungrafted PPQ. At this temperature, the polymer matrix remained in glassy-state, rendering impossible any visco-elastic deformation of the matrix and thus preventing gas nucleation. These temperatures are outside the foaming window of the polymer. $\mathrm{As}^{\mathrm{CO}_{2}}$ is known to plasticize polymer matrices[159], it was assumed that a blowing temperature superior to the $T_{g}$ of the $\mathrm{CO}_{2}$-plasticized PPQ, $T_{g}^{\mathrm{CO}_{2}}$, was required for the appearance of noticeable porosity. Nanocells $(<50 \mathrm{~nm})$ were generated for $210^{\circ} \mathrm{C}<\mathrm{T}_{\mathrm{b}}<240{ }^{\circ} \mathrm{C}$, suggesting that $T_{g}^{C 0_{2}} \sim 210^{\circ} \mathrm{C}$. Macrocells ( $>50 \mathrm{~nm}$ ) were formed for $\mathrm{T}_{\mathrm{b}}>250{ }^{\circ} \mathrm{C}$, and a combination of nanocells and macrocells was observed for $240{ }^{\circ} \mathrm{C}<\mathrm{T}_{\mathrm{b}}<250{ }^{\circ} \mathrm{C}$.

By a similar approach, Fukumaru et al. grafted $t$-Boc onto poly(hydroxyamide) (Figure 10b) the precursors of PBO [160] - for preparing PBO nanoporous films of very low $\kappa$ value.[156] In that case, $t$-Boc groups fulfilled a dual role: $(i)$ processing aid to obtain $t$-Boc grafted poly(hydroxyamide) film by solvent casting and (ii) in-situ blowing agent generator through thermal degradation under vacuum. 
(a)

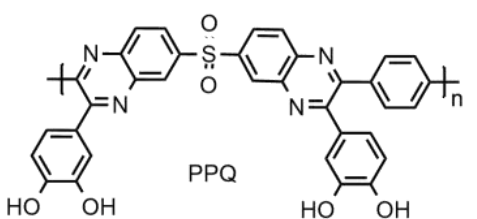

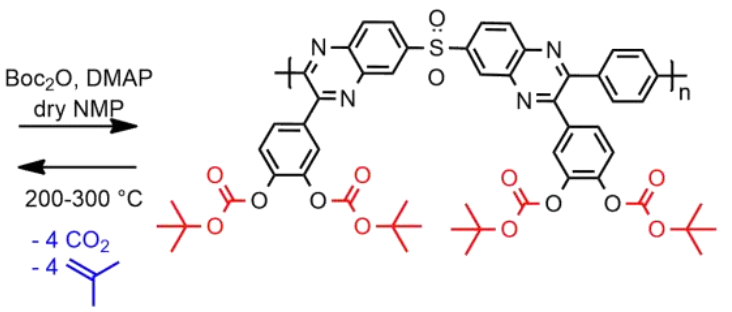

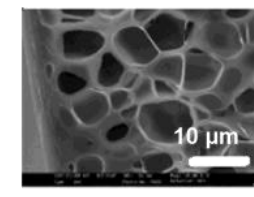

(b)
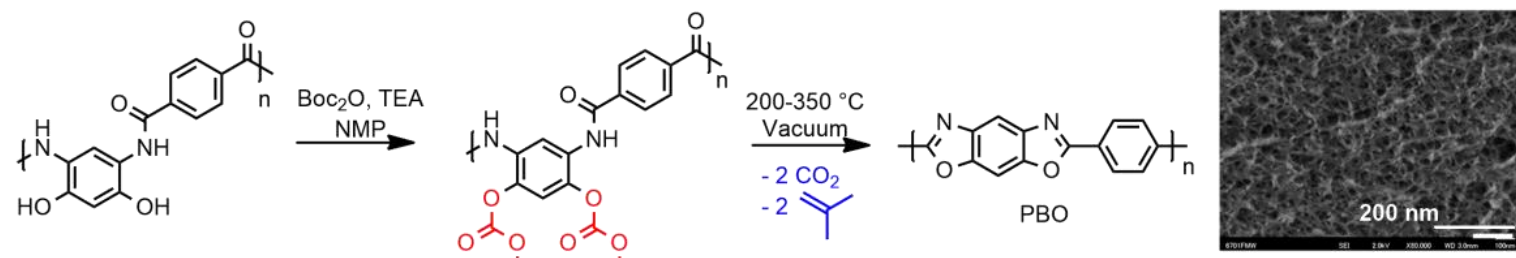

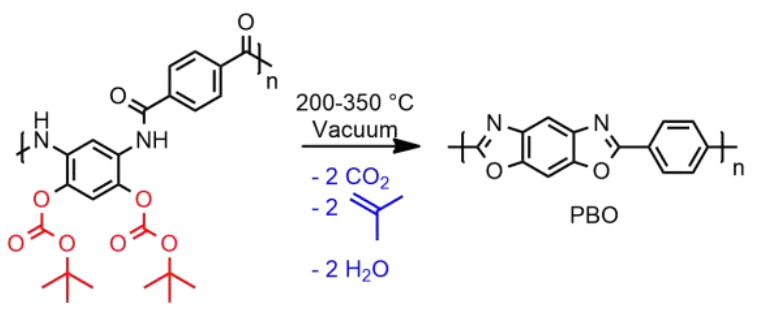

Figure 10: Preparation of (a) poly(phenylquinoxaline) (PPQ), and (b) aromatic poly(hydroxyamide) porous films by thermolysis of polymer precursors bearing t-Boc functions. (a) is adapted with permission from [98].Copyright (2008) American Chemical Society. (b) is Adapted from [160] with permission from the Royal Society of Chemistry, Copyright (2012).

More recently, $t$-Boc bearing copolymers were used for preparing dismantlable adhesive materials [161,162] (Figure 11a,b). The principle is to design polymers with good adhesive properties, which can undergo some structural or chemical modification once in place by insitu gas generation in order to jeopardize the adhesion. Typically, the radical polymerization of t-Boc-containing methacrylics or styrenics monomers provided polymers, with pendant $t$-Boc groups, that were processed as polymer films by solvent casting. Porous polymer films were then produced by thermal treatment $\left(\mathrm{T}_{\mathrm{b}}=210^{\circ} \mathrm{C}\right.$, Figure $\left.11 \mathrm{a}\right)$ or a combination of thermal activation $\left(\mathrm{T}_{\mathrm{b}}=90-130{ }^{\circ} \mathrm{C}\right)$ with an acid catalyst in order to lower the $t$-Boc decomposition temperature (Figure 11b).

(a)
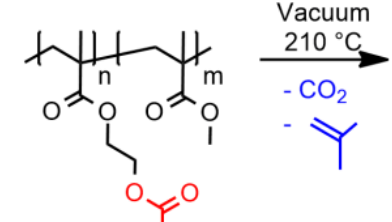<smiles>CCC(C)(C)C(=O)OCCO</smiles>

(b)
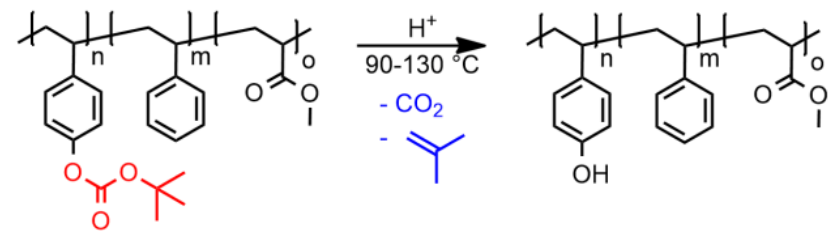

Figure 11: Preparation of dismantlable adhesive polymer films from polymers functionalized with $t$-Boc. Reproduced with permission from [161], Copyright (2018) Wiley Periodicals, Inc. and from [162], Copyright (2019) Elsevier Ltd.

It is worth mentioning that the use of carbonate functions as EnCB precursors is not limited to their grafting as pendant groups onto polymer backbones as described above. Aromatic difunctional carbonates were also used as both latent blowing agents and activated monomer precursors. Indeed, under acidic conditions, these compounds can thermally decompose into $\mathrm{CO}_{2}, \mathrm{H}_{2} \mathrm{O}$ and benzylic carbeniums (Figure 12a). The latter can react with another aromatic group via an electrophilic substitution. The repetition of this mechanism results in the growth of an aromatic polymer with the concomitant release of two endogenous blowing agent, $\mathrm{CO}_{2}$ and $\mathrm{H}_{2} \mathrm{O}$. The polymerization mechanism involves cationic centers that are not located on the growing chains, but on the monomers that are added to the chains. For these reasons, this polymerization can be referred as a cationic chain polymerization following an activated monomer (AM) mechanism, where the carbeniums are the AM. 
Wöckel et al. used this system to obtain self-blown polyaromatic foams (Figure 12b and Figure 12c).[163,164] They used different diaromatic carbonates, including difurfurylcarbonate (DFC) as well as the para- and meta-methoxybenzyl carbonates ( $p \mathrm{MBC}$ and $m \mathrm{MBC}$, respectively). With the less reactive monomers, $p \mathrm{MBC}$ and $m \mathrm{MBC}$, the addition of a crosslinker, the trioxane (TO), was required to observe the formation of a foam. TO promoted the cross-linking of the growing polyaromatic resin by the formation of methylene bridges between aromatic rings through Friedel-Crafts alkylation[165] (Figure 12c). This observation indicates that, for these monomers, the increase of the molecular weight resulting from the cationic polymerization of the activated carbeniums was not sufficient to promote the viscosification of the polymeric matrix, and in return the efficient trapping of the blowing agent $\left(\mathrm{CO}_{2}\right.$ and $\left.\mathrm{H}_{2} \mathrm{O}\right)$. An additional polymerization mechanism (Friedel-Crafts alkylation) is required. On the contrary, with the most reactive monomer, DFC (Figure 12b), foams are obtained even in the absence of the crosslinker, TO. Interestingly, the best foams were obtained for the TO-free system. In that case, the authors measured a 10-fold volume expansion by respect to the monomer precursor. This self-foaming system was used to develop materials with hierarchical pore morphologies and high surface-area that can find application as adsorbing media for purification purpose.[166]
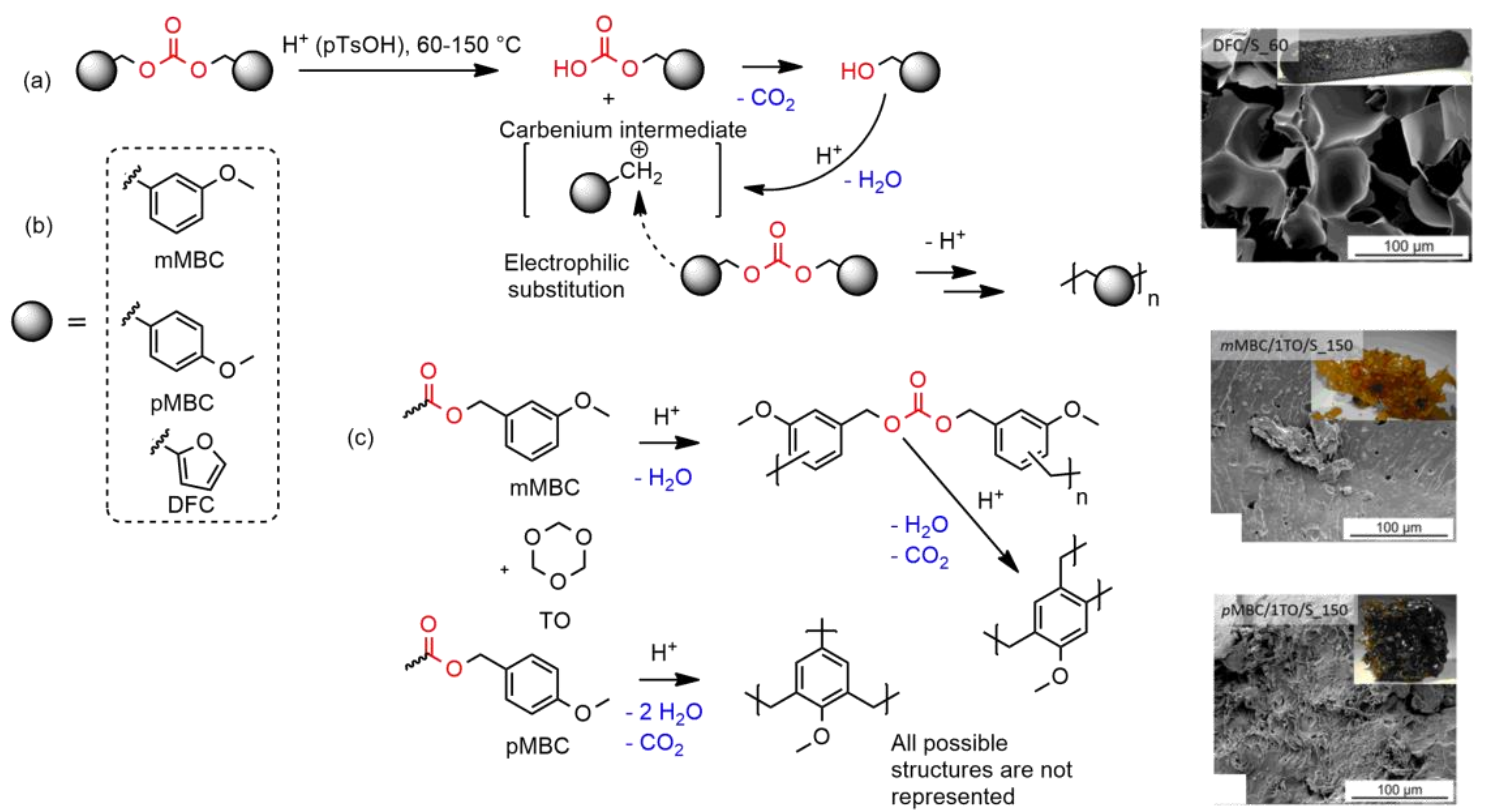

Figure 12: Self-blowing resins prepared by acid catalyzed polymerization of linear carbonates. Adapted from [167] with permission from the Royal Society of Chemistry, Copyright (2017).

\section{Ester precursors}

tert-Butyl ester ( $t$-Be) group can thermally decompose into gaseous isobutene[168]. When grafted to polymers, $t$-Be can act as endogeneous blowing agent, similarly to strategies discussed above for $t$-Boc, except that the activation mode is slightly different. As relevant example, highly ordered nanoporous polymethacrylate films were prepared by UV-induced acid-catalyzed degradation of pendant $t$-Be moieties, leading to in-situ isobutene generation under mild conditions (Figure 3.3, Figure 13).[169] The use of UV activation enabled to access to patterning of the material at the nanoscale (Figure 13).[168,170,171] Such nanoporous materials are reported to find applications in high-performance thermal insulation[172] or filtration[173] materials. They might also be attractive alternatives to nanoporous materials used as COVID19 protective masks that were prepared by a multi-step process consisting of using inorganic templates prior polymer material etching.[174] 

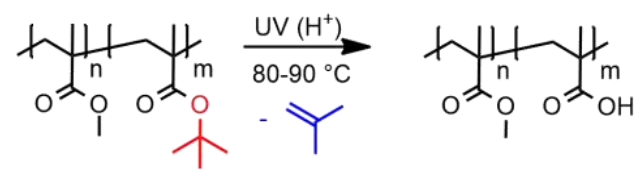

$\mathrm{P}(\mathrm{MMA}-\mathrm{b}-\mathrm{tBA})$

Figure 13: Preparation of nanoporous films by to UV-induced acid-catalyzed degradation of pendant $t$-Be moieties bond to a polymer backbone. Adapted with permission from[171] Copyright (2020) American Chemical Society.

\section{Carboxylic acids precursors}

Carboxylic acids are among the cardinal functions in organic chemistry. They hold also a central position in polymer chemistry as they can be seen as both latent curing and foaming agents. Indeed, carboxylic acid are mild nucleophiles that are known to react at high temperature with common electrophilic compounds used in material science, e.g., epoxides[175,176] and isocyanates.[121] They are notably used to obtain thermosetting polyesters when reacted with epoxy resins. The thermomechanical properties of these polyesters are competitive with those of above-mentioned epoxy-amine thermosets. In particular, they share the same resilience to thermal and mechanical stress. Therefore, acidepoxy thermosetting polyesters are also relevant materials in a myriad of applications related to prevention and protection against heat or impact related injuries.

On top of their thermally latent reactivity with electrophiles, carboxylic acids can undergo decarboxylation upon heating: (i) spontaneously[177,178] or (ii) in the presence of activating agents and catalysts (Figure 3.4) [179-182]. Thus, they are intrinsic reservoirs of $\mathrm{CO}_{2}$ and can be used as chemical blowing agents. On the other hand, contrarily to carbamates, carboxylic acids do not enclose a combination of a dormant reactive function and a blowing agent. Once involved in the crosslinking of the network, they cannot contribute to the foaming and vice versa. When used simultaneously as crosslinking and blowing agent, for the synthesis of an acid-epoxy thermosetting foams for instance, the properties of the final material (e.g., crosslinking density and porosity) will depend on the reactant stoichiometry ([acid]/[epoxy] ratio) and on the relative kinetics of the nucleophilic addition (crosslinking reaction) and the decarboxylation at the operating temperature.

Among carboxylic acids, $\beta$-carbonyl carboxylic acids spontaneously undergo decarboxylation at relatively mild temperatures in between 70 and $150{ }^{\circ} \mathrm{C}[183,184]$. The mechanism involves a six-membered cyclic transition state in which a proton is transferred from the carboxylate atom to the carbonyl oxygen to provide an enol that rapidly tautomerizes[185,186] (Figure 14). Advantageously, the decarboxylation occurs in the same temperature window than the classical acid-epoxy reactions used in thermoset technologies. These are the ideal conditions to ensure the simultaneous initiation of the crosslinking reaction and the $\mathrm{CO}_{2}$ release, and to guarantee the nucleation of the gas in the form of stable bubbles in the final material.

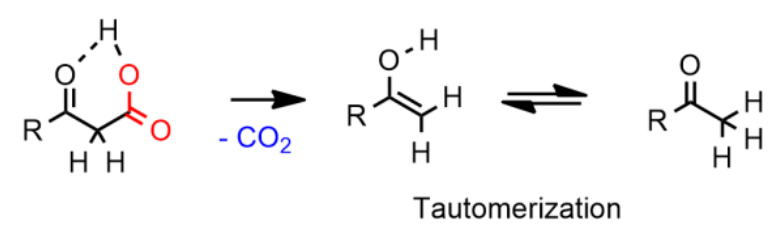

Figure 14: Decarboxylation mechanism of $\beta$-carbonyl carboxylic acids.

For this reason, Dogan et al. first proposed to use malonic acid, the simplest $\beta$-carbonyl carboxylic diacid, to crosslink and foam a polyfunctional epoxy resin, namely epoxidized soybean oil (ESO).[187] The author developed a methodology where malonic acid is first grafted onto ESO by addition of only one of its terminal acid functions onto an epoxy group. The resulting molecule is thus a triglyceride with both epoxide groups and malonic acid 
monoester (MAME). It is noted MAME-ESO (Figure 15). Interestingly, the authors studied this system at various curing-blowing temperature, $T_{c-b}$, and for different malonic acid to epoxy ratios, $r=$ [malonic acid]/[epoxy]. For a given value of $r$, the authors observed that the increase of $T_{c-b}$ resulted in an increase of the decarboxylation rate and an increase of the epoxy conversion. Moreover, the density of the foams decreased with increasing $T_{c-b}$, typically from 494 to $238 \mathrm{~kg} \mathrm{~m}^{-3}$ when $T_{c-b}$ varying from $65{ }^{\circ} \mathrm{C}$ to $95{ }^{\circ} \mathrm{C}(r=2.8)$. It is worth noting that, in this system ( $r=2.8$, i.e., excess of acid), even for the highest value of $T_{c-b}\left(100{ }^{\circ} \mathrm{C}\right)$ when the decarboxylation rate was maximal, all the epoxy functions were reacted with an acid, meaning the crosslinking density was maximal. Thus, the decarboxylation of MAMEs did not interfere with the crosslinking reaction. Interestingly, the authors demonstrated that these foams are biodegradable.

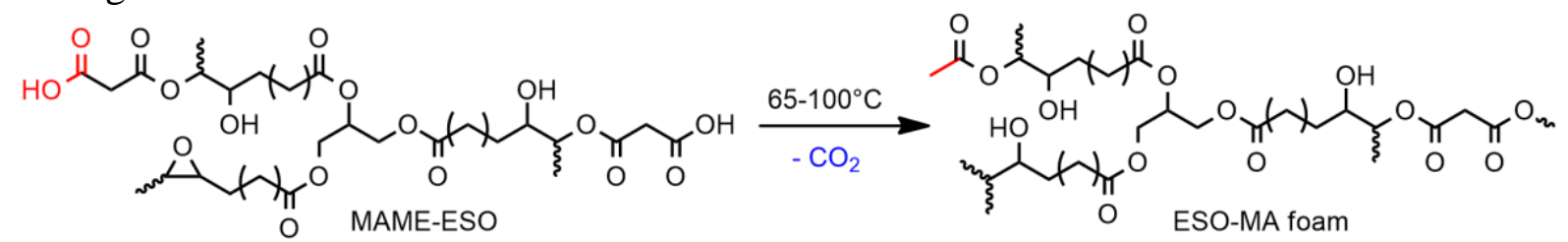

Figure 15: Preparation of polyester foams by decarboxylation of carboxylic acid functionalized epoxidized soybean oil. Reproduced with permission from [187], Copyright (2008) Wiley Periodicals, Inc

Only few acids have been used as thermolatent curing-blowing agents besides malonic acid. One reason is that the spontaneous decarboxylation of regular alkyl carboxylic acids usually occurs at temperatures above $200{ }^{\circ} \mathrm{C}$, i.e., much higher than the initiation temperature of most classical crosslinking reactions (e.g., epoxy-amine, epoxy-acid, isocyanate-alcohol, etc.). High$T_{g}$ phenolic resins are however conceived to operate at these temperatures. It is for instance the case of polybenzoxazine ( $\mathrm{PBz}$ ), a new class of high- $T_{g}$ phenolic resins, that has retained a lot of attention over the past decade. Three-dimensional polybenzoxazine networks were obtained through the ring opening polymerization of bifunctional benzoxazine.[188] The thermally induced opening of the six-membered oxazine rings was usually observed at a temperature around $200{ }^{\circ} \mathrm{C}[189]$ that is classically required for the spontaneous decarboxylation of regular carboxylic acids. Moreover, like most high- $T_{g}$ phenolic resins, $\mathrm{PBz}$ vitrified during their crosslinking reaction, a process that resulted in an intense increase of the viscosity, which is important to stabilize nucleating bubbles.

As an example, Zúñiga et al. described the self-foaming of a bifunctional benzoxazine containing a pendent carboxylic acid.[57,190] It is derived from a renewable diphenolic acid and noted DPA-Bz (Figure 16).[191] The authors demonstrated that the decarboxylation of the pendent carboxylic acid was initiated at a temperature above $200{ }^{\circ} \mathrm{C}$. Foams were obtained by pre-curing the samples at $140{ }^{\circ} \mathrm{C}$ and $160{ }^{\circ} \mathrm{C}$ in order to obtain rigid samples that were subsequently exposed to the curing-blowing temperature $\left(T_{c-b}\right)$ in order to complete the crosslinking reaction and to promote the foaming. We should notice that in this case, the ring opening of benzoxazines can be initiated at a lower temperature thanks to the catalytic effect of carboxylic acids toward this reaction.[192] For $T_{c-b}$ ranging from $200{ }^{\circ} \mathrm{C}$ to $230{ }^{\circ} \mathrm{C}$, the authors observed a large expansion of the material, proving that the decarboxylation of the carboxylic acid occurred. Interestingly, the carboxylic acids were also involved into the formation of ester bridges by reaction with the phenol groups released during the polymerization of benzoxazine. Thus, the carboxylic groups were contributing to increase the crosslinking density of the resin. In accordance with the results obtained by Dogan et al. for foams obtained from malonic acid and epoxidized soybean oil, the density of the polybenzoxazine foams decreased with increasing $T_{c-b}$. Typically, it varied from 76.8 to $38.4 \mathrm{~kg} \mathrm{~m}^{-3}$ for $T_{c-b}$ varying from $200{ }^{\circ} \mathrm{C}$ to 230 ${ }^{\circ} \mathrm{C}$ (note: $T_{g}$ 's $\sim 240{ }^{\circ} \mathrm{C}$ ). 


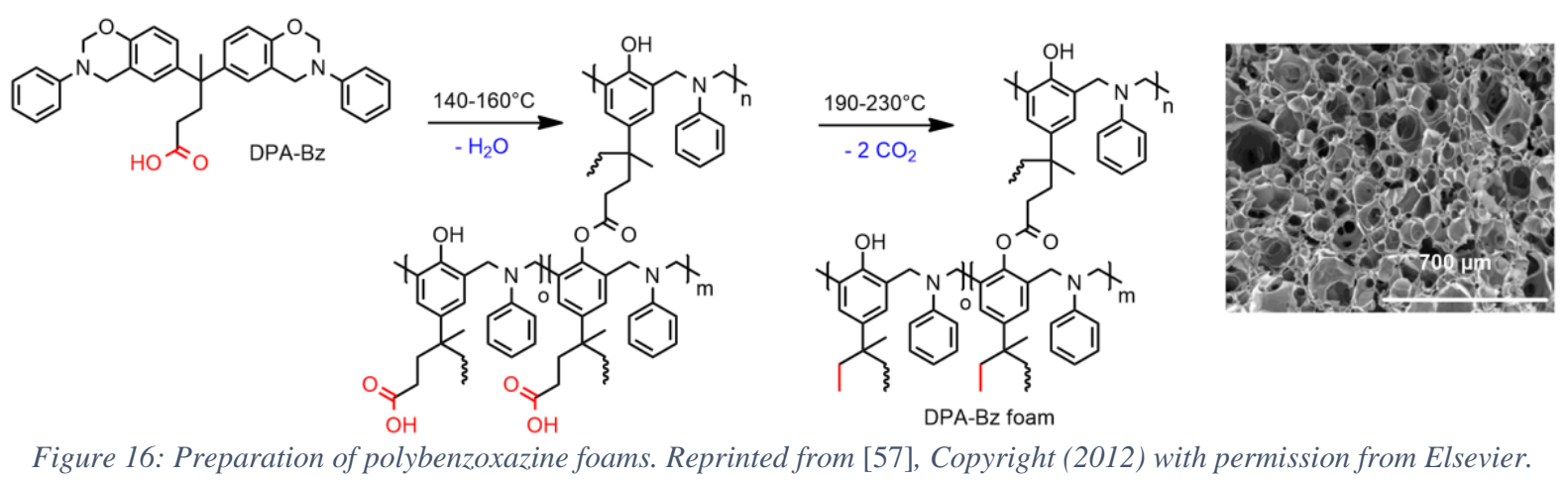

Feng et al. used these self-foaming polybenzoxazines to develop new magnetic carbon absorbents.[193,194] The authors dispersed ferrous acetylacetonate particles into the bifunctional benzoxazine containing a carboxylic acid function. The resulting mixture was cured and expanded using the protocol developed by Zúñiga to provide composite foams. They were subsequently carbonized to yield the composite carbon materials containing dispersed magnetic particles of $\mathrm{Fe}_{3} \mathrm{O}_{4}$. Remarkably, the materials retained a heterogeneous open-cell morphology after carbonization. Thanks to their large specific surface area $\left(330 \mathrm{~m}^{2} \mathrm{~g}^{-1}\right)$, they were effective absorbents for toxic cationic dyes that are present in waste waters (the magnetic composites are negatively charged because of the presence of oxygen-containing groups embedded in carbon material). These self-foamed composites are thus promising for applications related to purification and sensing. They can inspire new developments in domains related to the management of safety issues.

Another relevant example relies on graphene oxide (GO) nanosheets for the thermal expansion of polyimide foams. Xu et al. reported the grafting of GO on a polyimide precursor, a poly(amide ester) (PAE), by reaction between epoxide functions of GO and terminal amine groups of PAE following a process illustrated in Figure 17.[195] This grafting allowed the homogeneous dispersion of GO in the precursor prior the blowing step that was carried out at selected temperature, $\mathrm{T}_{\mathrm{b}}$, between 170 and $300{ }^{\circ} \mathrm{C}$. Blowing agents originated from various sources, i.e. evaporation of (i) residual THF used as solvent for the synthesis, (ii) methanol released during imidization (i.e. during the intramolecular cyclisation of PAE), and (iii) $\mathrm{CO}_{2}$ and water formed during decomposition of carboxylic acids at the GO surface. The amount of grafted GO was reported to influence the blowing ability, i.e. the more GO, the lower the density of the resulting rigid closed-cell foam (between 75 and $150 \mathrm{~kg} \mathrm{~m}^{-3}$ ). This is explained by the thermal degradation of more oxygen-containing groups (e.g. $\mathrm{COOH}$ and $\mathrm{OH})$ present at the $\mathrm{GO}$ surface, and the consequent larger amount of generated BA. In this case, the expansion of the polymer matrix results from the combination of exogenous (e.g. residual THF) and endogenous blowing agents. Among the endogenous blowing agents, one originates from the degradation of a thermolabile function $(\mathrm{COOH})$ and the other one is liberated by a condensation reaction $(\mathrm{MeOH})$. Thus, these GO-polyimides composite foams can be considered as a hybrid foaming system. The case of self-foaming polyimides based on the intramolecular condensation reactions of PAE (i.e. imidization) is further developed in the next section of this review (Figure 23).

It is worth noting that GO incorporation was reported to improve the heat-transfer, heterogeneous nucleation and gas barrier properties of the composite foam, all these playing a role for an optimal expansion of the material. 


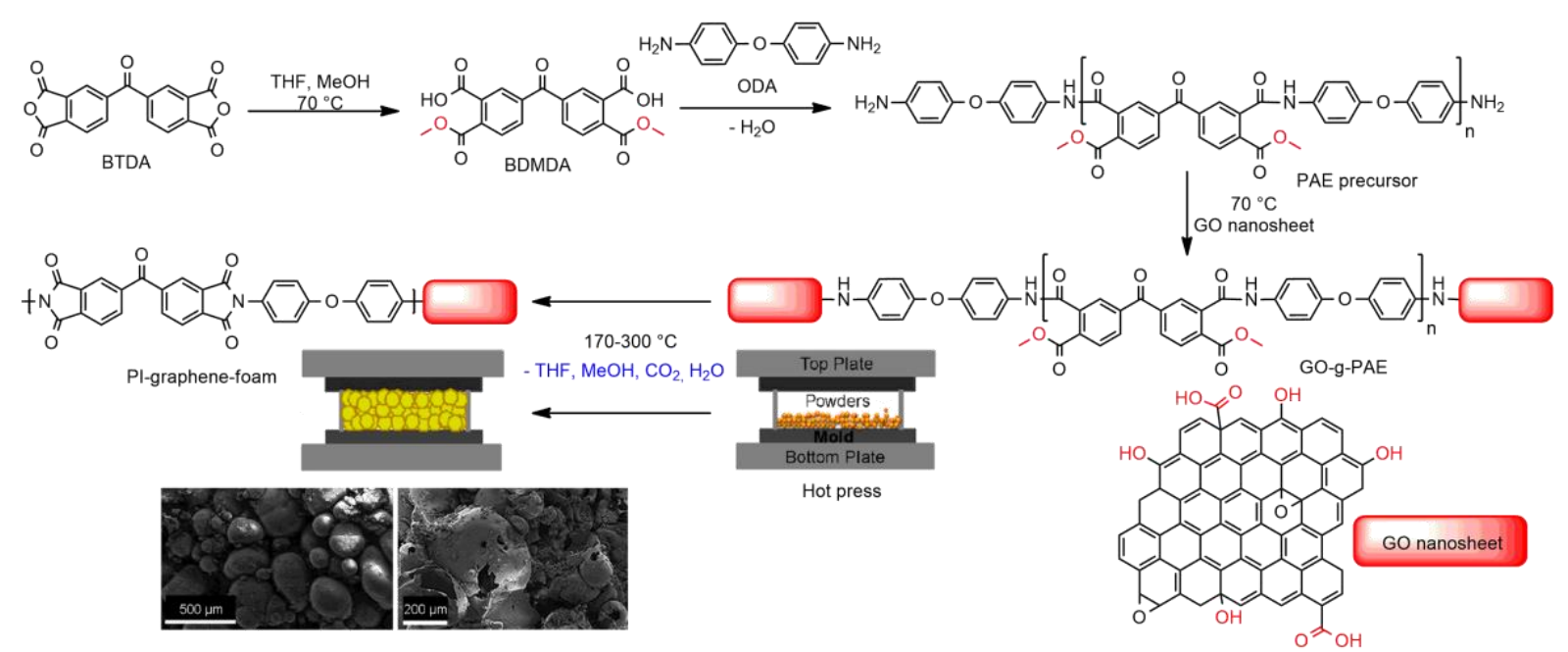

Figure 17: Route towards graphene/polyimide composite foams by thermal treatment of GO-g-PAE powder in a press at various temperatures to give samples with tuned GO content. Adapted with permission from [195]. Copyright (2015) American Chemical Society.

All the above-mentioned examples demonstrate that, polymer precursors containing carboxylic acids are potent self-foaming agents. Given the diversity of readily available and potentially biosourced polyfunctional carboxylic acids, e.g., amino acids or fatty acids, they represent excellent candidates to develop the next generation of cost-effective and environmentally friendly foams. One major obstacle is the incompatibility of the decarboxylation temperature of most carboxylic acids with the curing temperature of conventional thermosetting polymers. However, the recent developments in organocatalysts that facilitate decarboxylation in milder conditions should open up new avenues for implementing carboxylic acids to foaming technologies.[196]

\section{Meldrum's acid precursors}

Since their discovery more than a century ago, Meldrum's acid have risen great interest, notably as precursors of ketenes[197,198]. Indeed, ketenes can be formed through thermal treatment of Meldrum's acid (MA), with the concomitant release of acetone and $\mathrm{CO}_{2}$ (Figure 3.5)[199]. They can dimerize or quantitatively react by condensation or addition reactions with a wide range of nucleophiles, making them highly appealing reagents in organic chemistry[200-205] and polymer science.[206-209] Various studies reported the combination of MA to high $T_{g}$ polymers, i.e. polybenzoxazine (PBz)[210] or styrene bearing precursors[211] to prepare low$\kappa$ thermosetting resins. The low dielectric constant was reported to be partly due to cavities at the molecular-scale resulting from the volatile compounds generated during MA degradation. The presence of MA on polymers was also reported to improve their solubility in organic solvents and to lower their $T_{g}$.

As illustrated in Figure 18, Lin et al. exploited MAs to crosslink polysulfide thermosets.[212] In this work, the authors used a styrene-based monomer functionalized with a MA moiety (MA$\mathrm{St}$ ) that was copolymerized with elemental sulfur, $\mathrm{S}_{8}$, to provide MA-containing polysulfide, poly(S-MA-St). By thermal treatment of poly(S-MA-St) $\left(200^{\circ} \mathrm{C}\right)$, pendent ketenes groups were released and their dimerization resulted in the crosslinking of the polymer, yielding a thermosetting material. The release of gaseous carbon dioxide and acetone within the thermosetting network resulted in the formation of open-cell foams. 


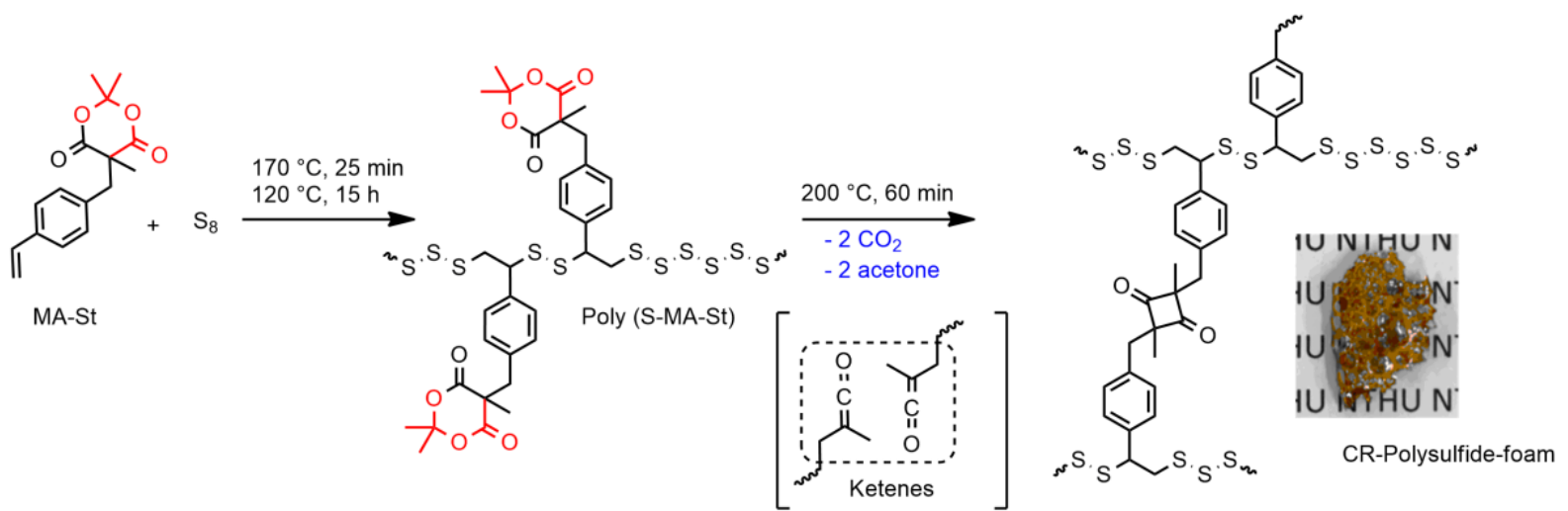

Figure 18: Preparation of self-foaming polysulfide by thermally-induced degradation of meldrum acids pendants. Adapted with permission from [212]. Copyright (2019) American Chemical Society.

These polysulfide foams exhibited many valuable features, notably in the perspective of PPE applications. First, they were obtained from a very abundant by-product of the petroleum industry, $\mathrm{S}_{8}$. Their production on the tone scale is thus possible, notably for the fabrication of low-cost consumer goods such as disposable PPEs. Moreover, Lin et al. demonstrated that these materials were self-reparable by simple thermal treatment thanks to the dynamic covalent S-S bonds. It is thus anticipated that these foams are recyclable and could be used for the fabrication of reusable PPE. Advantageously, the morphology of the porous structure of the foams is hierarchical, meaning it consists of both large voids $(>1 \mu \mathrm{m})$ and submicrometer pores. This combination ensures the high permeability of the foams, thanks to the large voids, while ensuring good absorption and filtration performances, due to the submicrometer ones. These are two fundamental properties in the perspective of fabricating separation membranes, notably for PPE. In this field, Lin et al. illustrated the potential of these foams for the purification of aqueous solution contaminated with mercury(II) as the result of the high ability of polysulfides to bind to heavy metals. They measured a $66 \%$ decrease of the mercury(II) concentration in the solution treated with the polysulfide foams. This performance is however less than the one of physically blown (supercritical $\mathrm{CO}_{2}$ ) polysulfide foams (96\%)[213]. Optimization of the endogenous foaming process should enable to fill this gap, according to the authors.

It is noteworthy that the Meldrum's acid foaming strategy is versatile and can be transferred to many other chemistries, besides polysulfide. For instance, Leibfarth et al. developed the efficient synthesis of MA-containing monomers for both radical (free or controlled) and ring opening metathesis polymerizations.[207] As a representative example, MA-St can be copolymerized with various vinylic monomers to obtain conventional organic thermosetting foams after curing of the polymer. It is thus anticipated that MAs will be further used as EnCB in the near future, potentially for fabricating the new-generation of PPE.

\section{Nadimide precursors}

Wang et al. reported the preparation of self-blowing polyimides based on the thermal degradation of norbornene end-capped polyimide oligomers (NAIO; Figure 3.6) prepared according to the strategy illustrated in Figure 19.[214] A treatment between 300 and $330{ }^{\circ} \mathrm{C}$ allowed to thermally decompose the end-capping moiety of these oligomers through reverse Diels-Alder reaction, promoting cross-linking along with cyclopentadiene evolution as the blowing agent.[215,216] Rigid foams with closed-cells, densities ranging from 50 to $400 \mathrm{~kg} \mathrm{~m}^{-}$ ${ }^{3}$ and pore size between 200 and $600 \mu \mathrm{m}$ were obtained. These self-foaming polyimides can find applications in thermal or phonic insulation. 


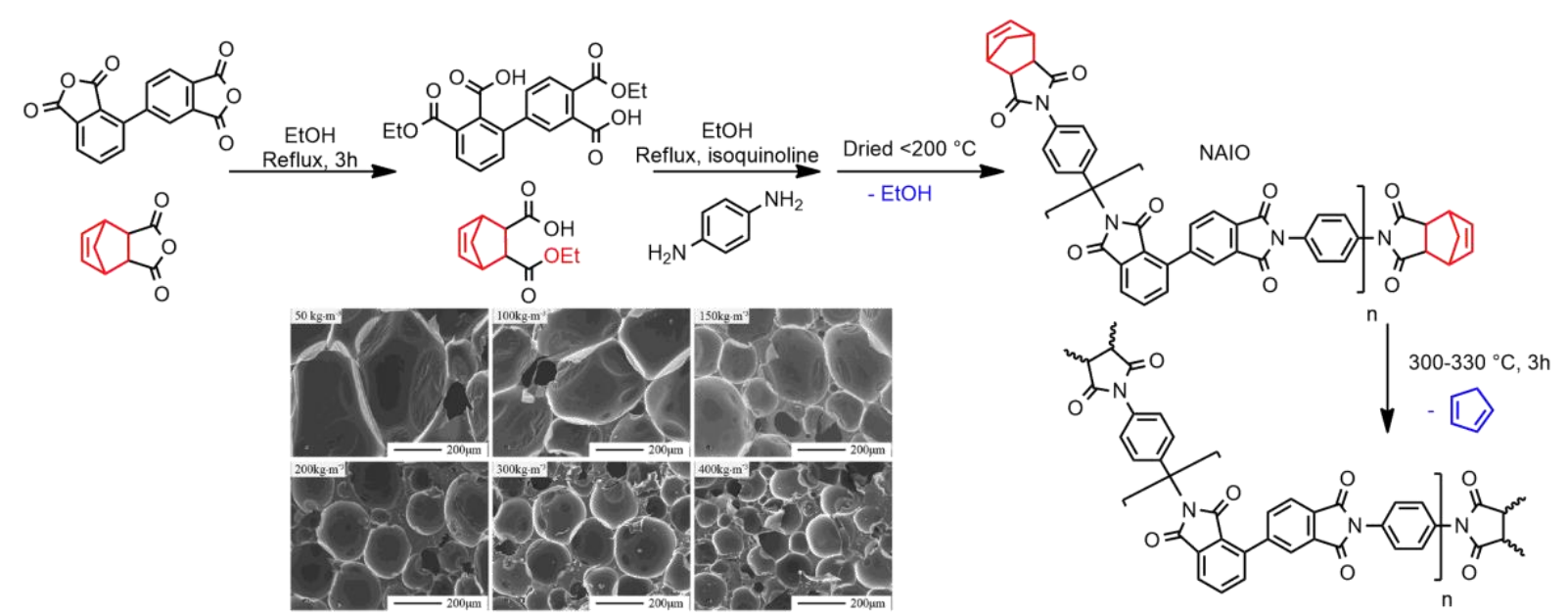

Figure 19: Polyimide foam preparation from norbornene end-capped polyimide oligomers (NAIO) precursors: reaction scheme and representative foams of different densities. Adapted from [214] Copyright (2013) Wiley Periodicals, Inc.

\section{Self-foaming polymers obtained via condensation and polycondensation reactions}

In this section, envisaged EnCB precursors are characterized by an intrinsic foaming ability of the polymer precursors. Indeed, at the contrary of most thermolysis-based EnCB discussed above, the chemical compound responsible for the formation of the blowing agent does not necessitate to design specific precursors. The generation of the blowing agent is intrinsic to the reaction(s) leading to the formation of the polymer chain/network. As a consequence, such materials preparation usually involves a unique step in which both curing and blowing phenomena occur simultaneously.

In these self-foaming systems, the blowing agent is a small molecule (e.g. water, methanol, acetic acid, etc.) generated by the condensation of two functional groups of the polymers - or the precursors of the polymer. Advantageously, most of these systems are based on readily available precursors. Indeed, the condensations and polycondensations introduced below are well established chemistries using industrially available and usually low-cost molecules. This is a clear asset over some of the previous self-foaming systems that required complicated chemical synthesis to introduce thermolabile groups on the polymer or its precursor.

In Figure 20 are summarized the condensation chemistries that have been used so far for constructing self-foaming polymers. Interestingly, they span all categories of polymers, from high $T_{g}$ thermoplastics to soft thermosetting polymers. 


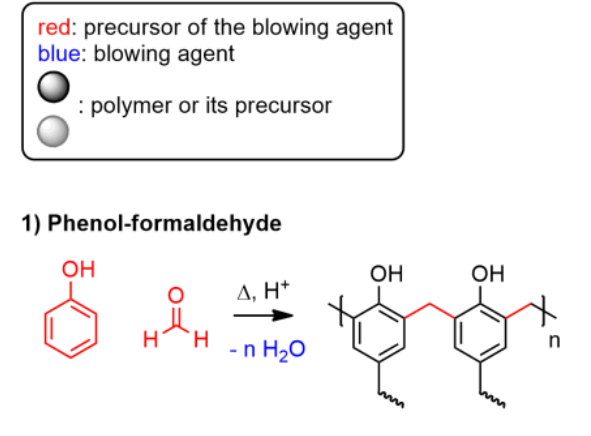

2) Esterification

3) Imine formation

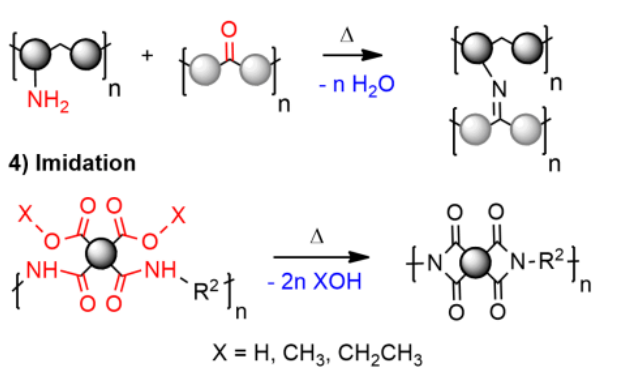

5) Siloxane/silazane and amine condensation

-A. In epoxy formulations

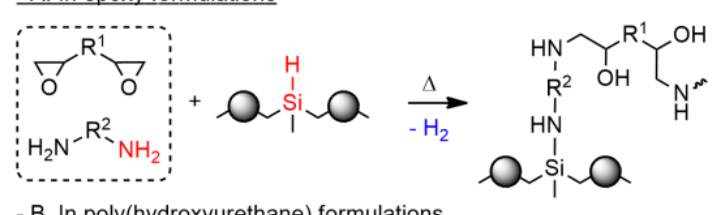

-B. In poly(hydroxyurethane) formulations

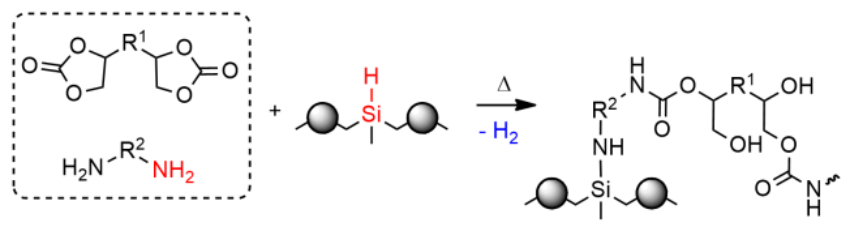

6) Decarboxylation of cyclic carbonates

\section{-A. By aminolysis of sorbitol biscarbonate}

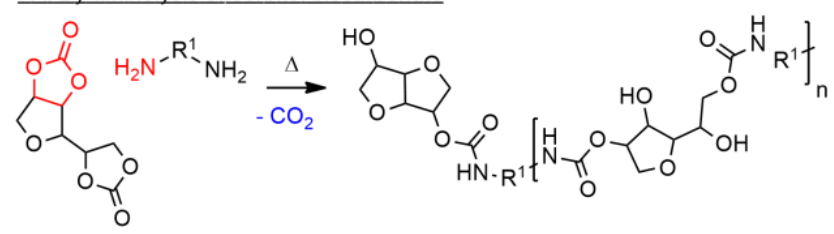

-B. By thiolation of cyclic carbonates in PHU formulations

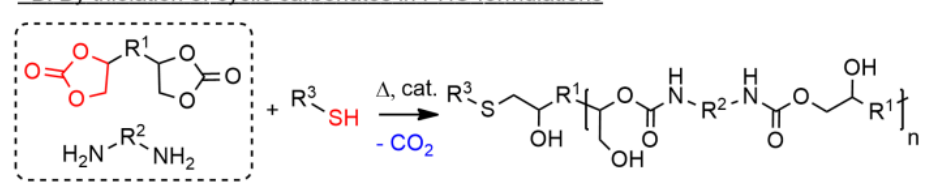

Figure 20: General strategies for self-foaming polymers by (poly)condensation.

\section{Polycondensation of phenol with formaldehyde}

Phenolic resins are obtained by polycondensation of phenol and formaldehyde with the release of water (Figure 20.1).[217,218] They are considered as the oldest synthetic polymer used by humankind. In these materials, the nucleation of water produced during the polycondensation has long been identified as a source of voids that were historically perceived as a drawback due to their negative impact on the thermomechanical properties of the final resins. In order to avoid these cavities, very long heating cycles were used during the production of the resins. These time and energy consuming curing procedures are still considered as one of the major drawbacks of the phenolic resins industry.[99]

Recently, Hamad et al. suggested to accelerate the curing cycle by using acid-based catalysts combined with high curing temperatures.[100] Under these conditions, they achieved a synchronization of the kinetics of both the gelation of the resin and the phase separation of water, which resulted in a foamed phenolic resin with uniformly distributed small-size voids ( $500 \mathrm{~nm}$ ) and an overall solid density of $70 \%$. Assuming a density of about $1200 \mathrm{~kg} \mathrm{~m}^{-3}$ for the unfoamed phenolic resin, the density of the porous resin is estimated to be $d \sim 840 \mathrm{~kg} \mathrm{~m}^{-3}$. The authors also demonstrated that the mechanical properties of the porous materials were competitive with those of void-free resins. It is however important to point out that the resulting foams have higher densities than phenolic foams obtained using exogenous blowing agent such as pentane for which $d \lesssim 100 \mathrm{~kg} \mathrm{~m}^{-3}$.[218]

Thanks to their high flexural strength and modulus, these resins are of particular interest as light and robust materials for the aerospace industry, and might be of interest in many PPE related applications, notably as energy-adsorbing foams for the prevention of mechanical hazards.

It is worth mentioning that most precursors of phenolic resins are provided as water-based formulations. In the system described by Hamad et al., the initial amount of water played the 
role of an exogenous blowing agent that accelerated the phase separation process resulting in the porous structure. For this reason, these phenolic resins can be considered as hybrid foamingsystems with both exogenous and endogenous blowing agent involved in the growth of the cavities.

\section{Polycondensation of carboxylic acids and alcohols}

Polyesters obtained by polycondensation of dicarboxylic acids and diols were among the first synthetic polymers used for industrial purposes. For instance poly(ethylene terephthalate) (PET) was patented in 1941.[219,220] Polyester foams are usually obtained by using ExCB or physical blowing agents [3,221,222]. However, examples of self-foaming polyesters were also reported by using the water released during the condensation of acid and alcohols as an endogenous blowing agent (Figure 20.2).

The fully bio-based and biodegradable resins developed by Plantics are typical examples of polyester foams produced by this process.[223] The resins are based on simple mixtures of widely available glycerol and citric acid heated between 80 and $180^{\circ} \mathrm{C}$ (Figure 21a). Rigid and flexible foams were prepared, with density ranging from 100 to $800 \mathrm{~kg} \mathrm{~m}^{-3}$. Interestingly, for curing temperatures above $140{ }^{\circ} \mathrm{C}$, an additional self-foaming mechanism was operational. Indeed, the slow decarboxylation of citric acid resulted in the formation of itaconic acid with the concomitant release of $\mathrm{CO}_{2}$ and additional water. The Plantics system is thus nicely illustrating that both a condensation reaction and the degradation of a thermolabile group can be simultaneously involved in the self-foaming process. It is now being produced on the ton scale in The Netherlands under the trade names Glycix and Plantics-GX.[224] This type of resin has a huge potential as alternative to petro-based foams in a variety of real-life applications, including in the PPE sector.

Alternatively, polyester resins can also be obtained by polycondensation of carboxylic acids and acetoxy terminated precursors (i.e. protected alcohols). This reaction was exploited by Bakir et al. for producing branched aromatic thermosetting copolyesters (ATSP; Figure 21b).[225,226] They used curing-blowing temperatures, $T_{c-b}$, comprised between $200{ }^{\circ} \mathrm{C}$ and $330{ }^{\circ} \mathrm{C}$. For $T_{c-b} \geq 275{ }^{\circ} \mathrm{C}$, they observed that the acetic acid released during the polycondensation reaction expanded the material. The densities of the resulting foams are ranged from 400 to $700 \mathrm{~kg} \mathrm{~m}^{-3}$.[74,75,227] ATSP foams were characterized by their high thermal stability, good chemical resistance, low moisture uptake and low dielectric constant. They have been used as bone substitutes.[228] To our knowledge, they have never been used for the fabrication of PPE, but they could be of interest as thermal or electrical insulators.

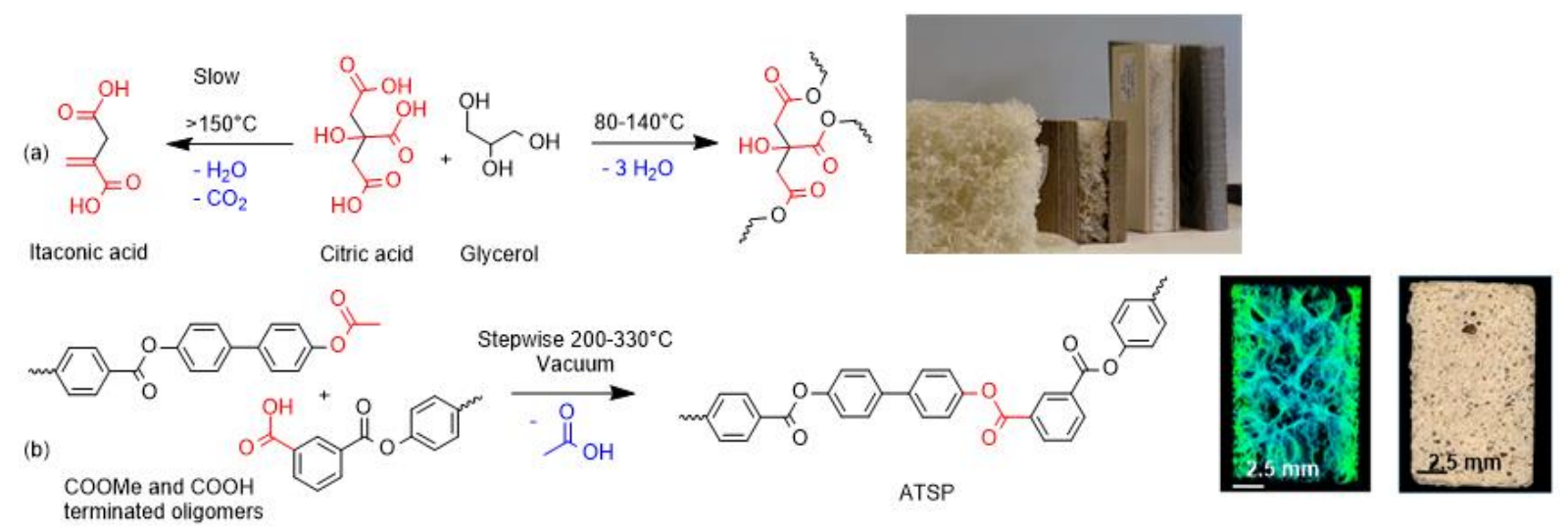

Figure 21: Self-foaming (a) biobased Plantics and (b) aromatic polyesters. (a) is adapted from [223] with permission from the Royal Society of Chemistry, Copyright (2017) and (b) is adapted with permission from [74], Copyright (2016), American Chemical Society. 


\section{3. (Ket)imine formation}

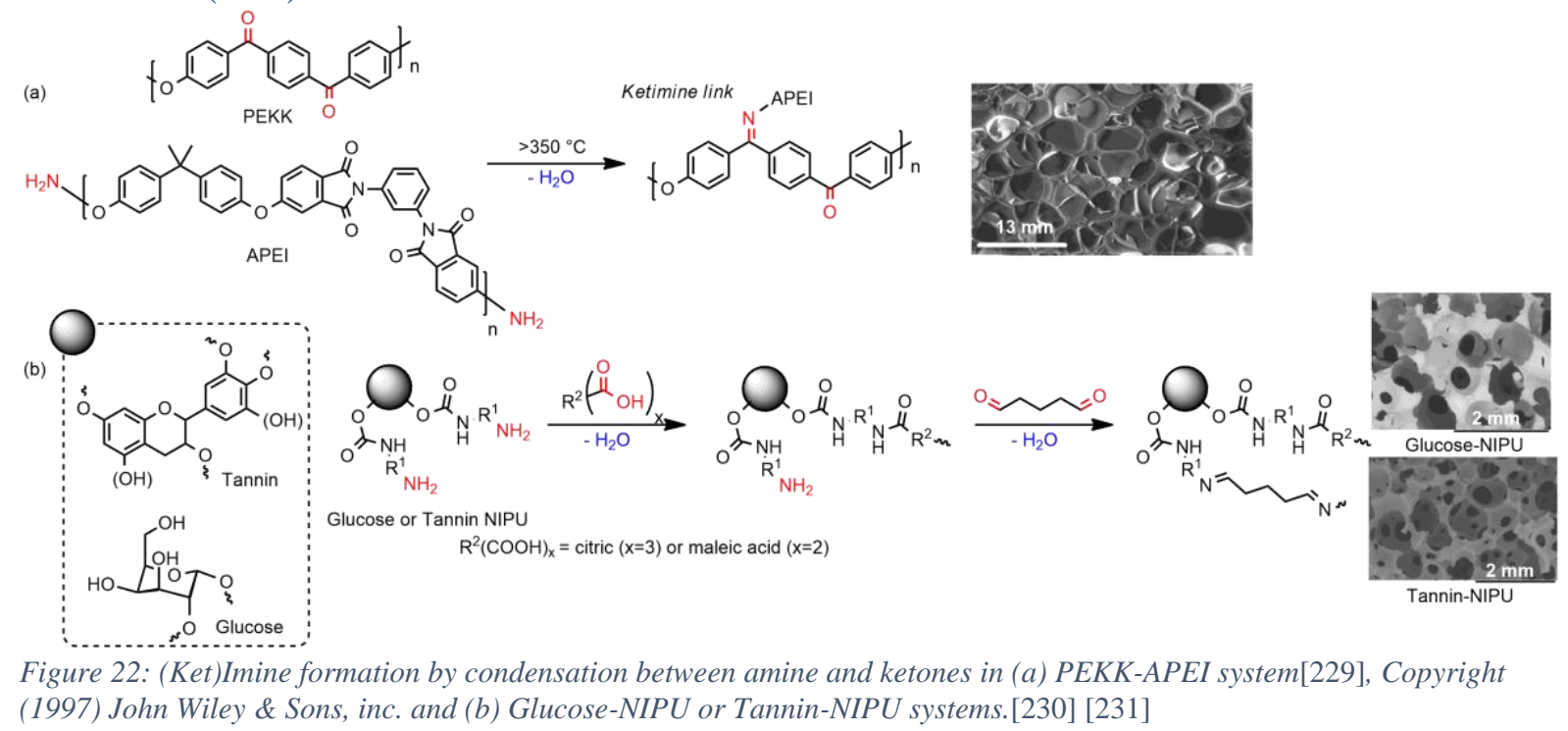

The condensation of amine and carbonyl (e.g. aldehydes or ketones) is another example of reaction resulting in the in-situ production of water that can be exploited to expand polymers (Figure 20.3). To our knowledge, Brandom $e t$ al. were the first to report the use of this reaction for the production of self-foamed polymers.[229] An amine-terminated polyetherimide (APEI) was blended with a poly(aryl ether ketone) (PAEK) in an extruder at $300^{\circ} \mathrm{C}$ resulting in the concomitant crosslinking of the blend and the in-situ production of gaseous water (Figure 22a). By playing with the various parameters of the system, including the composition of the prepolymers, the screws' speed, the extrusion temperature and the residence time in the extruder, the authors obtained foamed materials with densities varying between 400 and 1200 $\mathrm{kg} \mathrm{m}^{-3}$. As the resulting polymers presented a high $T_{g}$ polymers and low smoke emissions when exposed to a flame, the potential applications of these foams can be found in aircraft cabins, space vehicles and other transports environments where life or equipment might be endangered by overheating. According to Brandom et al., the ketimine-foam process is an easily exploitable system to engineer foams with thermal and acoustic insulating properties.

This type of reaction was also exploited by Pizzi et al. for blowing glucose and tannin based non-isocyanate polyurethanes (NIPU) (Figure 22b).[230-232] The authors described the crosslinking of a NIPU bearing pendent amino functions with glutaraldehyde. After water evaporation, they obtained foams with densities between 80 and $130 \mathrm{~kg} \mathrm{~m}^{-3}$ in the case of the glucose-based NIPU and between 120 and $260 \mathrm{~kg} \mathrm{~m}^{-3}$ in the case of the tannin-based NIPU. Both open and closed cells were observed. It is worth mentioning that maleic and citric acid were used as co-crosslinkers of glutaraldehyde. The condensation of the $\mathrm{NH}_{2}$ functions of the NIPU precursors with the $\mathrm{COOH}$ groups of maleic and citric acid resulted in the formation of further crosslinking points (amide bonds) as well as additional water that contributes to the foaming step.

According to the authors, these foams could be useful as thermal insulation materials. It is important to point out that these examples are not purely self-foamed materials. Indeed, glutaraldehyde used for the reaction was provided as a 50\% water solution. Thus, similarly to the phenolic resins mentioned earlier, an initial amount of water was present in the system. Both exogenous and endogenous water were thus involved in this foaming procedure. 


\section{Intramolecular condensation of poly(amide acid)s and poly(amide ester)s}

Polyimide foams (PIF) were prepared from poly(amide acid) (PAA) or poly(amide ester) (PAE) precursors as illustrated in Figure 20.4 and Figure 23. The intramolecular cyclisation of the poly(amide acid/ester) - by condensation of the amide with the ester or the acid - is usually referred to as an imidization reaction. Imidization results in the formation of the polyimide with the evolution of volatile $\mathrm{XOH}(\mathrm{X}=\mathrm{H}$ or alkyl). The latter can be used as an endogenous blowing agent. In particular, the American National Aeronautics and Space Administration (NASA) developed a series of polyimide foams obtained by treating a poly(amide ester) $(\mathrm{X}=$ methyl) at selected temperatures between $150^{\circ} \mathrm{C}$ and $220^{\circ} \mathrm{C}$. The authors assumed that methanol released during the formation of the imide moieties contributed to the expansion of the matrix together with the evaporation of residual THF used for the synthesis of the poly(amide ester) (Figure 23).[233-236] Again, this is an hybrid foaming system using both endogenous and exogenous blowing agents. The resulting foams exhibited high thermal stability and compressive strength, as well as low thermal conductivity. They were thus used as cryogenic insulators in Reusable Launch Vehicles.[237]

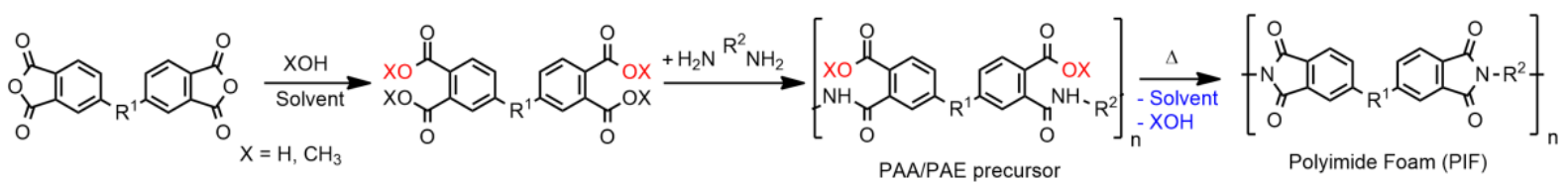

Figure 23: General procedure for the preparation of polyimide foams.

As mentioned earlier in section II, polyimide foams were also obtained by using endogenous blowing agents resulting from the thermal degradation of functional groups attached to polyimide precursors. These functional groups include carbamic anhydrides (Figure 7), carboxylic acid (Figure 17), and nadimide (Figure 19). In reality, for those systems, the selffoaming mechanism based on thermolysis is often concomitant with the intramolecular condensation of the PAA or PAE precursors, meaning that two self-foaming mechanisms are simultaneously at play. In this review, they were treated separately for the sake of clarity. Comprehensive review describing the possible interplay between the different foaming mechanisms and with side reactions involved in polyimide synthesis can be consulted elsewhere [238,239].

The interest of polyimide foams in personal protection relies on their excellent thermal stability, which is a big asset for application where fire resistance or extreme cold are issues. Their tunable thermal and mechanical properties render them suitable for many heavy-duty functions, e.g. thermal, EMI or acoustic wave shielding among others.[239] Their very low density (i.e. usually below $100 \mathrm{~kg} \mathrm{~m}^{-3}$ ) associated with good mechanical properties allow their use in sectors were lightweight structural materials are required, e.g. aeronautics or spatial applications.

\section{Polycondensation of hydrosiloxanes and amines}

The use of poly(methylhydrosiloxane) (PMH) compounds as a mean to prepare self-blowing epoxy foams was first reported decades ago.[240,241] Stefani et al. reported the use of commercially available PMH to prepare closed-cell epoxy foams finding applications in various sectors such as in automotive or aeronautics.[242] The blowing agent was gaseous dihydrogen 
resulting from the condensation of the hydrosiloxane with the amine hardener comprised in the formulation leading to a silazane moiety incorporated in the network (Figure 20.5A).

This work inspired more recent developments with the use of $\mathrm{PMH}$ as blowing agents for various biobased polymer matrices. Epoxy foams based on cashew nut shell liquid extract,[243] microalgae oil,[244] pin[87] and soybean oil,[86,245] were self-foamed by using PMH as a cohardener of the epoxy resin. They find potential applications as structural materials, adhesives, electronical systems components, thermal and vibration isolation or for biomedical applications. Cavasin et al. studied glass-fiber reinforced epoxy foams blown by PMH for thermal insulation.[246]

Cheng et al. expanded epoxy formulations with a polysilazane (PSN) compound instead of PMH.[247] The difference with PMH is the nature of the released gazes. In the case of PSN, gaseous dihydrogen is released first, followed by the formation of ammonia as schematized in Figure 24a.

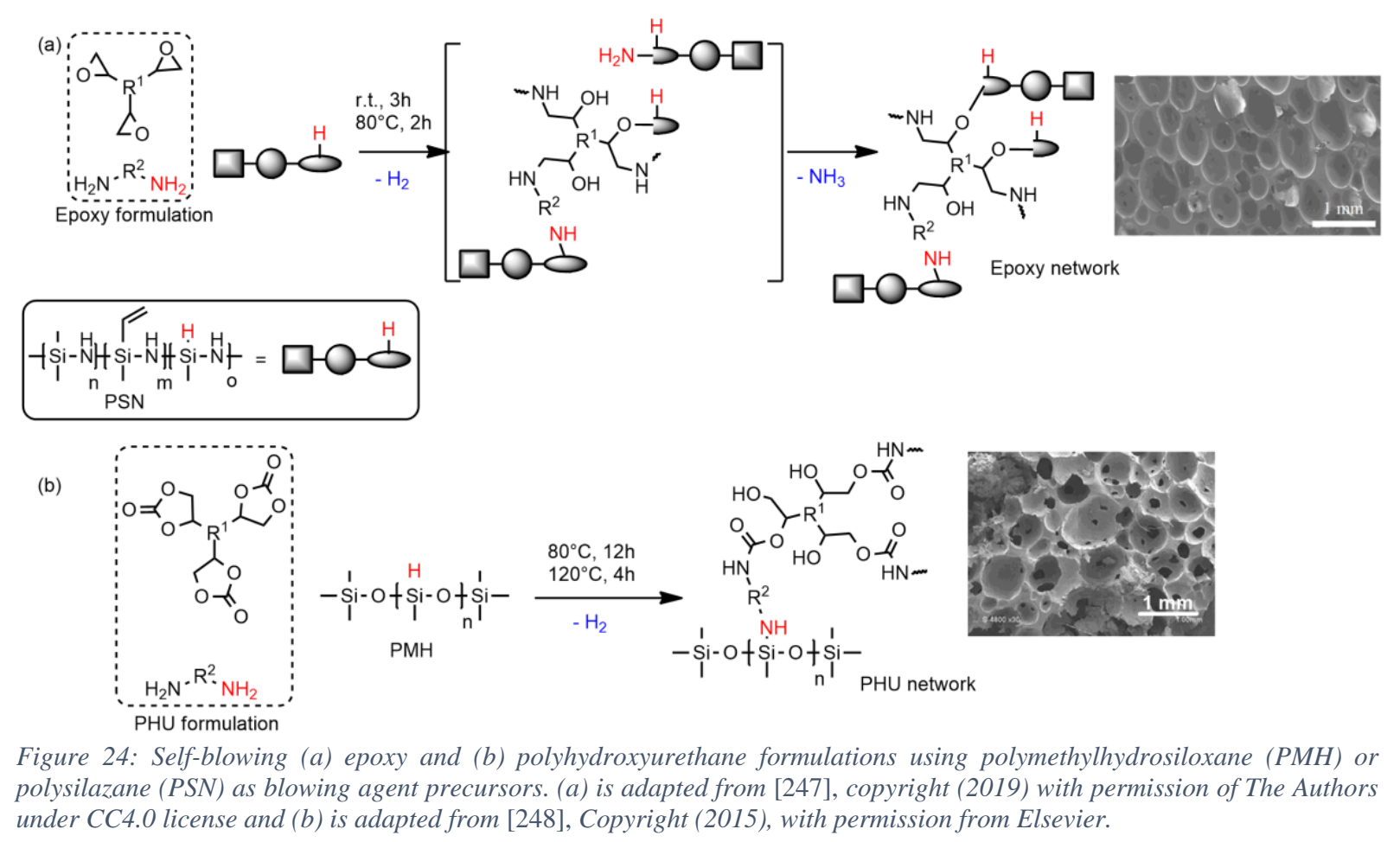

The concept was also extended to other matrices that are difficult to foam by endogenous BA, such as poly(hydroxyurethane) (PHU), a family of non-isocyanate polyurethanes, that are accessible by the polyaddition of poly(cyclic carbonate)s to polyamines (Figure 20.5B).[249,250] As the formulation does not contain isocyanates, they cannot foam by thermal decomposition of carbamic acids. The preparation of high density, flexible self-foaming PHU was recently reported by Caillol et al. by adding PMH to a PHU formulation.[248,251] The concomitant aminolysis of the cyclic carbonate provided the urethane linkage of the polymer matrix and the reaction of $\mathrm{PMH}$ with amine liberated the blowing agent, i.e. $\mathrm{H}_{2}$, while $\mathrm{PMH}$ was grafted to the PHU matrix (Figure 24b).

\section{6. (Poly)condensation of cyclic carbonates with thiols}

In recent years, cyclic carbonates have risen great interest as $\mathrm{CO}_{2}$-sourced polymer precursors,[252,253] notably for preparing PHUs, the most widely investigated non-isocyanate polyurethanes. Although self-foaming PHUs were reported by Caillol as discussed above by generating in-situ $\mathrm{H}_{2}$ as the blowing agent, huge efforts were devoted to mimic the conventional 
self-foaming PU that utilizes $\mathrm{CO}_{2}$ as the blowing agent, generated by hydrolysis of isocyanates during the polymer construction (see section III.1). However, cyclic carbonates are much less sensitive to hydrolysis than isocyanates and do not generate spontaneously $\mathrm{CO}_{2}$ under the operating conditions used for preparing PHUs.

Clark et al. was the first to report the preparation of self-foaming PHUs by a partial decarboxylation of a particular 5-membered cyclic carbonate, sorbitol bis-carbonate (Figure 20.6A).[254] In this work, once the cyclic carbonate reacted with a diamine to form PHU, the cyclic carbonate chain-end underwent an intramolecular decarboxylation, leading to both $\mathrm{CO}_{2}$ generation and chain termination (Figure 25a). Fully bio-based porous materials were prepared however, the formulation scope was limited to this specific bis-cyclic carbonate.

Recently, Detrembleur et al. described a robust and versatile self-blowing PHU process by adding (di)thiol(s) to PHU formulations in the presence of a suitable catalyst (Figure 20.6B).[58,59] Beside the formation of PHU by aminolysis of the cyclic carbonate, Sthioalkylation of the cyclic carbonate occurred with the formation of a thioether bond and the release of $\mathrm{CO}_{2}$ as the blowing agent (Figure 25b). Depending on the formulation, flexible or rigid PHU foams with an open porosity and a density ranging from 60 to $400 \mathrm{~kg} \mathrm{~m}^{-3}$ were prepared at 80 to $120^{\circ} \mathrm{C}$. As this process is highly versatile with a multitude of accessible cyclic carbonates, amines and thiols, and is compatible to the use of reinforcing nanofillers (such as (nano)clay), it thus offers the first realistic alternative to conventional self-blown PU foams to cover a broad range of applications, including in PPE. For instance, the highly flexible PHU foams [58,59] are of great promise for comfort applications (for matrasses, cushions, etc.) or shock absorption (shoes soles, helmet, etc.). Development of PHU foams with a closed-cell structure is also highly appealing for designing thermal insulating panels for the construction sector.

(a)

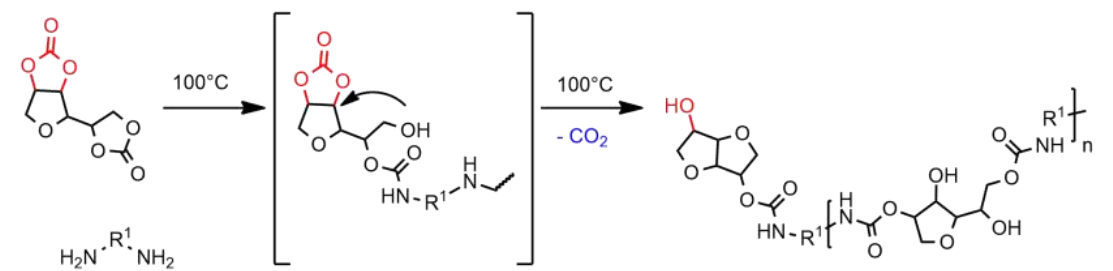

One of four possible repeating units is represented

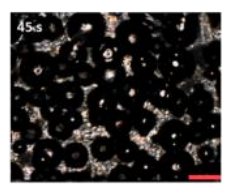

(b)
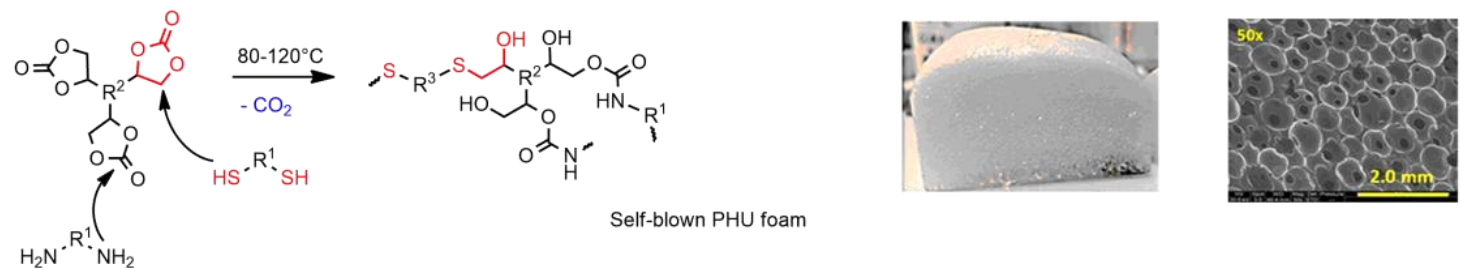

Figure 25: Self-blowing PHU formulations prepared by (a) intramolecular decarboxylation of a sorbitol biscyclic carbonate and $(b)$ decarboxylation promoted by S-thioalkylation. (a) is adapted with permission from [254] Copyright (2018) WILEYVCH Verlag GmbH \& Co. KGaA, Weinheim and (b) is adapted with permission from [58] Copyright (2020) Wiley-VCH Verlag GmbH \& Co. KGaA, Weinheim

\section{Discussion, conclusion and perspectives}

This work summarizing the state-of-the-art of self-foaming polymers reveals that endogenous chemical blowing agents - i.e. chemical blowing agents embedded in the molecular structure of the macromolecules or its precursors - go far beyond the mainstream isocyanate chemistry. An assorted range of self-foaming polymers has been described over the past decades and is now available to address new technological challenges, including in the field of PPE. Two self- 
foaming strategies have been distinguished. They are based on the release of a blowing gas stemming from $(i)$ the decomposition of thermolabile groups, or (ii) a (poly)condensation reaction that is involved in the construction of the polymer, respectively.

All these systems share common advantages that help overcoming some of the persistent limitations of exogenous blowing agents during the three conventional stages of a foaming process: $(i)$ the blend, (ii) the blowing and (iii) the foam stabilization. Remarkably, the blowing agent being covalently attached to the (pre)polymer, it is naturally homogeneously dispersed in the system, with no need of intricate mixing procedure to ensure the blend of the (pre)polymer and the blowing agent. Moreover, as underlined in the precedent classification, the release of the blowing agent results in a modification of the molecular structure of the (pre)polymer that usually triggers the phase transition of the latter via an increase of the $T_{g}$ or/and of the molecular weight. Thus, the in-situ release of the blowing agent and the phase transition of the polymer are concomitant. The resulting synchronization of both transformations help ensuring the success of the blowing and the stabilization steps. In the end, the main limitations of classical foaming methodologies (i.e., inhomogeneous mixing and out-of-sync transformations of the polymer and the blowing agent) are naturally circumvented in self-foaming polymers.

From the processing viewpoint, self-foaming (pre)polymers are one-pack, ready-to-use systems, with a very simple procedures for the operator. They can adapt to virtually all processing technologies including casting, injection molding or extrusion. It is also worth noting that the blowing agents released in these systems are usually small, environmentally benign molecules such as $\mathrm{CO}_{2}, \mathrm{H}_{2} \mathrm{O}$ or halide-free alkanes (see Table 1 and 2). For these reasons, most of self-foamed (pre)polymers can be used for the synthesis of advanced foamed materials in an eco-friendly fashion and with a high degree of safety for the end-user. They are suitable for the production of the next generation of PPE, in accordance with the latest regulations for health and environment. Exceptions are the self-blown polymers produced by releasing isobutene or $\mathrm{H}_{2}$ that require special protected environment during foaming due to the release of these highly flammable blowing agents.

Table 1 and Table 2 summarize the typical range of density, pore size and thermomechanical properties explored with the self-foaming processes based on (i) thermolysis and (ii) (poly)condensation, respectively.

Table 1: Typical properties of the foams obtained using self-foaming techniques based on thermolysis. * Polymer matrix that are obtained from readily available commercial precursors

\begin{tabular}{|c|c|c|c|c|c|c|c|}
\hline $\begin{array}{c}\text { Thermolabile } \\
\text { functions }\end{array}$ & $\begin{array}{l}\text { Blowing } \\
\text { gas }\end{array}$ & Polymer matrix & $\begin{array}{c}\text { Densities } \\
\left(\mathrm{kg} \mathrm{m}^{-3}\right)\end{array}$ & Morphology & Pore size, $\mathbf{D}(\mu \mathrm{m}$ & $T_{g}\left({ }^{\circ} \mathrm{C}\right)$ & $\begin{array}{c}\text { Mechanical } \\
\text { behavior }\end{array}$ \\
\hline carbamic acid & $\mathrm{CO}_{2}$ & $\begin{array}{c}\text { Polyurethane }+ \\
\text { polyurea[105,106]* }\end{array}$ & $40-500$ & $\begin{array}{c}\text { Open or closed } \\
\text { cells }\end{array}$ & $100-300$ & $-40-110$ & Flexible or Rigid \\
\hline \multirow{2}{*}{$\begin{array}{l}\text { carbamic } \\
\text { anhydrides }\end{array}$} & \multirow{2}{*}{$\mathrm{CO}_{2}$} & $\begin{array}{c}\text { Polyurethane + } \\
\text { polyamide[123]* }\end{array}$ & $45-76$ & $\begin{array}{l}\text { Mix of open and } \\
\text { closed cells }\end{array}$ & NA & $2-5$ & Flexible \\
\hline & & Aromatic polyimide[126]* & $13-15$ & Open cells & $400-1300$ & $287-299$ & Rigid \\
\hline $\begin{array}{c}\text { Covalent } \\
\text { carbamates }\end{array}$ & $\mathrm{CO}_{2}$ & $\begin{array}{c}\text { Aromatic epoxy-amine } \\
\text { resin[137] }\end{array}$ & NA & Closed cells & $10-400$ & $112-163$ & Rigid \\
\hline \multirow{2}{*}{$\begin{array}{c}\text { Ionic } \\
\text { carbamates }\end{array}$} & \multirow{2}{*}{$\mathrm{CO}_{2}$} & $\begin{array}{l}\text { Aromatic epoxy-amine } \\
\text { resin }[56,144,145]\end{array}$ & $110-496$ & Closed cells & $55-5000$ & $76-146$ & Rigid \\
\hline & & Polyurethanes[146-148] & $86-169$ & Closed cells & NA & NA & NA \\
\hline \multirow{2}{*}{$\begin{array}{l}\text { Carbonate } \\
(t \text {-Boc })\end{array}$} & \multirow{2}{*}{$\begin{array}{c}\mathrm{CO}_{2} / \\
\text { isobutene }\end{array}$} & $\begin{array}{l}\text { poly(phenylquinoxaline)s [ } \\
98,158]\end{array}$ & NA & Closed cells & $0.008-5$ & 370 & Rigid \\
\hline & & poly(hydroxyamide)[160] & 1020 & Open cells & $0.010-0.100$ & NA & Rigid \\
\hline $\begin{array}{l}\text { Diaromatic } \\
\text { carbonate }\end{array}$ & $\mathrm{CO}_{2} / \mathrm{H}_{2} \mathrm{O}$ & Aromatic resin[ $[167,255]$ & $170-1100$ & $\begin{array}{l}\text { Mix of open and } \\
\text { closed cells }\end{array}$ & $77-117$ & NA & NA \\
\hline tert-butyl ester & isobutene & Polyacrylates[169-171] & NA & $\begin{array}{l}\text { Mix of open and } \\
\text { closed cells }\end{array}$ & $0.120-0.200$ & 40 & NA \\
\hline
\end{tabular}




\begin{tabular}{|c|c|cccccc}
\hline & & $\begin{array}{c}\text { Aliphatic epoxy-acid } \\
\text { resin[187]* }\end{array}$ & $230-500$ & Closed & NA \\
\cline { 3 - 6 } $\begin{array}{c}\text { Carboxylic } \\
\text { acid }\end{array}$ & $\mathrm{CO}_{2}$ & Polybenzoxazine[57,190] & $38-228$ & $\begin{array}{c}\text { Open cells } \\
\text { Or mix of open } \\
\text { and closed cells }\end{array}$ & $69-218$ & $228-244$ \\
\cline { 2 - 6 } & & Aromatic Polyimide[195] & $75-150$ & Closed cells & $100-500$ & $248-260$ \\
\hline $\begin{array}{c}\text { Meldrum's } \\
\text { acid }\end{array}$ & $\begin{array}{c}\mathrm{CO}_{2} / \\
\text { Acetone }\end{array}$ & $\begin{array}{c}\text { Polysulfide } \\
\text { thermosets[212] }\end{array}$ & NA & Open cells & NA \\
\hline Niadimide & $\begin{array}{c}\text { Cyclopenta } \\
\text { diene }\end{array}$ & Aromatic polyimide[214] & $50-400$ & Closed cells & $200-600$ & $361-389$ \\
\hline
\end{tabular}

Table 2: Typical properties of the foams obtained using self-foaming techniques based on (poly)condensation. * Polymer matrix that are obtained from readily available commercial precursors

\begin{tabular}{|c|c|c|c|c|c|c|c|}
\hline $\begin{array}{l}\text { Condensation } \\
\text { reaction }\end{array}$ & $\begin{array}{l}\text { Blowing } \\
\text { gas }\end{array}$ & Polymer matrix & $\begin{array}{l}\text { Densities } \\
\left(\mathrm{kg} \mathrm{m}^{-3}\right)\end{array}$ & Morphology & $\begin{array}{c}\text { Pore size, } \\
\text { D }(\mu \mathrm{m})\end{array}$ & $T_{g}\left({ }^{\circ} \mathrm{C}\right)$ & $\begin{array}{l}\text { Mechanical } \\
\text { behavior }\end{array}$ \\
\hline $\begin{array}{l}\text { Phenol- } \\
\text { Formaldehyde }\end{array}$ & $\mathrm{H}_{2} \mathrm{O}$ & Phenolic resin[100]* & 840 & NA & 0.5 & NA & Rigid \\
\hline $\begin{array}{l}\text { Carboxylic } \\
\text { acid-alcohol }\end{array}$ & $\mathrm{CO}_{2}$ & Aliphatic Polyester[223]* & $100-800$ & $\begin{array}{l}\text { Open or closed } \\
\text { cells }\end{array}$ & NA & $70-80$ & Flexible and Rigid \\
\hline $\begin{array}{l}\text { Carboxylic } \\
\text { acid-acetoxy }\end{array}$ & $\mathrm{CH}_{3} \mathrm{COOH}$ & $\begin{array}{c}\text { Aromatic } \\
\text { Polyester[ }[74,75,227,228]\end{array}$ & $420-630$ & $\begin{array}{l}\text { Mix of open } \\
\text { and closed cells }\end{array}$ & NA & $170-190$ & Rigid \\
\hline \multirow{3}{*}{ Amine-ketone } & \multirow{3}{*}{$\mathrm{H}_{2} \mathrm{O}$} & $\begin{array}{l}\text { poly(aryl ether ketone) } \\
\text { (PAEK)[229]* }\end{array}$ & $400-1200$ & Closed cells & NA & NA & Rigid \\
\hline & & Glucose-NIPU[230,232] & $80-130$ & $\begin{array}{l}\text { Mix of open } \\
\text { and closed cells }\end{array}$ & NA & NA & Rigid \\
\hline & & Tannin-NIPU[231] & $120-260$ & Open cells & NA & NA & Rigid \\
\hline $\begin{array}{c}\text { Intramolecular } \\
\text { condensation } \\
\text { of poly(amide } \\
\text { acid or ester)s } \\
\text { (PAA-PAE) } \\
\end{array}$ & $\begin{array}{c}\mathrm{ROH} \\
(\mathrm{R}=\mathrm{H}, \mathrm{Me}, \mathrm{Et})\end{array}$ & Aromatic polyimide[ $[233,234]$ & $32-128$ & NA & NA & $237-320$ & Rigid \\
\hline \multirow{3}{*}{$\begin{array}{l}\text { Amine- } \\
\text { hydrosiloxane }\end{array}$} & \multirow{3}{*}{$\mathrm{H}_{2}$} & Aromatic Epoxy-amine[242]* & $170-500$ & Closed cells & $240-310$ & 90 & Rigid \\
\hline & & $\begin{array}{l}\text { Aliphatic Epoxy- } \\
\text { amine[243,244]* }\end{array}$ & $172-557$ & $\begin{array}{l}\text { Closed cells or } \\
\text { mix of open } \\
\text { and closed cells }\end{array}$ & $150-1100$ & $-10-47$ & Rigid or flexible \\
\hline & & Polyhydroxyurethanes $[248,251]^{*}$ & $194-295$ & Open cells & $140-1300$ & $-18-19$ & Flexible \\
\hline $\begin{array}{c}\text { Cyclic } \\
\text { carbonate-thiol }\end{array}$ & $\mathrm{CO}_{2}$ & $\begin{array}{c}\text { Aliphatic } \\
\text { Polyhydroxyuréthanes[58,59] }\end{array}$ & $78-315$ & $\begin{array}{l}\text { Mix of open } \\
\text { and closed cells }\end{array}$ & $600-980$ & $2.4-7.9$ & Flexible \\
\hline
\end{tabular}

In terms of end-properties of the resulting foams, self-foaming of polyurethanes through the decomposition of in-situ generated carbamic acid is by far the most versatile and the most mature technology on the market since decades. This approach is based on one of the oldest chemistries of polymer history, the isocyanate chemistry, that has been adapted to all sorts of precursors (aliphatic, aromatic, etc.) and processing techniques (casting, extrusion, etc.). The attainable properties of the foams obtained by using this chemistry are virtually infinite in terms of density, $d$, $\left(40-500 \mathrm{~kg} \mathrm{~m}^{-3}\right)$, pore size, $D,(100-300 \mu \mathrm{m})$ morphology (open or closed cells), and thermo-mechanical properties (flexible or rigid foams with $-40{ }^{\circ} \mathrm{C}<T_{g}<110{ }^{\circ} \mathrm{C}$ ). In comparison, the present review demonstrates that no other self-foaming methods has been developed to the same degree of maturity. 
However, the diversity of the other available approaches permits to foam other polymer matrices including thermoplastics and thermosets, and to span the entire range of common foam densities and thermo-mechanical properties. This is well illustrated in Figure 26, representing the range of density and $T_{g}$ that can be explored by the different self-foaming methods described in the present review (when provided by the authors). It is important to note that these ranges are those reported in the cited works and for most of the processes, it is expected that they might be extended by adapting the formulations (e.g. composition, content of endogenous blowing agent, catalyst, etc.) and the foaming conditions (e.g. temperature).

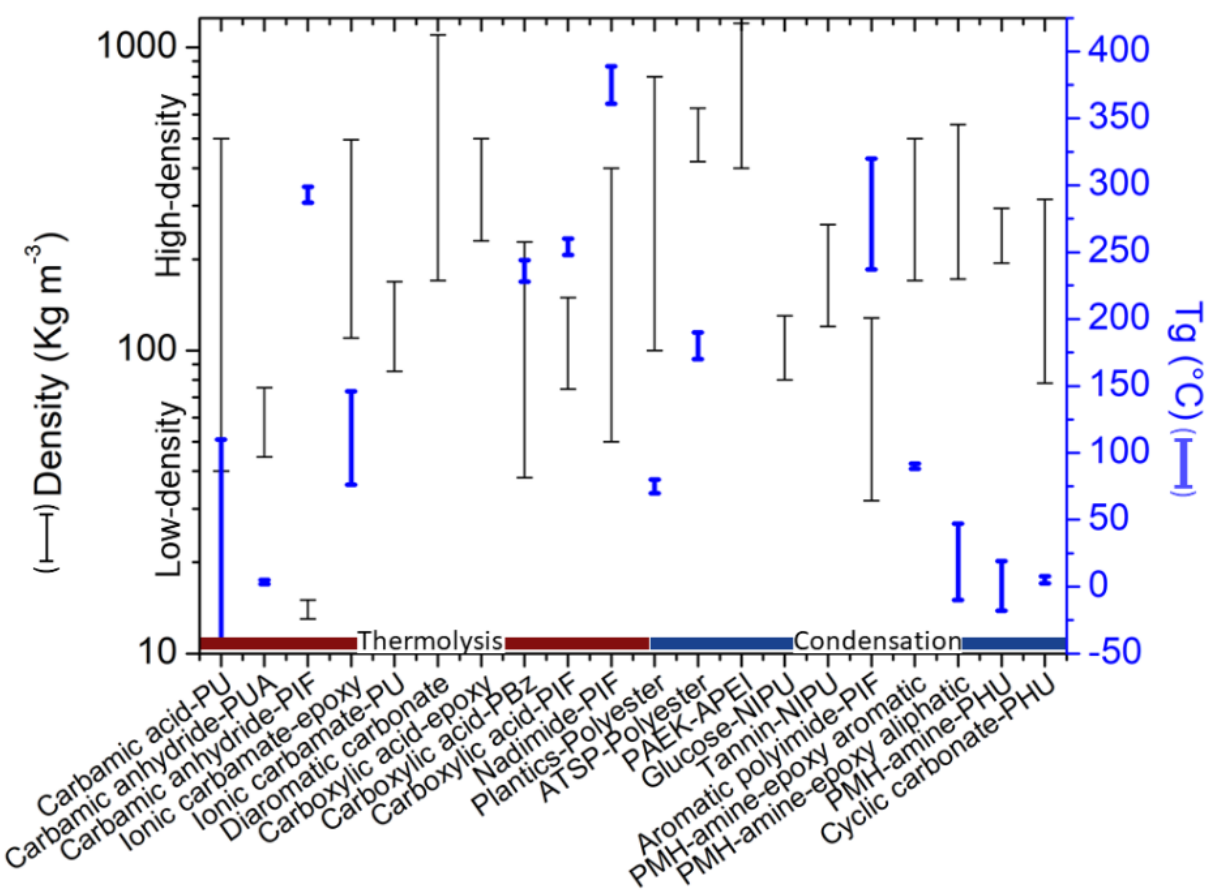

Figure 26: The typical range of foam density and glass transition temperature (Tg) obtained by using self-foaming method presented in the review (when provided). $[56-59,74,75,98,100,105,106,123,126,137,144-$ $148,158,160,167,170,171,187,190,195,212,214,223,227-229,233,237,242-244,248,251,255]$

In the context of toxicity concerns related to the use of isocyanates, the other self-foaming techniques described in this review are offering promising alternatives to develop safer and environmentally benign foaming technologies, notably for the sector of PPE. Their transfer to the industry is probably just a question of time and more importantly, cost. To our opinion and at the present stage, the most promising self-blowing techniques are certainly those for epoxy resins using ionic carbamates, polyimides and polyesters by polycondensation, and poly(hydroxyurethane)s by S-thioalkylation of cyclic carbonates. All these techniques are versatile in terms of polymer precursors and are quite easy to implement. Some of these selffoaming polymers are already on the market such as the polyester foam Plantics for composite sandwich panels or polyimide foams for aerospace applications.[224,256]

In the field of very high $T_{g}$ foams (> $300{ }^{\circ} \mathrm{C}$ ), it is interesting to note that self-foaming approaches have been rooted in the technological landscape for a long time. It is notably the case for polyimide foams. Their synthesis through the intramolecular condensation of poly(amide acid or ester) naturally results in the release of small molecules ( $\mathrm{ROH}, \mathrm{R}=\mathrm{H}, \mathrm{Me}$, Et) that contribute to the expansion of the matrix. Amine-ketone or amine-acid condensation reactions have also been used to develop self-foamed, high $T_{g}$, polymers for a long time (blowing gas $=\mathrm{H}_{2} \mathrm{O}$ ). One reason behind the interest for self-foaming methods in high $T_{g}$ polymers, is that glassy matrices can hardly be blown with conventional physical foaming 
methods due to the difficulty to homogeneously disperse a low boiling point compound in a vitrified polymer. It is however worth noting that these polymers are usually processed via a solvent assisted method, to lower the viscosity of the glassy domain, and that residual amounts of solvent always contribute to the foaming process. Thus, these systems are not purely selffoamed and were referred as hybrid systems in this review. The extent of the attainable densities $\left(40 \mathrm{~kg} \mathrm{~m}^{-3}<d<500 \mathrm{~kg} \mathrm{~m}^{-3}\right)$ and the diversity of the foam morphology (open or closed) are comparable with those of self-foaming PUs and illustrate the broad potential of hybrid approaches. The success of these hybrid approaches also supports the fact that, despite the numerous advantages of self-foamed (pre)polymers, they are not intended to supplant all the traditional foaming techniques based on exogenous blowing agent.

As emphasized earlier, the success of the most recent self-foaming methods is dependent on their industrial potential. Besides the conventional self-foaming polyurethanes that are on the market since decades, self-foaming epoxy resins based on ionic carbamates or poly(hydroxyurethane)s based on the thiol-carbonate chemistry are potentially meeting the requirements in terms of large-scale availability, cost and structural diversity of the precursors. They represent realistic alternatives in the field of thermosetting polymers and they will certainly find their place in the foam market, notably in response to new environmental legislations. There is still some room for improvements to compete with the cost and properties of self-foaming PUs, however their potential is high in many PPE sectors.

The sector of thermoplastic foams is largely dominated by very low-cost polymers (e.g., polyethylene, polypropylene, etc.), for which physical blowing methodologies (e.g. $\mathrm{CO}_{2}$, pentane) are very well developed, controlled and cost-effective. For this reason, the future of self-foaming thermoplastics is essentially located in the field of advanced and high value-added foams. In contrast to most thermosetting foams, the intrinsic nature of thermoplastics offers the opportunity to easily recycle the foam after the material end life, most often by melting and reshaping the polymer.

Independently of the industrial and economic viability of the self-foaming (pre)polymers presented in this review, a precise consideration of their potential in the different fields of the PPE sector is proposed below. Figure 27 summarizes the typical properties of the foams used to fulfill the protective functions of conventional PPE. These functions include: (i) filtration, in masks and membranes used to purify fluids involved in vital physiological functions (water, air),[11] (ii) sound insulation - or damping -, in hearing protective devices, [257] (iii) electrical insulation, for the protection against high-voltage discharge, $[258,259]$ (iv), thermal insulation, for the prevention of heat-cold induced injuries,[260] (v) EMI shielding, for the protection against electromagnetic pollution resulting from gigahertz electronic systems, [22,261] (vi) shock adsorption, for the prevention of mechanical hazards, $[19,262]$ (vii) flotation, in buoy and lifebelt used in recreative activities or rescuing emergencies,[263] and of course (viii) cushioning and comfort, to improve the wearability of PPEs, a decisive role to ensure the consistent use and thus the efficacy of a PPE.[264,265]

It is interesting to note that some characteristic features associated to a protective function are essentially dependent on $(a)$ the morphology of the porous network, while others mostly depend on $(b)$ the chemical nature of the matrix. For instance, the connectivity of the porous network of a filtration membrane - necessary to ensure the mass transportation of the fluid through the membranes - is mainly dependent on the open morphology of the cells. Inversely, the electrical conductivity of a composite foam used in EMI shielding is essentially dependent on the chemical nature of the polymer and the associated conducting fillers (e.g. carbon black, carbon nanotubes, graphene, metal-based particles, etc.). But the global protective function of the foam results from the synergetic association of its morphological and chemical features. Obviously, 
the function-properties associations suggested in this figure are just general, ideal tendencies based on non-quantitative criteria. It is virtually impossible to provide a range of densities or flexural modulus for applications as vast as sound insulation or shock absorption. They are provided as a guide to help drawing the general trends when considering a foam for a PPE application. We also recommend a specific book for more details on the structure-properties relationship of polymer foams which also greatly inspired this discussion.[266]

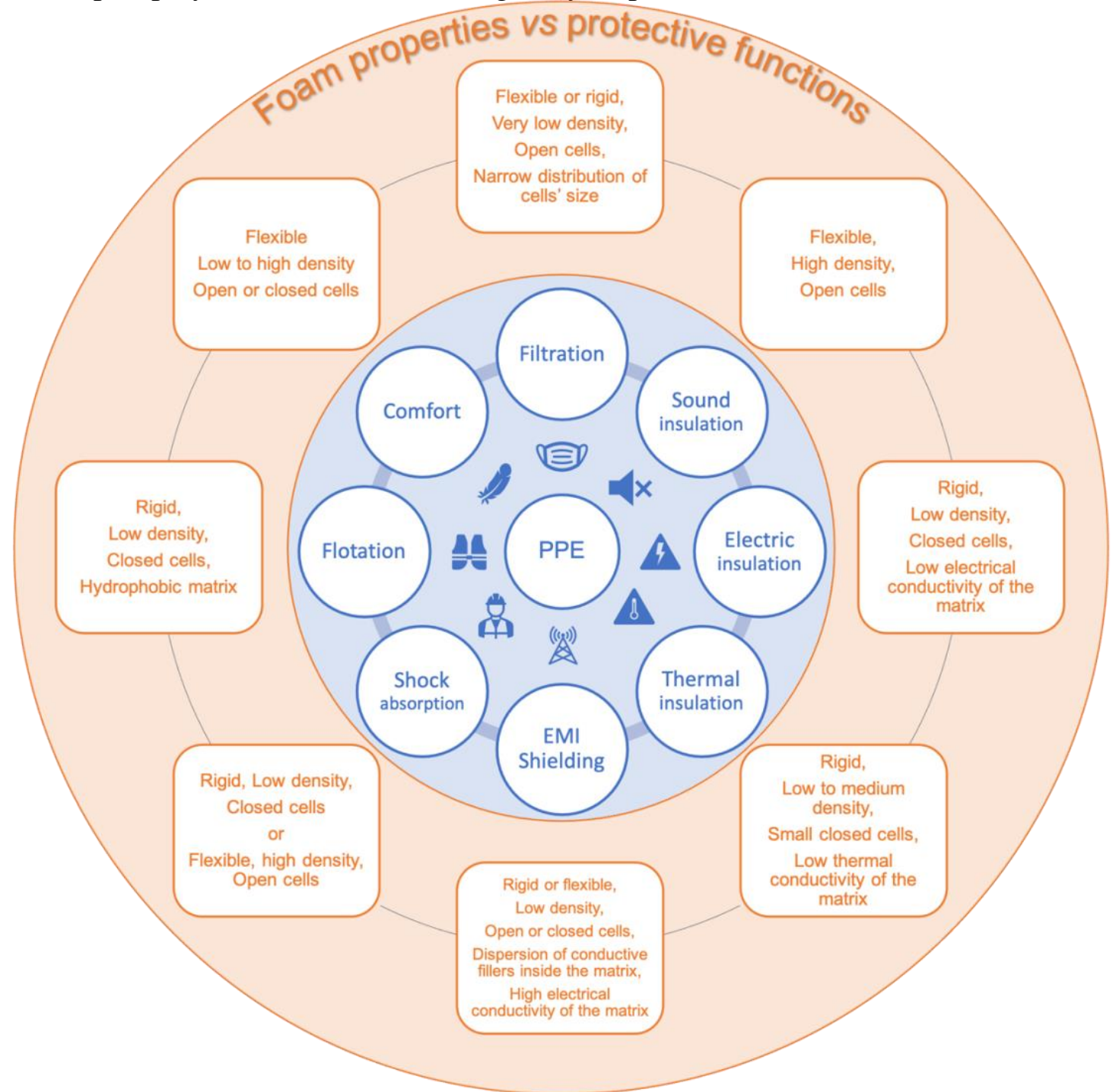

Figure 27: Typical properties expected from foams to fulfill protective functions in foam-containing PPE.[11,19,22,257-266]

When the function-properties associations of Figure 27 are viewed in parallel with the properties of the self-foaming (pre)polymers summarized in Table 1 and Table 2, it is possible to relate each self-foaming (pre)polymers to potential PPE applications. Table 3 summarizes the feasible associations. Again, it is important to emphasize that these associations are just provided as indicative guidelines to help scientists and $R \& D$ researchers from the foam sector - particularly in the field of foam-containing PPE devices - in identifying the most promising self-foaming methods for a given application, at the present time. They should not be considered as permanent rules for several reasons. First, they are based on the current development of the different self-foaming methods presented in the review. It is evident that self-foamed polyurethanes based on the in-situ generation of carbamic acid, that have been studied for decades, exhibit a wider range of properties than the most recent self-foamed polymers - for instance polyhydroxyurethanes - and are thus adapted to a larger number of PPE applications. The latest self-foaming methods will be extended to other PPE applications with 
their future applications to new chemical precursors and processing methods. A second reason explaining the potential variability of the associations suggested in Table 3 , is the intrinsic subjectivity of this type of classification, mostly based on non-quantitative criteria. For instance, the associations reported in Table 3 are based on the arbitrary criterium that any densities below $200 \mathrm{~kg} \mathrm{~m}^{-3}$ can be considered as a "low density". Moreover, the criteria purely associated to the properties of the polymeric matrix, such as the thermal or the electrical conductivity of the polymer, are not considered in Table 3 because these characteristics are usually not provided in the studies of the self-foaming polymers.

With all these precisions in mind, the analysis of Table 3 can be used to define general tendencies regarding the immediate potential of self-foaming polymers in the PPE sector. First, for all protective functions, there are at least three self-foaming (pre)polymers that could meet the expectations of the PPE sector. They are a priori immediately operational. As expected, for a given self-foaming mechanism, the PPE-association depends on the nature of the polymeric matrix. Indeed, the end properties of the foam (e.g., density, cell connectivity, flexural modulus, $T_{g}$ ), that dictate the PPE-association, depend on the physicochemical nature of the self-foaming precursors (e.g., molecular weight, aromaticity, viscosity) as much as they depend on the selffoaming mechanism. For instance, the polyurethanes foams obtained by decomposition of carbamic anhydrides are flexible, partially closed-cell materials that are adapted to comfort or shock absorption applications. Inversely, the polyimide foams obtained using the same selffoaming mechanism, are rigid, open-cell materials that are unsuitable for the aforementioned applications and are adapted to filtration purposes.

Unsurprisingly, self-foaming polyurethanes are ready to be used for all protective applications. Interestingly, when excluding all the self-foaming mechanisms based on isocyanate chemistry, at least one isocyanate-free alternative is available for all protective functions.

It is also worth mentioning that the self-blowing techniques with the most promising industrial potential, including self-foaming epoxy resins using ionic carbamates and self-foaming aliphatic polyesters based on the polycondensation of glycerol and citric acid (Plantics), can already meet the expectations of most protective functions. Given the sustainability and the innocuity of the precursors involved in these techniques, it is probably just a question of time before they are implemented in the PPE sector. Self-foaming polyhydroxyurethanes based on the S-thioalkylation of cyclic carbonates are still under development and are adapted to a limited number of protective functions. But the use of the same self-foaming mechanism with new precursors (e.g., aromatic) and processing technics (e.g., closed mold, extrusion), will certainly offer self-foamed materials spanning the entire range of PPE functions.

Table 3: Reported and potential PPE applications of self-foaming systems. Not exhaustive.

\begin{tabular}{|c|c|c|c|c|c|c|c|c|c|c|}
\hline \multicolumn{2}{|c|}{$\begin{array}{l}\text { Self-foaming } \\
\text { mechanism }\end{array}$} & Polymer matrix & $\begin{array}{l}\text { Water/air } \\
\text { filtration }\end{array}$ & $\begin{array}{c}\text { EMI } \\
\text { shielding }\end{array}$ & $\begin{array}{c}\text { Electric } \\
\text { discharge } \\
\text { protection }\end{array}$ & $\begin{array}{l}\text { Thermal } \\
\text { insulation }\end{array}$ & $\begin{array}{l}\text { Sound } \\
\text { insulation }\end{array}$ & $\begin{array}{c}\text { Shock } \\
\text { absorption }\end{array}$ & Flotation & Comfort \\
\hline \multirow{6}{*}{ 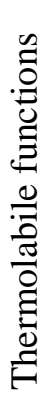 } & carbamic acid & $\begin{array}{c}\text { Polyurethane }+ \\
\text { polyurea[105,106] }\end{array}$ & $x$ & $x$ & $x$ & $x$ & $x$ & $x$ & $x$ & $x$ \\
\hline & \multirow{2}{*}{$\begin{array}{l}\text { carbamic } \\
\text { anhydrides }\end{array}$} & $\begin{array}{c}\text { Polyurethane }+ \\
\text { polyamide[123] }\end{array}$ & - & $x$ & - & - & $x$ & $x$ & - & $x$ \\
\hline & & Aromatic polyimide[126] & $x$ & $x$ & - & - & - & - & - & - \\
\hline & $\begin{array}{l}\text { Covalent } \\
\text { carbamates }\end{array}$ & $\begin{array}{c}\text { Aromatic epoxy-amine } \\
\text { resin[137] }\end{array}$ & - & $x$ & $x$ & $x$ & - & $x$ & $x$ & - \\
\hline & \multirow{2}{*}{$\begin{array}{c}\text { Ionic } \\
\text { carbamates }\end{array}$} & $\begin{array}{c}\text { Aromatic epoxy-amine resin } \\
{[56,144,145]}\end{array}$ & - & $x$ & $x$ & $x$ & - & $x$ & $x$ & - \\
\hline & & Polyurethanes[146-148] & - & $x$ & $x$ & $x$ & - & $x$ & $x$ & - \\
\hline
\end{tabular}




\begin{tabular}{|c|c|c|c|c|c|c|c|c|c|c|}
\hline \multirow{9}{*}{ 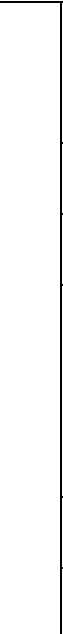 } & \multirow{2}{*}{$\begin{array}{c}\text { Carbonate } \\
(t \text {-Boc })\end{array}$} & $\begin{array}{l}\text { poly(phenylquinoxaline)s }[98 \\
, 158]\end{array}$ & - & $x$ & $x$ & $x$ & - & $\times$ & - & - \\
\hline & & poly(hydroxyamide)[160] & - & $x$ & - & - & - & - & - & - \\
\hline & $\begin{array}{l}\text { Diaromatic } \\
\text { carbonate }\end{array}$ & Aromatic resin[167,255] & - & $x$ & - & - & - & $x$ & - & - \\
\hline & tert-butyl ester & Polyacrylates[169-171] & $x$ & - & - & $x$ & - & - & - & - \\
\hline & & $\begin{array}{l}\text { Aliphatic epoxy-acid } \\
\text { resin[187] }\end{array}$ & - & $x$ & $\mathrm{x}$ & $\mathrm{x}$ & - & $\times$ & - & - \\
\hline & $\begin{array}{l}\text { Carboxylic } \\
\text { acid }\end{array}$ & Polybenzoxazine[57,190] & $x$ & $x$ & - & - & - & $x$ & - & - \\
\hline & & Aromatic Polyimide[195] & - & $x$ & $\mathrm{x}$ & $\mathrm{x}$ & - & $x$ & $x$ & - \\
\hline & $\begin{array}{l}\text { Meldrum's } \\
\text { acid }\end{array}$ & Polysulfide thermosets[212] & $x$ & - & - & - & - & - & - & - \\
\hline & Niadimide & Aromatic polyimide[214] & - & $x$ & $x$ & x & - & $x$ & $\mathrm{x}$ & - \\
\hline \multirow{11}{*}{ 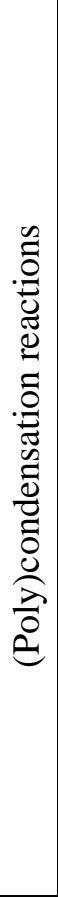 } & $\begin{array}{l}\text { Phenol- } \\
\text { Formaldehyde }\end{array}$ & Phenolic resin[100] & - & - & $x$ & $x$ & - & $x$ & - & - \\
\hline & $\begin{array}{c}\text { Carboxylic } \\
\text { acid-alcohol }\end{array}$ & Aliphatic Polyester[223] & $\mathrm{X}$ & $x$ & $x$ & $\mathrm{X}$ & $\mathrm{X}$ & $x$ & $\mathrm{X}$ & $x$ \\
\hline & $\begin{array}{c}\text { Carboxylic } \\
\text { acid-acetoxy }\end{array}$ & $\begin{array}{c}\text { Aromatic } \\
\text { Polyester[74,75,227,228] }\end{array}$ & - & $x$ & $x$ & $x$ & - & $\times$ & - & - \\
\hline & \multirow{3}{*}{ Amine-ketone } & $\begin{array}{l}\text { poly(aryl ether ketone) } \\
\text { (PAEK)[229] }\end{array}$ & - & $x$ & $\mathrm{x}$ & $\mathrm{x}$ & - & $x$ & - & - \\
\hline & & Glucose-NIPU[230,232] & - & $x$ & - & - & - & $x$ & - & - \\
\hline & & Tannin-NIPU[231] & $x$ & $x$ & - & - & $\mathrm{x}$ & - & - & - \\
\hline & $\begin{array}{c}\text { Intramolecular } \\
\text { condensation } \\
\text { of poly(amide } \\
\text { acid or ester)s } \\
\text { (PAA-PAE) }\end{array}$ & $\begin{array}{c}\text { Aromatic } \\
\text { polyimide[233,234] }\end{array}$ & - & $x$ & $\mathrm{X}$ & $\mathrm{x}$ & - & $x$ & - & - \\
\hline & \multirow{3}{*}{$\begin{array}{l}\text { Amine- } \\
\text { hydrosiloxane }\end{array}$} & Aromatic Epoxy-amine[242] & - & $x$ & $\mathrm{x}$ & $x$ & - & $x$ & $x$ & - \\
\hline & & $\begin{array}{l}\text { Aliphatic Epoxy- } \\
\text { amine[243,244] }\end{array}$ & - & - & $\mathrm{X}$ & $\mathrm{X}$ & - & $x$ & $\mathrm{X}$ & $x$ \\
\hline & & $\begin{array}{c}\text { Polyhydroxyurethanes }[248,2 \\
51]\end{array}$ & $x$ & - & - & - & $x$ & $x$ & - & $x$ \\
\hline & $\begin{array}{c}\text { Cyclic } \\
\text { carbonate-thiol }\end{array}$ & $\begin{array}{c}\text { Aliphatic } \\
\text { Polyhydroxyuréthanes }[58,59 \\
]\end{array}$ & - & $x$ & - & - & $x$ & $x$ & - & $x$ \\
\hline
\end{tabular}

a: Usually combined with the use of a suitable conductive filler.

To conclude, the perspectives of the PPE sector are in line with the flourishing number of new self-foaming thermosetting polymers, including self-foamed epoxy resins based on ionic carbamates or self-foaming polyhydroxyurethane based on thiol-carbonate condensation. Indeed, the industry of PPE is experiencing a growing demand in terms of resilient cellular thermosets with advanced and high value-added properties. With the emergence of new hazards, such as electromagnetic pollution, composite foams will be more and more desirable for the design of lightweight, comfortable and resistant PPE, such as EMI shields.[112] More generally speaking, smart composite foams[267] that are self-actuated (e.g., depollution[268]) with sensing properties (e.g., damage sensing[269] and/or self-healing abilities[270]) are the future of sustainable and digitally connected PPE.[271] From the processing viewpoint, selffoaming (pre)polymers present numerous advantages for the development of new composite foams. It is indeed easier to disperse solid fillers in ready-to-use, one-pack, formulations. Moreover, the crosslinking reaction of self-foamed thermosets is usually thermo-latent - 
because it is correlated to the thermal latency of the release of the blowing gas - and provides the operator with a time window to disperse the fillers within the matrix.

For all these reasons, self-foaming (pre)polymers have a bright future in the field of PPE and the comprehensive review provided in this paper should help industrial and academic researchers in developing new self-foaming materials adapted to the demands of the sector.

\section{ACKNOWLEDGMENT}

The authors from Liege thank the "Fonds National pour la Recherche Scientifique" (F.R.S.FNRS) and the Fonds Wetenschappelijk Onderzoek - Vlaanderen (FWO) for financial support in the frame of the Excellence of Science (EOS) project $n^{\circ} \mathrm{O} 019618 \mathrm{~F}$ (ID EOS: 30902231), FNRS in the frame of the "CO${ }_{2}$ Switch" project, and the CESAM Research Unit for additional financial support. C.D. is F.R.S.-FNRS Research Director.

\section{References}

[1] N.V. Gama, A. Ferreira, B.T. Ana, Polyurethane foams: Past, Present, and Future, Materials. 11:1841 (2018).

[2] J. Li, W.-Y. Wong, X. Tao, Recent advances in soft functional materials: preparation, functions and applications, Nanoscale. 12 (2020) 1281-1306. https://doi.org/10.1039/C9NR07035D.

[3] G. Coste, C. Negrell, S. Caillol, From gas release to foam synthesis, the second breath of blowing agents, Eur. Polym. J. 140 (2020) 110029. https://doi.org/10.1016/j.eurpolymj.2020.110029.

[4] Fan-Long Jin, Miao Zhao, Mira Park, S.-J. Park, Recent Trends of Foaming in Polymer Processing: A Review, Polymers. 11 (2019) 953.

[5] M.L. Ranney, V. Griffeth, A.K. Jha, Critical Supply Shortage-The Need for Ventilators and Personnal Protective Equipment during the covid-19 Pandemic, N. Engl. J. Med. 38 (2020) e41. https://doi.org/10.1056/NEJMp2006141.

[6] M.S. Bergman, D.J. Viscusi, B.K. Heimbuch, J.D. Wander, A.R. Sambol, R.E. Shaffer, Evaluation of Multiple (3-Cycle) Decontamination Processing for Filtering Facepiece Respirators, J. Eng. Fiber. Fabr. 5 (2010) 155892501000500. https://doi.org/10.1177/155892501000500405.

[7] D. Paul, A. Gupta, A.K. Maurya, Exploring options for reprocessing of N95 Filtering Facepiece Respirators (N95-FFRs) amidst COVID-19 pandemic: A systematic review, PLoS One. 15 (2020) e0242474. https://doi.org/10.1371/journal.pone.0242474.

[8] M.H. Chua, W. Cheng, S.S. Goh, J. Kong, B. Li, J.Y.C. Lim, L. Mao, S. Wang, K. Xue, L. Yang, E. Ye, K. Zhang, W.C.D. Cheong, B.H. Tan, Z. Li, B.H. Tan, X.J. Loh, Face Masks in the New COVID-19 Normal: Materials, Testing, and Perspectives, Research. 2020 (2020) 140. https://doi.org/10.34133/2020/7286735.

[9] K. Munckton, K.M. Ho, G.J. Dobb, M. Das-Gupta, S.A. Webb, The pressure effects of facemasks during noninvasive ventilation: a volunteer study, Anaesthesia. 62 (2007) 11261131. https://doi.org/10.1111/j.1365-2044.2007.05190.x.

[10] M. Pacis, A. Azor-Ocampo, E. Burnett, C. Tanasapphaisal, B. Coleman, Prophylactic Dressings for Maintaining Skin Integrity of Healthcare Workers When Using N95 Respirators While Preventing Contamination Due to the Novel Coronavirus, J. Wound, Ostomy Cont. Nurs. 47 (2020) 551-557. https://doi.org/10.1097/WON.0000000000000713.

[11] S. Gunashekar, K.M. Pillai, B.C. Church, N.H. Abu-Zahra, Liquid flow in polyurethane foams for filtration applications: a study on their characterization and permeability estimation, $\mathrm{J}$. Porous Mater. 22 (2015) 749-759. https://doi.org/10.1007/s10934-015-9948-2.

[12] M. Briffa, S. Decelis, J.P. Brincat, J.N. Grima, R. Gatt, V. Valdramidis, Evaluation of polyurethane foam materials as air filters against fungal contamination, Food Control. 73 (2017) 91-100. https://doi.org/10.1016/j.foodcont.2016.05.028. 
[13] A. Shokrani, E.G. Loukaides, E. Elias, A.J.G. Lunt, Exploration of alternative supply chains and distributed manufacturing in response to COVID-19; a case study of medical face shields, Mater. Des. 192 (2020) 108749. https://doi.org/10.1016/j.matdes.2020.108749.

[14] V. Kalyaev, A.I. Salimon, A.M. Korsunsky, A.A. Denisov, Fast Mass-Production of Medical Safety Shields under COVID-19 Quarantine: Optimizing the Use of University Fabrication Facilities and Volunteer Labor, Int. J. Environ. Res. Public Health. 17 (2020) 3418. https://doi.org/10.3390/ijerph17103418.

[15] C. Çiriş Yildiz, H. Ulaşli Kaban, F.Ş. Tanriverdi, COVID-19 pandemic and personal protective equipment: Evaluation of equipment comfort and user attitude, Arch. Environ. Occup. Health. (2020) 1-8. https://doi.org/10.1080/19338244.2020.1828247.

[16] Measuring the Impact of Covid-19 on the Foam and Adhesives \& Bonding Industries., (n.d.). https://www.foam-expo.eu/resources/covid-19-report/.

[17] C.-C. Chiu, T.-J. Wan, Individual Fit Testing of Hearing-Protection Devices Based on Microphones in Real Ears among Workers in Industries with High-Noise-Level Manufacturing, Int. J. Environ. Res. Public Health. 17 (2020) 3242. https://doi.org/10.3390/ijerph17093242.

[18] A. Dancer, P. Grateau, A. Cabanis, G. Barnabé, G. Cagnin, T. Vaillant, D. Lafont, Effectiveness of earplugs in high-intensity impulse noise, J. Acoust. Soc. Am. 91 (1992) 16771689. https://doi.org/10.1121/1.402447.

[19] N.J. Mills, C. Fitzgerald, A. Gilchrist, R. Verdejo, Polymer foams for personal protection: Cushions, shoes and helmets, Compos. Sci. Technol. 63 (2003) 2389-2400. https://doi.org/10.1016/S0266-3538(03)00272-0.

[20] Y. Chen, S. Zhang, S. Cao, S. Li, F. Chen, S. Yuan, C. Xu, J. Zhou, X. Feng, X. Ma, B. Wang, Roll-to-Roll Production of Metal-Organic Framework Coatings for Particulate Matter Removal, Adv. Mater. 29 (2017) 1606221. https://doi.org/10.1002/adma.201606221.

[21] Y.-J. Chen, Y. Chen, C. Miao, Y.-R. Wang, G.-K. Gao, R.-X. Yang, H.-J. Zhu, J.-H. Wang, S.L. Li, Y.-Q. Lan, Metal-organic framework-based foams for efficient microplastics removal, J. Mater. Chem. A. 8 (2020) 14644-14652. https://doi.org/10.1039/D0TA04891G.

[22] J.-M.M. Thomassin, C. Jérôme, T. Pardoen, C. Bailly, I. Huynen, C. Detrembleur, Polymer/carbon based composites as electromagnetic interference (EMI) shielding materials, Mater. Sci. Eng. R Reports. 74 (2013) 211-232. https://doi.org/10.1016/j.mser.2013.06.001.

[23] A.K. Singh, A. Shishkin, T. Koppel, N. Gupta, A review of porous lightweight composite materials for electromagnetic interference shielding, Compos. Part B Eng. 149 (2018) 188-197. https://doi.org/10.1016/j.compositesb.2018.05.027.

[24] S. Geetha, K.K. Satheesh Kumar, C.R.K. Rao, M. Vijayan, D.C. Trivedi, EMI shielding: Methods and materials-A review, J. Appl. Polym. Sci. 112 (2009) 2073-2086. https://doi.org/10.1002/app.29812.

[25] R. Verdejo, M.M. Bernal, L.J. Romasanta, F.J. Tapiador, M.A. Lopez-Manchado, Reactive Nanocomposite Foams, Cell. Polym. 30 (2011) 45-62. https://doi.org/10.1177/026248931103000201.

[26] M.M. Bernal, I. Molenberg, S. Estravis, M.A. Rodriguez-Perez, I. Huynen, M.A. LopezManchado, R. Verdejo, Comparing the effect of carbon-based nanofillers on the physical properties of flexible polyurethane foams, J. Mater. Sci. 47 (2012) 5673-5679. https://doi.org/10.1007/s10853-012-6331-4.

[27] B. Zhao, M. Hamidinejad, S. Wang, P. Bai, R. Che, R. Zhang, C.B.B. Park, Advances in electromagnetic shielding properties of composite foams, J. Mater. Chem. A. (2021). https://doi.org/10.1039/D1TA00417D.

[28] H.W. Engels, H.G. Pirkl, R. Albers, R.W. Albach, J. Krause, A. Hoffmann, H. Casselmann, J. Dormish, Polyurethanes: Versatile materials and sustainable problem solvers for today's challenges, Angew. Chem. Int. Ed. 52 (2013) 9422-9441. https://doi.org/10.1002/anie.201302766.

[29] J.M. Kim, D.H. Kim, J. Kim, J.W. Lee, W.N. Kim, Effect of graphene on the sound damping properties of flexible polyurethane foams, Macromol. Res. 25 (2017) 190-196. https://doi.org/10.1007/s13233-017-5017-9.

[30] R. Verdejo, R. Stämpfli, M. Alvarez-Lainez, S. Mourad, M.A. Rodriguez-Perez, P.A. Brühwiler, M. Shaffer, Enhanced acoustic damping in flexible polyurethane foams filled with 
carbon nanotubes, Compos. Sci. Technol. 69 (2009) 1564-1569.

https://doi.org/10.1016/j.compscitech.2008.07.003.

[31] C.-T. Lee, M. Friedman, H.G. Poovey, S.R. Ie, R.J. Rando, G.W. Hoyle, Pulmonary toxicity of polymeric hexamethylene diisocyanate aerosols in mice, Toxicol. Appl. Pharmacol. 188 (2003) 154-164. https://doi.org/10.1016/S0041-008X(03)00096-6.

[32] D. Bello, S.R. Woskie, R.P. Streicher, Y. Liu, M.H. Stowe, E.A. Eisen, M.J. Ellenbecker, J. Sparer, F. Youngs, M.R. Cullen, C.A. Redlich, Polyisocyanates in occupational environments: A critical review of exposure limits and metrics, Am. J. Ind. Med. 46 (2004) 480-491. https://doi.org/10.1002/ajim.20076.

[33] S.E. Anderson, B.J. Meade, Potential Health Effects Associated with Dermal Exposure to Occupational Chemicals, Environ. Health Insights. 8s1 (2014) EHI.S15258. https://doi.org/10.4137/EHI.S15258.

[34] S.N. Singh, Blowing Agents for Polyurethane Foams, Rapra Technol. 12 (2001).

[35] S.S. Dhomse, W. Feng, S.A. Montzka, R. Hossaini, J. Keeble, J.A. Pyle, J.S. Daniel, M.P. Chipperfield, Delay in recovery of the Antarctic ozone hole from unexpected CFC-11 emissions, Nat. Commun. 10 (2019) 1-12. https://doi.org/10.1038/s41467-019-13717-x.

[36] G.M. Rusch, The development of environmentally acceptable fluorocarbons, Crit. Rev. Toxicol. 48 (2018) 615-665. https://doi.org/10.1080/10408444.2018.1504276.

[37] G.J.M. Velders, A.R. Ravishankara, M.K. Miller, M.J. Molina, J. Alcamo, J.S. Daniel, D.W. Fahey, S.A. Montzka, S. Reimann, Preserving Montreal Protocol Climate Benefits by Limiting HFCs, Science (80-. ). 335 (2012) 922-923. https://doi.org/10.1126/science.1216414.

[38] O. Secretariat, Handbook for the Montreal Protocol on Substances that Deplete the Ozone Layer., Unep. (2020).

[39] E. Di Maio, E. Kiran, Foaming of polymers with supercritical fluids and perspectives on the current knowledge gaps and challenges, J. Supercrit. Fluids. 134 (2018) 157-166. https://doi.org/10.1016/j.supflu.2017.11.013.

[40] L.J.M. Jacobs, M.F. Kemmere, J.T.F. Keurentjes, Sustainable polymer foaming using high pressure carbon dioxide: a review on fundamentals, processes and applications, Green Chem. 10 (2008) 731. https://doi.org/10.1039/b801895b.

[41] M. Sauceau, J. Fages, A. Common, C. Nikitine, E. Rodier, M. Sauceau, J. Fages, A. Common, C. Nikitine, E. Rodier, New challenges in polymer foaming: A review of extrusion processes assisted by supercritical carbon dioxide, Prog. Polym. Sci. 36 (2011) 749-766. https://doi.org/10.1016/j.progpolymsci.2010.12.004.

[42] C. Forest, P. Chaumont, P. Cassagnau, B. Swoboda, P. Sonntag, Polymer nano-foams for insulating applications prepared from CO2 foaming, Prog. Polym. Sci. 41 (2015) 122-145. https://doi.org/10.1016/j.progpolymsci.2014.07.001.

[43] X. Fan, G. Zhang, J. Li, Z. Shang, H. Zhang, Q. Gao, J. Qin, X. Shi, Study on foamability and electromagnetic interference shielding effectiveness of supercritical $\mathrm{CO} 2$ foaming epoxy/rubber/MWCNTs composite, Compos. Part A Appl. Sci. Manuf. 121 (2019) 64-73. https://doi.org/10.1016/j.compositesa.2019.03.008.

[44] Q. Gao, G. Zhang, X. Fan, H. Zhang, Y. Zhang, F. Huang, R. Xiao, X. Shi, J. Qin, Enhancements of foamability, electromagnetic interference shielding and mechanical property of epoxy microcellular composite foam with well-dispersed f-MWCNTs, Compos. Part A Appl. Sci. Manuf. 138 (2020) 106060. https://doi.org/10.1016/j.compositesa.2020.106060.

[45] L. Monnereau, L. Urbanczyk, J.-M. Thomassin, T. Pardoen, C. Bailly, I. Huynen, C. Jérôme, C. Detrembleur, Gradient foaming of polycarbonate/carbon nanotube based nanocomposites with supercritical carbon dioxide and their EMI shielding performances, Polymer. 59 (2015) 117-123. https://doi.org/10.1016/j.polymer.2014.11.063.

[46] M.-P. Tran, J.-M. Thomassin, M. Alexandre, C. Jerome, I. Huynen, C. Detrembleur, Nanocomposite Foams of Polypropylene and Carbon Nanotubes: Preparation, Characterization, and Evaluation of their Performance as EMI Absorbers, Macromol. Chem. Phys. 216 (2015) 1302-1312. https://doi.org/10.1002/macp.201500031.

[47] I. Huynen, N. Quiévy, C. Bailly, P. Bollen, C. Detrembleur, S. Eggermont, I. Molenberg, J.M. Thomassin, L. Urbanczyk, T. Pardoen, Multifunctional hybrids for electromagnetic absorption, Acta Mater. 59 (2011) 3255-3266. https://doi.org/10.1016/j.actamat.2011.01.065. 
[48] J.-M. Thomassin, C. Pagnoulle, L. Bednarz, I. Huynen, R. Jerome, C. Detrembleur, Foams of polycaprolactone/MWNT nanocomposites for efficient EMI reduction, J. Mater. Chem. 18 (2008) 792. https://doi.org/10.1039/b709864b.

[49] H.-B. Zhang, Q. Yan, W.-G. Zheng, Z. He, Z.-Z. Yu, Tough Graphene-Polymer Microcellular Foams for Electromagnetic Interference Shielding, ACS Appl. Mater. Interfaces. 3 (2011) 918924. https://doi.org/10.1021/am200021v.

[50] Q. Jiang, X. Liao, J. Li, J. Chen, G. Wang, J. Yi, Q. Yang, G. Li, Flexible thermoplastic polyurethane/reduced graphene oxide composite foams for electromagnetic interference shielding with high absorption characteristic, Compos. Part A Appl. Sci. Manuf. 123 (2019) 310-319. https://doi.org/10.1016/j.compositesa.2019.05.017.

[51] Q. Jiang, X. Liao, J. Yang, G. Wang, J. Chen, C. Tian, G. Li, A two-step process for the preparation of thermoplastic polyurethane/graphene aerogel composite foams with multi-stage networks for electromagnetic shielding, Compos. Commun. 21 (2020) 100416. https://doi.org/10.1016/j.coco.2020.100416.

[52] B. Grignard, J. M. Thomassin, S. Gennen, L. Poussard, L. Bonnaud, J. M. Raquez, P. Dubois, M. P. Tran, C. B. Park, C. Jerome, C. Detrembleur, CO2-blown microcellular non-isocyanate polyurethane (NIPU) foams: from bio- and $\mathrm{CO}_{2}$-sourced monomers to potentially thermal insulating materials, Green Chem. 18 (2015) 2206-2215.

[53] M. Haurat, M. Dumon, Amorphous Polymers' Foaming and Blends with Organic Foaming-Aid Structured Additives in Supercritical CO2, a Way to Fabricate Porous Polymers from Macro to Nano Porosities in Batch or Continuous Processes, Molecules. 25 (2020) 5320. https://doi.org/10.3390/molecules25225320.

[54] D.L. Tomasko, A. Burley, L. Feng, S.-K. Yeh, K. Miyazono, S. Nirmal-Kumar, I. Kusaka, K. Koelling, Development of CO2 for polymer foam applications, J. Supercrit. Fluids. 47 (2009) 493-499. https://doi.org/10.1016/j.supflu.2008.10.018.

[55] F.I. Altuna, R.A. Ruseckaite, P.M. Stefani, Biobased Thermosetting Epoxy Foams: Mechanical and Thermal Characterization, ACS Sustainable. Chem. Eng. 3 (2015) 1406-1411. https://doi.org/10.1021/acssuschemeng.5b00114.

[56] Q. Ren, S. Zhu, One-Pack expoxy foaming with $\mathrm{CO} 2$ as latent Blowing agent, ACS Macro Lett. 4 (2015) 693-697.

[57] C. Zúniga, G. Lligadas, J. C. Ronda, M. Galià, V. Cádiz, Self-foaming diphenolic acid benzoxazine, Polymer. 53 (2012) 3089-3095.

[58] F. Monie, B. Grignard, J. Thomassin, R. Mereau, T. Tassaing, C. Jerome, C. Detrembleur, Chemo- and Regioselective Additions of Nucleophiles to Cyclic Carbonates for the Preparation of Self-Blowing Non-Isocyanate Polyurethane Foams, Angew. Chem. Int. Ed. 59 (2020) 17033-17041. https://doi.org/10.1002/anie.202006267.

[59] C. Detrembleur, J.M. Thomassin, B. Grignard, F. Monie, C. Jérôme, Self-blowing isocyanatefree polyurethane foams, WO/2021/004993A1, 2021.

https://patentscope. $w i p o . i n t / s e a r c h / e n / d e t a i l . j s f ? d o c I d=W O 2021004993 \& \_c i d=P 12-K L N J 1 P-$ 72295-1.

[60] G. Wypych, Handbook of Foaming and Blowing agents, ChemTech, Toronto, 2017.

[61] S.N.S. Leung, Mechanisms of cell nucleation, growth, and coarsening in plastic foaming: theory, simulation and experiment, Toronto, 2009.

https://tspace.library.utoronto.ca/bitstream/1807/19285/6/Leung_Siu_NS_200911_PhD_thesis. pdf.

[62] S.N. Leung, C.B. Park, D. Xu, H. Li, R.G. Fenton, Computer Simulation of Bubble-Growth Phenomena in Foaming, Ind. Eng. Chem. Res. 45 (2006) 7823-7831. https://doi.org/10.1021/ie060295a.

[63] M. Mokhtari Motameni Shirvan, M.H.N. Famili, A. Golbang, A Review on the Application of Nucleation Theories in Thermoplastic Foams, Plast. Polym. Technol. 4 (2016) 11. https://doi.org/10.14355/papt.2016.04.002.

[64] D.W. Van Krevelen, K. Te Nijenhuis, Properties of Polymers, 4th ed., Elsevier, Amsterdam, 2009.

[65] J.-P. Pascaults, H. Sautereau, J. Verdu, R.J.J. Williams, Thermosetting Polymers, New York, 2002. 
[66] M. Altan, Thermoplastic Foams: Processing, Manufacturing, and Characterization, in: Recent Res. Polym., InTech, 2018. https://doi.org/10.5772/intechopen.71083.

[67] T. Vidil, M. Cloître, F. Tournilhac, Control of Gelation and Network Properties of Cationically Copolymerized Mono- and Diglycidyl Ethers, Macromolecules. 51 (2018) 5121-5137. https://doi.org/10.1021/acs.macromol.8b00406.

[68] C. Bowman, F. Du Prez, J. Kalow, Introduction to chemistry for covalent adaptable networks, Polym. Chem. 11 (2020) 5295-5296. https://doi.org/10.1039/D0PY90102D.

[69] N. Van Herck, D. Maes, K. Unal, M. Guerre, J.M. Winne, F.E. Du Prez, Covalent Adaptable Networks with Tunable Exchange Rates Based on Reversible Thiol-yne Cross-Linking, Angew. Chem. Int. Ed. 59 (2020) 3609-3617. https://doi.org/10.1002/anie.201912902.

[70] J.M. Winne, L. Leibler, F.E. Du Prez, Dynamic covalent chemistry in polymer networks: a mechanistic perspective, Polym. Chem. 10 (2019) 6091-6108. https://doi.org/10.1039/C9PY01260E.

[71] Z. Yang, T. Liu, D. Hu, Z. Xu, L. Zhao, Foaming window for preparation of microcellular rigid polyurethanes using supercritical carbon dioxide as blowing agent, J. Supercrit. Fluids. 147 (2019) 254-262. https://doi.org/10.1016/j.supflu.2018.11.001.

[72] L. Sorrentino, M. Aurilia, S. Iannace, Polymeric foams from high-performance thermoplastics, Adv. Polym. Technol. 30 (2011) 234-243. https://doi.org/10.1002/adv.20219.

[73] B.J. Rashmi, D. Rusu, K. Prashantha, M.F. Lacrampe, P. Krawczak, Development of waterblown bio-based thermoplastic polyurethane foams using bio-derived chain extender, J. Appl. Polym. Sci. 128 (2013) 292-303. https://doi.org/10.1002/app.38183.

[74] M. Bakir, J. L. Meyer, J. Economy, I. Jasiuk, Heat-induced polycondensation reaction with self-generated blowing agent forming aromatic thermosetting copolyester foams, Macromolecules. 49 (2016) 6489-6496.

[75] M. Bakir, J. L. Meyer, J. Economy, I. Jasiuk, Aromatic thermosetting copolyester nanocomposite foams: High thermal and mechanical performance lightweight structural materials, Polymer. 123 (2017) 311-320.

[76] L.A. Mondy, R.R. Rao, H. Moffat, D. Adolf, M. Celina, Structural Epoxy Foams, in: Epoxy Polym., Wiley-VCH Verlag GmbH \& Co. KGaA, Weinheim, Germany, 2010: pp. 303-324. https://doi.org/10.1002/9783527628704.ch16.

[77] X.-Z. Wang, M.-S. Lu, J.-B. Zeng, Y. Weng, Y.-D. Li, Malleable and thermally recyclable polyurethane foam, Green Chem. 23 (2021) 307-313. https://doi.org/10.1039/D0GC03471A.

[78] D.K. Schneiderman, M.E. Vanderlaan, A.M. Mannion, T.R. Panthani, D.C. Batiste, J.Z. Wang, F.S. Bates, C.W. Macosko, M.A. Hillmyer, Chemically Recyclable Biobased Polyurethanes, ACS Macro Lett. 5 (2016) 515-518. https://doi.org/10.1021/acsmacrolett.6b00193.

[79] S. Doroudiani, C.B. Park, M.T. Kortschot, Effect of the crystallinity and morphology on the microcellular foam structure of semicrystalline polymers, Polym. Eng. Sci. 36 (1996) 26452662. https://doi.org/10.1002/pen.10664.

[80] L. Sorrentino, E. Di Maio, S. Iannace, Poly(ethylene terephthalate) foams: Correlation between the polymer properties and the foaming process, J. Appl. Polym. Sci. 116 (2010) 27-35. https://doi.org/10.1002/app.31427.

[81] Z. Yang, C. Xin, W. Mughal, Z. Wang, X. Bai, Y. He, Prediction of foamability of polyethylene terephthalate using viscous and elastic parameters, Adv. Polym. Technol. 37 (2018) 2344-2353. https://doi.org/10.1002/adv.21910.

[82] D.-C. Li, T. Liu, L. Zhao, W.-K. Yuan, Foaming of linear isotactic polypropylene based on its non-isothermal crystallization behaviors under compressed CO2, J. Supercrit. Fluids. 60 (2011) 89-97. https://doi.org/10.1016/j.supflu.2011.07.015.

[83] C. Brondi, M.R. Di Caprio, G. Scherillo, E. Di Maio, T. Mosciatti, S. Cavalca, V. Parenti, M. Corti, S. Iannace, Thermosetting polyurethane foams by physical blowing agents: Chasing the synthesis reaction with the pressure, J. Supercrit. Fluids. 154 (2019) 104630. https://doi.org/10.1016/j.supflu.2019.104630.

[84] O. Takiguchi, D. Ishikawa, M. Sugimoto, T. Taniguchi, K. Koyama, Effect of rheological behavior of epoxy during precuring on foaming, J. Appl. Polym. Sci. 110 (2008) 657-662. https://doi.org/10.1002/app.28727.

[85] E. Mazzon, P. Guigues, J.-P. Habas, Biobased structural epoxy foams derived from plant-oil: 
Formulation, manufacturing and characterization, Ind. Crops Prod. 144 (2020) 111994. https://doi.org/10.1016/j.indcrop.2019.111994.

[86] S. Shukla, S. Agnihotri, S.A. Pradeep, S. Pilla, Delayed Addition Foaming of Bio-epoxy Blends: Balancing Performance Requirements and Sustainability, ACS Sustainable Chem. Eng. 6 (2018) 17051-17058. https://doi.org/10.1021/acssuschemeng.8b04415.

[87] N. F. Brown, S. A. Pradeep, S. Agnihotri, S. Pilla, The power of processing: Creating high strength foams from epoxidized pine oil, ACS Sustainable Chem. Eng. 5 (2017) 8641-8647.

[88] X. Liu, H. Lu, L. Xing, Effect of Prepolymerization Time on Morphology and Properties of Epoxy-modified Bismaleimide Foams, Int. Polym. Process. 27 (2012) 617-625. https://doi.org/10.3139/217.2629.

[89] J.A. Villamil Jiménez, N. Le Moigne, J.-C. Bénézet, M. Sauceau, R. Sescousse, J. Fages, Foaming of PLA Composites by Supercritical Fluid-Assisted Processes: A Review, Molecules. 25 (2020) 3408. https://doi.org/10.3390/molecules25153408.

[90] C. Gualandi, L.J. White, L. Chen, R.A. Gross, K.M. Shakesheff, S.M. Howdle, M. Scandola, Scaffold for tissue engineering fabricated by non-isothermal supercritical carbon dioxide foaming of a highly crystalline polyester, Acta Biomater. 6 (2010) 130-136. https://doi.org/10.1016/j.actbio.2009.07.020.

[91] L. Wang, Y. Ji, X. Peng, A new two-step process to prepare microcellular epoxy foams based on kinetic analysis, J. Mater. Sci. 53 (2018) 1540-1555. https://doi.org/10.1007/s10853-0171583-7.

[92] J. Peyrton, L. Avérous, Structure-properties relationships of cellular materials from biobased polyurethane foams, Mater. Sci. Eng. R Reports. 145 (2021) 100608. https://doi.org/10.1016/j.mser.2021.100608.

[93] L. Wang, H. Zhou, X. Wang, J. Mi, Evaluation of Nanoparticle Effect on Bubble Nucleation in Polymer Foaming, J. Phys. Chem. C. 120 (2016) 26841-26851.

https://doi.org/10.1021/acs.jpcc.6b08723.

[94] J.S. Colton, N.P. Suh, The nucleation of microcellular thermoplastic foam with additives: Part I: Theoretical considerations, Polym. Eng. Sci. 27 (1987) 485-492. https://doi.org/10.1002/pen.760270702.

[95] X. Chen, N. Guigo, A. Pizzi, N. Sbirrazzuoli, B. Li, E. Fredon, C. Gerardin, Ambient Temperature Self-Blowing Tannin-Humins Biofoams, Polymers. 12 (2020) 2732. https://doi.org/10.3390/polym12112732.

[96] H. Guo, Y.J. Tan, G. Chen, Z. Wang, G.J. Susanto, H.H. See, Z. Yang, Z.W. Lim, L. Yang, B.C.K. Tee, Artificially innervated self-healing foams as synthetic piezo-impedance sensor skins, Nat. Commun. 11 (2020) 5747. https://doi.org/10.1038/s41467-020-19531-0.

[97] M.C. Basso, S. Giovando, A. Pizzi, H. Pasch, N. Pretorius, L. Delmotte, A. Celzard, Flexibleelastic copolymerized polyurethane-tannin foams, J. Appl. Polym. Sci. 131 (2014) n/a-n/a. https://doi.org/10.1002/app.40499.

[98] S. Merlet, C. Marestin, O. Romeyer, R. Mercier, "Self-Foaming" Poly(phenylquinoxaline)s for the designing of macro and nanoporous materials, Macromolecules. 41 (2008) 4205-4215.

[99] C. Pupin, A. Ross, C. Dubois, J.-C. Rietsch, E. Ruiz, Predicting porosity formation in phenolic resins for RTM manufacturing: The porosity map, Compos. Part A Appl. Sci. Manuf. 100 (2017) 294-304. https://doi.org/10.1016/j.compositesa.2017.05.023.

[100] S.F. Hamad, N. Farr, T. Fei, N.F. Shukor, J.S. Dean, S.A. Hayes, J.P. Foreman, C. Rodenburg, Optimizing size and distribution of voids in phenolic resins through the choice of catalyst types, J. Appl. Polym. Sci. 136 (2019) 48249. https://doi.org/10.1002/app.48249.

[101] R.J. Ouellette, J.D. Rawn, Synthetic Polymers, in: Org. Chem., Elsevier, 2018: pp. 861-887. https://doi.org/10.1016/B978-0-12-812838-1.50027-X.

[102] https://www.marketsandmarkets.com/Market-Reports/polyurethane-foams-market-1251.html (Accessed March 2020), (n.d.).

[103] J.G. Gwon, S.K. Kim, J.H. Kim, Development of cell morphologies in manufacturing flexible polyurethane urea foams as sound absorption materials, J. Porous Mater. 23 (2016) 465-473. https://doi.org/10.1007/s10934-015-0100-0.

[104] A.D. Easley, M.B.B. Monroe, S.M. Hasan, A.C. Weems, J. Frederick, D.J. Maitland, Shape memory polyurethane-urea foams with improved toughness, J. Appl. Polym. Sci. 136 (2019) 
47268. https://doi.org/10.1002/app.47268.

[105] W.J. Seo, H.C. Jung, J.C. Hyun, W.N. Kim, Y.-B. Lee, K.H. Choe, S.-B. Kim, Mechanical, morphological, and thermal properties of rigid polyurethane foams blown by distilled water, J. Appl. Polym. Sci. 90 (2003) 12-21. https://doi.org/10.1002/app.12238.

[106] J.G. Gwon, G. Sung, J.H. Kim, Modulation of cavities and interconnecting pores in manufacturing water blown flexible poly (urethane urea) foams, Int. J. Precis. Eng. Manuf. 16 (2015) 2299-2307. https://doi.org/10.1007/s12541-015-0295-7.

[107] J. Reignier, P. Alcouffe, F. Méchin, F. Fenouillot, The morphology of rigid polyurethane foam matrix and its evolution with time during foaming - New insight by cryogenic scanning electron microscopy, J. Colloid Interface Sci. 552 (2019) 153-165. https://doi.org/10.1016/j.jcis.2019.05.032.

[108] S. Yi, Y. Cho, J. Roh, Improved dimensional stability of water-blown polyurethane foam with aluminum hydroxide and magnesium hydroxide, J. Appl. Polym. Sci. 137 (2020) 49510. https://doi.org/10.1002/app.49510.

[109] H. Lim, E.Y. Kim, B.K. Kim, Polyurethane foams blown with various types of environmentally friendly blowing agents, Plast. Rubber Compos. 39 (2010) 364-369. https://doi.org/10.1179/174328910X12691245469835.

[110] J. Peyrton, C. Chambaretaud, A. Sarbu, L. Avérous, Biobased Polyurethane Foams Based on New Polyol Architectures from Microalgae Oil, ACS Sustainable Chem. Eng. 8 (2020) 1218712196. https://doi.org/10.1021/acssuschemeng.0c03758.

[111] X. Luo, A. Mohanty, M. Misra, Lignin as a reactive reinforcing filler for water-blown rigid biofoam composites from soy oil-based polyurethane, Ind. Crops Prod. 47 (2013) 13-19. https://doi.org/10.1016/j.indcrop.2013.01.040.

[112] A. Kausar, Polyurethane Composite Foams in High-Performance Applications: A Review, Polym. - Plast. Technol. Eng. 57 (2018) 346-369. https://doi.org/10.1080/03602559.2017.1329433.

[113] B.E. Obi, Applications of Polymeric Foams in Automobiles and Transportation, Polym. Foam. Struct. (2018) 341-366. https://doi.org/10.1016/b978-1-4557-7755-6.00012-4.

[114] T. Allen, J. Shepherd, T.A.M. Hewage, T. Senior, L. Foster, A. Alderson, Low-kinetic energy impact response of auxetic and conventional open-cell polyurethane foams, Phys. Status Solidi Basic Res. 252 (2015) 1631-1639. https://doi.org/10.1002/pssb.201451715.

[115] Y. Yao, S. Jin, X. Ma, R. Yu, H. Zou, H. Wang, X. Lv, Q. Shu, Graphene-containing flexible polyurethane porous composites with improved electromagnetic shielding and flame retardancy, Compos. Sci. Technol. 200 (2020) 108457. https://doi.org/10.1016/j.compscitech.2020.108457.

[116] S. Zhu, Q. Zhou, M. Wang, J. Dale, Z. Qiang, Y. Fan, M. Zhu, C. Ye, Modulating electromagnetic interference shielding performance of ultra-lightweight composite foams through shape memory function, Compos. Part B Eng. 204 (2021) 108497. https://doi.org/10.1016/j.compositesb.2020.108497.

[117] M. Kurańska, R. Barczewski, M. Barczewski, A. Prociak, K. Polaczek, Thermal insulation and sound absorption properties of open-cell polyurethane foams modified with bio-polyol based on used cooking oil, Materials. 13 (2020) 5673. https://doi.org/10.3390/ma13245673.

[118] G. Sung, J.W. Kim, J.H. Kim, Fabrication of polyurethane composite foams with magnesium hydroxide filler for improved sound absorption, J. Ind. Eng. Chem. 44 (2016) 99-104. https://doi.org/10.1016/j.jiec.2016.08.014.

[119] Y. Savelyev, A. Rudenko, L. Robota, E. Koval, O. Savelyeva, L. Markovskaya, V. Veselov, Novel polymer materials for protecting crew and structural elements of orbital station against microorganisms attack throughout long-term operation, Acta Astronaut. 64 (2009) 36-40. https://doi.org/10.1016/j.actaastro.2008.06.013.

[120] B.E. Obi, Overview of Applications of Polymeric Foams, in: Polym. Foam. Struct., Elsevier, 2018: pp. 3-14. https://doi.org/10.1016/B978-1-4557-7755-6.00001-X.

[121] W.R. Sorenson, Reaction of an isocyanate and a carboxylic acid in dimethyl sulfoxide, J. Org. Chem. 24 (1959) 978-980.

[122] M. Stanzione, V. Russo, M. Oliviero, L. Verdolotti, A. Sorrentino, M. Di Serio, R. Tesser, S. Iannace, M. Lavorgna, Characterization of sustainable polyhydroxyls, produced from bio-based 
feedstock, and polyurethane and copolymer urethane-amide foams, Data Br. 21 (2018) 269275. https://doi.org/10.1016/j.dib.2018.09.077.

[123] M. Stanzione, V. Russo, M. Oliviero, L. Verdolotti, A. Sorrentino, M. Di Serio, R. Tesser, S. Iannace, M. Lavorgna, Synthesis and characterization of sustainable polyurethane foams based on polyhydroxyls with different terminal groups, Polymer. 149 (2018) 134-145. https://doi.org/10.1016/j.polymer.2018.06.077.

[124] R. Herrington, K. Hock, Flexible Polyurethane Foams, 2nd ed., The Dow Chem Co, 1998.

[125] B.D. Kaushiva, Structure-Property Relationships Of Flexible Polyurethane Foams By, Virginia Polytechnic Institute and State University, 1999.

[126] X.Y. Liu, M.S. Zhan, K. Wang, Y. Li, Y.F. Bai, Preparation and performance of a novel polyimide foam, Polym. Adv. Technol. 23 (2012) 677-685. https://doi.org/10.1002/pat.1945.

[127] X.Y. Liu, M.S. Zhan, K. Wang, Preparation and characterization of electromagnetic interference shielding polyimide foam, J. Appl. Polym. Sci. 127 (2013) 4129-4137. https://doi.org/10.1002/app.37996.

[128] J. Ma, M. Zhan, K. Wang, Ultralightweight Silver Nanowires Hybrid Polyimide Composite Foams for High-Performance Electromagnetic Interference Shielding, ACS Appl. Mater. Interfaces. 7 (2015) 563-576. https://doi.org/10.1021/am5067095.

[129] F.L. Jin, X. Li, S.J. Park, Synthesis and application of epoxy resins: A review, J. Ind. Eng. Chem. 29 (2015) 1-11. https://doi.org/10.1016/j.jiec.2015.03.026.

[130] Q. Fabrizio, L. Santo, S.E. Anna, Shape memory epoxy foams for space applications, Mater. Lett. 69 (2012) 20-23. https://doi.org/10.1016/j.matlet.2011.11.050.

[131] K.S. Santhosh Kumar, R. Biju, C.P. Reghunadhan Nair, Progress in shape memory epoxy resins, React. Funct. Polym. 73 (2013) 421-430. https://doi.org/10.1016/j.reactfunctpolym.2012.06.009.

[132] X. Fan, G. Zhang, Q. Gao, J. Li, Z. Shang, H. Zhang, Y. Zhang, X. Shi, J. Qin, Highly expansive, thermally insulating epoxy/Ag nanosheet composite foam for electromagnetic interference shielding, Chem. Eng. J. 372 (2019) 191-202. https://doi.org/10.1016/j.cej.2019.04.069.

[133] C. Méjean, L. Pometcu, R. Benzerga, A. Sharaiha, C. Le Paven-Thivet, M. Badard, P. Pouliguen, Electromagnetic absorber composite made of carbon fibers loaded epoxy foam for anechoic chamber application, Mater. Sci. Eng. B Solid-State Mater. Adv. Technol. 220 (2017) 59-65. https://doi.org/10.1016/j.mseb.2017.03.009.

[134] Reichspatentamt, Patentschrift N728981, (1942).

[135] O. Bayer, Das Di-isocyanat-polyadditionsverfahren (Polyurethane), Angew. Chem. 59 (1947) 257-288.

[136] A. Peeters, R. Ameloot, D.E. De Vos, Carbon dioxide as a reversible amine-protecting agent in selective Michael additions and acylations, Green Chem. 15 (2013) 1550-1557.

[137] D. A. Unruh, S. J. Pastine, J. C. Moreton, J.M.J. Fréchet, Thermally activated, single component epoxy systems, Macromolecules. 44 (2011) 6318-6325.

[138] T. Nishikubo, E. Takehara, A. Kameyama, Novel thermal curing reactions of epoxy resin and polyurethane oligomers using photo-generated poly-functional amines, Polym. J. 25 (1993) 421-425.

[139] T. Nishikubo, E. Takehara, A. Kameyama, Photogeneration of polyfunctional amines and novel thermal curing reactions of epoxy resin and polyurethane oligomer using these amines, J. Polym. Sci. Part A Polym. Chem. 31 (1993) 3013-3020. https://doi.org/10.1002/pola.1993.080311217.

[140] K. Arimitsu, Y. Takemori, A. Nakajima, A. Oguri, M. Furutani, T. Gunji, Y. Abe, Photobase generators derived from trans-o-coumaric acid for anionic UV curing systems without gas generation, J. Polym. Sci. Part A Polym. Chem. 53 (2015) 1174-1177. https://doi.org/10.1002/pola.27552.

[141] C.G. Bochet, Photolabile protecting groups and linkers, J. Chem. Soc. Perkin 1. 2 (2002) 125142. https://doi.org/10.1039/b009522m.

[142] I. S. Bechara, US4542214 Carbamate and carbonate salts of tertiary amines, United State Pat. (1985).

[143] O. Coulembier, S. Moins, R. Todd, P. Dubois, External and reversible CO2 regulation of ring- 
opening polymerizations based on a primary alcohol propagating species, Macromolecules. 47 (2014) 486-491. https://doi.org/10.1021/ma4024944.

[144] Q. Ren, H. Xu, Q. Yu, S. Zhu, Development of epoxy foaming with CO2 as latent blowing agent and principle in selection of amine curing agent, Ind. Eng. Chem. Res. 54 (2015) 1105611064.

[145] C. Bethke, S. A. Sanchez-Vazquez, D. Raps, G. Bakis, S. Bard, U. L. D. Ngoc, A. Volker, Effect of resin and blocked/unblocked hardener mixture on the production of epoxy foams with CO2 blocked hardener in batch foaming process, Polymers. 11 (2019) 793-819.

[146] X. Da, C. Liu, Y. Long, X. Xie, Polyurethane foaming with CO\$_ $\{2\} \$$ adducts from C\$_ $\{8\} \$$ alkyl grafted polyethyleneimines: Optimization of the grafting rate and application of the blowing agents, J. Appl. Polym. Sci. 137 (22) (2019) 48752.

[147] Y. Long, X.X. J. An, CO2-releasing blowing agents from modified polyethylenimines slightly consume isocyanate groups while foaming polyurethanes, Arab. J. Chem. 13 (2020) 32263235.

[148] C. Liu, Y. Long, J. Xie, X. Xie, Toward green polyurethane foams via renewable castor oilderived polyol and carbon dioxide releasing blowing agents from alkylated polyethylenimines, Polymer. 116 (2017) 240-250.

[149] K.E. Krakowiak, J.S. Bradshaw, Thermal Removal of Boc-Protecting Groups During Preparation of Open-Chain Polyamines, Synth. Commun. 26 (1996) 3999-4004.

[150] D.M. Wirth, A. Jaquez, S. Gandarilla, J.D. Hochberg, D.C. Church, J.K. Pokorski, Highly Expandable Foam for Lithographic 3D Printing, ACS Appl. Mater. Interfaces. 12 (2020) 19033-19043.

[151] P.M. Hergenrother, H.H. Levine, Phenyl-substituted polyquinoxalines, J. Polym. Sci. Part A-1 Polym. Chem. 5 (1967) 1453-1466. https://doi.org/10.1002/pol.1967.150050626.

[152] W. Volksen, R.D. Miller, G. Dubois, Low Dielectric Constant Materials, Chem. Rev. 110 (2010) 56-110.

[153] J. F. Wolfe, F. E. Arnold, Rigid-rod polymers. 1. Synthesis and thermal properties of paraaromatic polymers with 2,6-benzobisoxazole units in the main chain, Macromolecules. 14 (1981) 909-915.

[154] V. V. Korshak, S.-S.A. Pavlova, P.N. Gribkova, I.V. Vlasova, A.M. Berlin, Y.S. Krongauz, N.M. Kofman, Thermal-oxidative breakdown of polyphenyl quinoxaline, Polym. Sci. U.S.S.R. 19 (1977) 740-745.

[155] J. F. Wolfe, B. H. Loo, F. E. Arnold, Rigid-rod polymers. 2. Synthesis and thermal properties of para-aromatic polymers with 2,6-benzobisthiazole units in the main chain, Macromolecules. 14 (1981) 915-920.

[156] D. Shamiryan, T. Abell, F. Iacopi, K. Maex, Low-k dielectric materials, Mater. Today. 7 (2004) 34-39. https://doi.org/10.1016/S1369-7021(04)00053-7.

[157] M.M. Hansen, J.R. Riggs, A novel protecting group for hindered phenols, Tetrahedron Lett. 39 (1998) 2705-2706. https://doi.org/10.1016/S0040-4039(98)00411-0.

[158] S. Merlet, C. Marestin, F. Schiets, O. Romeyer, R. Mercier, Preparation and characterization of nanocellular poly(phenylquinoxaline) foams. A new approach to nanoporous high-performance polymers, Macromolecules. 40 (2007) 2070-2078.

[159] B. Krause, H.J.P. Sijbesma, P. Münüklü, N.F.A. van der Vegt, M. Wessling, Bicontinuous Nanoporous Polymers by Carbon Dioxide Foaming, Macromolecules. 34 (2001) 8792-8801. https://doi.org/10.1021/ma010854j.

[160] T. Fukumaru, T. Fujigaya, N. Nakashima, Design and preparation of porous polybenzoxazole films using the tert-butoxycarbonyl group as a pore generator and their application for patternable low-k materials, Polym. Chem. 3 (2012) 369-376.

[161] M. Iseki, Y. Hiraoka, C. Jing, H. Okamura, E. Sato, A. Matsumoto, Effect of glass transition temperature on heat-responsive gas bubbles formation from polymers containing tertbutoxycarbonyl moiety, J. Appl. Polym. Sci. 135 (2018) 46252.

[162] C. Jing, Y. Suzuki, A. Matsumoto, Thermal decomposition of methacrylate polymers containing tert-butoxycarbonyl moiety, Polym. Degrad. Stab. 166 (2019) 145-154.

[163] G.A. Olah, Mechanism of Electrophilic Aromatic Substitutions1, Acc. Chem. Res. 4 (1971) 240-248. https://doi.org/10.1021/ar50043a002. 
[164] J. Clayden, N. Greeves, S. Warren, Organic Chemistry, 2nd ed., 2012.

[165] C.C. Price, The alkylation of aromatic compounds by the Friedel-Crafts Method, in: Wiley (Ed.), Org. React., 2011.

[166] Z. Li, J. Xu, D. Sun, T. Lin, F. Huang, Nanoporous Carbon Foam for Water and Air Purification, ACS Appl. Nano Mater. 3 (2020) 1564-1570. https://doi.org/10.1021/acsanm.9b02347.

[167] L. Wöckel, A. Seifert, C. Mende, I. Roth-Panke, L. Kroll, S. Spange, Resin and carbon foam production by cationic step-growth polymerization of organic carbonates, Polym. Chem. 8 (2017) 404-413. https://doi.org/10.1039/c6py01572g.

[168] J. Kojima, T. Takada, F. Jinno, Thin microcellular plastic sheet incorporating designed foaming patterns made by photochemical foaming technology, J. Cell. Plast. 43 (2007) 103109. https://doi.org/10.1177/0021955X06076573.

[169] P. Rattanakawin, W. Fan, S. Yamago, K. Yoshimoto, M. Ohshima, Synthesis of Photocleavable Block Copolymers for UV Induced Foaming, J. Photopolym. Sci. Technol. 31 (2018) 647-650. https://doi.org/10.2494/photopolymer.31.647.

[170] P. Rattanakawin, K. Yamamura, K. Yoshimoto, M. Ohshima, Development and optimization of uv-induced chemical foaming process, J. Photopolym. Sci. Technol. 32 (2019) 693-698. https://doi.org/10.2494/photopolymer.32.693.

[171] P. Rattanakawin, K. Yoshimoto, Y. Hikima, A. Chandra, T. Hayakawa, M. Tosaka, S. Yamago, M. Ohshima, Highly Ordered Nanocellular Polymeric Foams Generated by UVInduced Chemical Foaming, ACS Macro Lett. 9 (2020) 1433-1438. https://doi.org/10.1021/acsmacrolett.0c00475.

[172] S. Liu, J. Duvigneau, G.J. Vancso, Nanocellular polymer foams as promising high performance thermal insulation materials, Eur. Polym. J. 65 (2015) 33-45. https://doi.org/10.1016/j.eurpolymj.2015.01.039.

[173] J. Pinto, M. Dumon, M.A. Rodriguez-Perez, R. Garcia, C. Dietz, Block copolymers selfassembly allows obtaining tunable micro or nanoporous membranes or depth filters based on PMMA; Fabrication method and nanostructures, J. Phys. Chem. C. 118 (2014) 4656-4663. https://doi.org/10.1021/jp409803u.

[174] N. El-Atab, N. Qaiser, H. Badghaish, S.F. Shaikh, M.M. Hussain, M.M. Hussain, Flexible Nanoporous Template for the Design and Development of Reusable Anti-COVID-19 Hydrophobic Face Masks, ACS Nano. 14 (2020) 7659-7665. https://doi.org/10.1021/acsnano.0c03976.

[175] C.A. Orr, J.J. Cernohous, P. Guegan, A. Hirao, H.K. Jeon, C.W. Macosko, Homogeneous reactive coupling of terminally functional polymers, Polymer. 42 (2001) 8171-8178. https://doi.org/10.1016/S0032-3861(01)00329-9.

[176] P. Guégan, C.W. Macosko, T. Ishizone, A. Hirao, S. Nakahama, Kinetics of Chain Coupling at Melt Interfaces, Macromolecules. 27 (1994) 4993-4997. https://doi.org/10.1021/ma00096a022.

[177] L.W. Clark, The kinetics of the decomposition of oxalic acid in non-aqueous solvents, J. Phys. Chem. 61 (1957) 699-701.

[178] L.W. Clark, Kinetic studies on the decarboxylation of several unstable acids in the molten state, J. Phys. Chem. 67 (1963) 138-140. https://doi.org/10.1021/j100795a033.

[179] L.J. Gooßen, K. Gooßen, N. Rodríguez, M. Blanchot, C. Linder, B. Zimmermann, New catalytic transformations of carboxylic acids, Pure Appl. Chem. 80 (2008) 1725-1733. https://doi.org/10.1351/pac200880081725.

[180] L.J. Gooßen, N. Rodríguez, A mild and efficient protocol for the conversion of carboxylic acids to olefins by a catalytic decarbonylative elimination reaction, Chem. Commun. 4 (2004) 724-725. https://doi.org/10.1039/b316613a.

[181] S. Cadot, N. Rameau, S. Mangematin, C. Pinel, L. Djakovitch, Preparation of functional styrenes from biosourced carboxylic acids by copper catalyzed decarboxylation in PEG, Green Chem. 16 (2014) 3089-3097. https://doi.org/10.1039/c4gc00256c.

[182] F. Van Der Klis, M.H. Van Den Hoorn, R. Blaauw, J. Van Haveren, D.S. Van Es, Oxidative decarboxylation of unsaturated fatty acids, Eur. J. Lipid Sci. Technol. 113 (2011) 562-571. https://doi.org/10.1002/ejlt.201000126.

[183] K. J. Pedersen, The ketonic decomposition of beta-keto carboxylic acids, J. Am. Chem. Soc. 51 
(1929) 2098-2107.

[184] G.A. Hall, The Kinetics of the decomposition of malonic acid in aqueous solution, J. Am. Chem. Soc. 71 (1949) 2691-2693.

[185] J. Kenyon, W.A. Ross, 749. The mechanism of the decarboxylation of substituted malonic acid derivatives, J. Chem. Soc. (1951) 3407. https://doi.org/10.1039/jr9510003407.

[186] H. Schenkel, M. Schenkel-Rudin, Beitrag zum Problem der Decarboxylierung. 3. Mitteilung. Theoretische Betrachtungen zum Problem der Decarboxylierungsreaktion, Helv. Chim. Acta. 31 (1948) 514-524. https://doi.org/10.1002/hlca.19480310231.

[187] E. Dogan, S. Küsefoglu, Synthesis and in situ foaming of biodegradable malonic acid ESO polymers, J. Appl. Polym. Sci. 110 (2008) 1129-1135.

[188] M. Arslan, B. Kiskan, Y. Yagci, Ring-Opening Polymerization of 1,3-Benzoxazines via Borane Catalyst, Polymers. 10 (2018) 239. https://doi.org/10.3390/polym10030239.

[189] N.N. Ghosh, B. Kiskan, Y. Yagci, Polybenzoxazines - New high performance thermosetting resins: Synthesis and properties, Prog. Polym. Sci. 32 (2007) 1344-1391. https://doi.org/10.1016/j.progpolymsci.2007.07.002.

[190] C. Zúñiga, M.S. Larrechi, G. Lligadas, J.C. Ronda, M. Galià, V. Cádiz, Phosphorus flame retardant polybenzoxazine foams based on renewable diphenolic acid, Polym. Degrad. Stab. 98 (2013) 2617-2626. https://doi.org/10.1016/j.polymdegradstab.2013.09.023.

[191] C. Zúniga, M. S. Larrechi, G. Lligadas, J. C. Ronda, M. Galiá, V. Cádiz, Polybenzoxazines from renewable diphenolic acid, J. Polym. Sci. Part A Polym. Chem. 49 (2011) 1219-1227.

[192] R. Andreu, J.A. Reina, J.C. Ronda, Carboxylic acid-containing benzoxazines as efficient catalysts in the thermal polymerization of benzoxazines, J. Polym. Sci. Part A Polym. Chem. 46 (2008) 6091-6101. https://doi.org/10.1002/pola.22921.

[193] Z. Feng, M. Zeng, D. Meng, J. Chen, W. Zhu, Q. Xu, J. Wang, A novel bio-based benzoxazine resin with outstanding thermal and superhigh-frequency dielectric properties, J. Mater. Sci. Mater. Electron. (2020).

[194] Z. Feng, M. Zeng, D. Meng, W. Zhu, Y. Liu, X. Huang, Novel recoverable porous magnetic carbons derived from biobased polybenzoxazine by self-foaming and activation treatment, Colloids Surfaces A. 591 (2020) 124559.

[195] L. Xu, S. Jiang, B. Li, W. Hou, G. Li, M.A. Memon, Y. Huang, J. Geng, Graphene Oxide: A Versatile Agent for Polyimide Foams with Improved Foaming Capability and Enhanced Flexibility, Chem. Mater. 27 (2015) 4358-4367. https://doi.org/10.1021/acs.chemmater.5b00981.

[196] L. Claes, M. Janssen, D.E. De Vos, Organocatalytic Decarboxylation of Amino Acids as a Route to Bio-based Amines and Amides, ChemCatChem. 11 (2019) 4297-4306. https://doi.org/10.1002/cctc.201900800.

[197] A.N. Meldrum, Beta-Lactonic Acid from Acetone and Malonic Acid, J. Chem. Soc. Trans. 93 (1908) 598-601.

[198] D. Davidson, S. A. Bernhard, The Structure of Meldrum's Supposed B-Lactonic Acid, J. Am. Chem. Soc. 70 (1948) 3426-3428.

[199] A.E.A.M. Gaber, H. McNab, Synthetic applications of the pyrolysis of Meldrum's acid derivatives, Synthesis (Stuttg). (2001) 2059-2074. https://doi.org/10.1055/s-2001-18057.

[200] L. Yuan, L. He, Y. Wang, X. Lang, F. Yang, Y. Zhao, H. Zhao, Two- And Three-Component Post-Polymerization Modifications Based on Meldrum's Acid, Macromolecules. 53 (2020) 3175-3181. https://doi.org/10.1021/acs.macromol.0c00482.

[201] C. H. Huang, Y.L. Liu, The Michael addition reaction of Meldrum's acid (MA): an effective route for the preparation of reactive precursors for MA-based thermosetting resins, Polym. Chem. 10 (2019) 1873-1881.

[202] C.-H. Huang, Y.-L. Liu, Self-polymerization of Meldrum's acid-amine compounds: an effective route for polyamides, Polym. Chem. (2020). https://doi.org/10.1039/d0py01341b.

[203] A.S. Ivanov, Meldrum's acid and related compounds in the synthesis of natural products and analogs, Chem. Soc. Rev. 37 (2008) 789-811. https://doi.org/10.1039/b716020h.

[204] M.A.M. Filho, L.L.B. de Santana, R. Rivelino, S. Cunha, A theoretical investigation on the nucleophilic behavior of Meldrum's acid linked to experimental evidences, Chem. Phys. Lett. 738 (2020) 136908. https://doi.org/10.1016/j.cplett.2019.136908. 
[205] K.L. Diehl, I. V. Kolesnichenko, S.A. Robotham, J.L. Bachman, Y. Zhong, J.S. Brodbelt, E. V. Anslyn, Click and chemically triggered declick reactions through reversible amine and thiol coupling via a conjugate acceptor, Nat. Chem. 8 (2016) 968-973. https://doi.org/10.1038/nchem.2601.

[206] F.A. Leibfarth, C.J. Hawker, The emerging utility of ketenes in polymer chemistry, J. Polym. Sci. Part A Polym. Chem. 51 (2013) 3769-3782. https://doi.org/10.1002/pola.26797.

[207] F.A. Leibfarth, M. Kang, M. Ham, J. Kim, L.M. Campos, N. Gupta, B. Moon, C.J. Hawker, A facile route to ketene-functionalized polymers for general materials applications, Nat. Chem. 2 (2010) 207-212. https://doi.org/10.1038/nchem.538.

[208] J.S.A. Ishibashi, J.A. Kalow, Vitrimeric Silicone Elastomers Enabled by Dynamic Meldrum's Acid-Derived Cross-Links, ACS Macro Lett. 7 (2018) 482-486.

https://doi.org/10.1021/acsmacrolett.8b00166.

[209] D.A. Gopakumar, D. Pasquini, M.A. Henrique, L.C. De Morais, Y. Grohens, S. Thomas, Meldrum's acid modified cellulose nanofiber-based polyvinylidene fluoride microfiltration membrane for dye water treatment and nanoparticle removal, ACS Sustainable Chem. Eng. 5 (2017) 2026-2033. https://doi.org/10.1021/acssuschemeng.6b02952.

[210] Y. Chen, L.K. Lin, S.J. Chiang, Y.L. Liu, A Cocatalytic Effect between Meldrum's Acid and Benzoxazine Compounds in Preparation of High Performance Thermosetting Resins, Macromol. Rapid Commun. 38 (2017) 1600616. https://doi.org/10.1002/marc.201600616.

[211] L.K. Lin, C.C. Hu, W.C. Su, Y.L. Liu, Thermosetting resins with high fractions of free volume and inherently low dielectric constants, Chem. Commun. 51 (2015) 12760-12763. https://doi.org/10.1039/c5cc03899e.

[212] H. K. Lin, Y. S. Lai, Y.L. Liu, Cross-linkable and self-foaming polysulfide materials for repairable and mercury capture applications, ACS Sustainable Chem. Eng. 7 (2019) 45154522.

[213] T. Hasell, D.J. Parker, H.A. Jones, T. McAllister, S.M. Howdle, Porous inverse vulcanised polymers for mercury capture, Chem. Commun. 52 (2016) 5383-5386.

[214] L. Wang, A. Hu, L. Fan, S. Yang, Structures and properties of closed-cell polyimide rigid foams, J. Appl. Polym. Sci. 130 (2013) 3282-3291. https://doi.org/10.1002/app.39567.

[215] R. Torrecillas, N. Regnier, B. Mortaigne, Thermal degradation of bismaleimide and bisnadimide networks - products of thermal degradation and type of crosslinking points, Polym. Degrad. Stab. 51 (1996) 307-318. https://doi.org/10.1016/0141-3910(95)00197-2.

[216] N. Amutha, M. Sarojadevi, Synthesis and characterization of pyridine and anthracene containing bismaleimides, bisnadimides and polyaspartimides, J. Polym. Res. 15 (2008) 487499. https://doi.org/10.1007/s10965-008-9193-3.

[217] Y. Xu, L. Guo, H. Zhang, H. Zhai, H. Ren, Research status, industrial application demand and prospects of phenolic resin, RSC Adv. 9 (2019) 28924-28935. https://doi.org/10.1039/C9RA06487G.

[218] C. Mougel, T. Garnier, P. Cassagnau, N. Sintes-Zydowicz, Phenolic foams: A review of mechanical properties, fire resistance and new trends in phenol substitution, Polymer. 164 (2019) 86-117. https://doi.org/10.1016/j.polymer.2018.12.050.

[219] J. Rex Whinfield, J. Tennant Dickson, US2465319 Polymeric Linear Terephtalic esters, United State Pat. (1945).

[220] F.I. Kenmore, US2534028 Production of Polyethylene Terephtalate, United State Pat. (1948).

[221] W.G. Joslyn, US3823098 Foaming Unsaturated Polyester Resins, United State Pat. (1971).

[222] J. Haberl, W. Krause, WO2017178500A1 Process for producing an open cell thermoplastic foam, World Intellect. Prop. (2016).

[223] A.H. Alberts, G. Rothenberg, Plantics-GX: A biodegradable and cost-effective thermoset plastic that is $100 \%$ plant-based, Faraday Discuss. 202 (2017) 111-120. https://doi.org/10.1039/c7fd00054e.

[224] Plantics B.V., (n.d.). https://plantics.nl/.

[225] W.J. Jackson, H.F. Kuhfuss, Liquid crystal polymers, I. Preparation and properties of phydroxybenzoic acid copolyesters, J. Polym. Sci. Part A Polym. Chem. 34 (1996) 3031-3046. https://doi.org/10.1002/pola.1996.863.

[226] D. Frich, K. Goranov, L. Schneggenburger, J. Economy., Novel high-temperature aromatic 
copolyesters thermosets: synthesis, characterization, and physical properties, Macromolecules. 29 (1996) 7734-7739.

[227] M. Bakir, C.N. Henderson, J.L. Meyer, J. Oh, N. Miljkovic, M. Kumosa, J. Economy, I. Jasiuk, Effects of environmental aging on physical properties of aromatic thermosetting copolyester matrix neat and nanocomposite foams, Polym. Degrad. Stab. 147 (2018) 49-56. https://doi.org/10.1016/j.polymdegradstab.2017.11.009.

[228] M. Bakir, J. L. Meyer, A. Sutrisno, J. Economy, I. Jasiuk., Aromatic thermosetting copolyester bionanocomposites as reconfigurable bone substitute materials: interfacial interactions between reinforcement particles and polymer network, Nat. Sci. Reports. 8(14869) (2018).

[229] D.K. Brandom, J.P. Desouza, D.G. Baird, G.L. Wilkes, New method for producing highperformance thermoplastic polymeric foams, J. Appl. Polym. Sci. 66 (1997) 1543-1550. https://doi.org/10.1002/(SICI)1097-4628(19971121)66:8<1543::AID-APP15>3.0.CO;2-4.

[230] X. Xi, A. Pizzi, C. Gerardin, H. Lei, X. Chen, S. Amirou, Preparation and Evaluation of Glucose Based Non-Isocyanate Polyurethane Self-Blowing Rigid Foams, Polymers. 11 (2019) 1802. https://doi.org/10.3390/polym11111802.

[231] X. Chen, X. Xi, A. Pizzi, E. Fredon, X. Zhou, J. Li, C. Gerardin, G. Du, Preparation and Characterization of Condensed Tannin Non-Isocyanate Polyurethane (NIPU) Rigid Foams by Ambient Temperature Blowing, Polymers. 12 (2020) 750. https://doi.org/10.3390/polym12040750.

[232] Xuedong Xi, Antonio Pizzi, Christine Gerardin, G. Du, Glucose-Biobased Non-Isocyanate Polyurethane Rigid Foams, J. Renew. Mater. 7 (2019) 301-312.

[233] T.-H. Hou, E.S. Weiser, E.J. Siochi, T.L. St. Clair, Processing Characteristics of TEEK Polyimide Foam, High Perform. Polym. 16 (2004) 487-504. https://doi.org/10.1177/0954008304039576.

[234] M.K. Williams, G.L. Nelson, J.R. Brenner, E.S. Weiser, T.L. St. Clair, High Performance Polyimide Foams, in: 2001: pp. 49-62. https://doi.org/10.1021/bk-2001-0797.ch005.

[235] E.S. Weiser, T.L. St Clair, US 6133330 Aromatic Polyimide Foams, 2000.

[236] E.S. Weiser, T.L. St Clair, US 6180746B1 Polyimide precursor solid residuum, 2001.

[237] C. Resewski, W. Buchgraber, Properties of new polyimide foams and polyimide foam filled honeycomb composites, Mater. Sci. Eng. Technol. 34 (2003) 365-369. https://doi.org/https://doi.org/10.1002/mawe.200390076.

[238] W. Volksen, Condensation polyimides: Synthesis, solution behavior, and imidization characteristics, in: High Perform. Polym., Springer-Verlag, Berlin/Heidelberg, 2006: pp. 111164. https://doi.org/10.1007/BFb0021198.

[239] W. Gu, G. Wang, M. Zhou, T. Zhang, G. Ji, Polyimide-Based Foams: Fabrication and Multifunctional Applications, ACS Appl. Mater. Interfaces. 12 (2020) 48246-48258. https://doi.org/10.1021/acsami.0c15771.

[240] M.I. Topchiashvili, T.F. Datsko, G.M. Kikvilashvili, L.A. Maisuradze, Foamed polymer semiconductor composition and a method of producing thereof US3956195, 1974.

[241] L. Domeier, M. Hunter, Epoxy Foam Encapsulant : Processing and Dielectric Characterization, (1999). https://doi.org/https://doi.org/10.2172/5988.

[242] P.M. Stefani, A.T. Barchi, J. Sabugal, A. Vazquez, Characterization of epoxy foams, J. Appl. Polym. Sci. 90 (2003) 2992-2996.

[243] S. Dworakowska, A. Cornille, D. Bogdal, B. Boutevin, S. Caillol, Formulation of bio-based epoxy foams from epoxidized cardanol and vegetable oil amine, Eur. J. Lipid Sci. Technol. 117 (2015) 1893-1902.

[244] C. Negrell, A. Cornille, P. de Andrade Nascimento, J.J. Robin, S. Caillol, New bio-based epoxy materials and foams from microalgal oil, Eur. J. Lipid Sci. Technol. 119 (2017) 1-13. https://doi.org/10.1002/ejlt.201600214.

[245] S. Agnihotri, S. Shukla, S.A. Pradeep, S. Pilla, Biobased thermosetting cellular blends: Exploiting the ecological advantage of epoxidized soybean oil in structural foams, Polymer. 177 (2019) 111-119. https://doi.org/10.1016/j.polymer.2019.05.063.

[246] M. Cavasin, S. Giannis, M. Salvo, V. Casalegno, M. Sangermano, Mechanical and thermal characterization of an epoxy foam as thermal layer insulation for a glass fiber reinforced polymer, J. Appl. Polym. Sci. 135 (2018) 1-7. https://doi.org/10.1002/app.46864. 
[247] Y. Chang, Y. Luo, C. Xu, J. Zhao, Polysilazane as a new foaming agent to prepare highstrength, low-density epoxy foam, R. Soc. Open Sci. 6 (2019) 182119.

[248] A. Cornille, S. Dworakowska, D. Bogdal, B. Boutevin, S. Caillol, A new way of creating cellular polyurethane materials: NIPU foams, Eur. Polym. J. 66 (2015) 129-138.

[249] L. Maisonneuve, O. Lamarzelle, E. Rix, E. Grau, H. Cramail, Isocyanate-Free Routes to Polyurethanes and Poly(hydroxy Urethane)s, Chem. Rev. 115 (2015) 12407-12439.

[250] G. Rokicki, P.G. Parzuchowski, M. Mazurek, Non-isocyanate polyurethanes: synthesis, properties, and applications, Polym. Adv. Technol. 26 (2015) 707-761.

[251] A. Cornille, C. Guillet, S. Benyahya, C. Negrell, S.C. B. Boutevin, Room temperature flexible isocyanate-free polyurethane foams, Eur. Polym. J. 84 (2016) 873-888.

[252] B. Grignard, S. Gennen, C. Jérôme, A. Kleij, C. Detrembleur, Advances in the use of $\mathrm{CO}_{2}$ as a renewable feedstock for the synthesis of polymers, Chem. Soc. Rev. 48 (2019) 4466-4514.

[253] N. Yadav, F. Seidi, D. Crespy, V. D’Elia, Polymers Based on Cyclic Carbonates as Trait d'Union Between Polymer Chemistry and Sustainable $\mathrm{CO}_{2}$ Utilization, ChemSusChem. 12 (2019) 724-754. https://doi.org/10.1002/cssc.201802770.

[254] J. H. Clark, T. J. Farmer, I. D. V. Ingram, Y. Lie, M. North, Renewable Self-Blowing NonIsocyanate Polyurethane Foams from Lysine and Sorbitol, European J. Org. Chem. 31 (2018) 4265-4271.

[255] L. Wöckel, T. Windberg, R. John, A. Seifert, S. Spange, Hierarchically structured carbon and silica by chemical foaming, Polym. Chem. 9 (2018) 1385-1396. https://doi.org/10.1039/c7py01888f.

[256] Dupont, Vespel Polyimide foam (Accessed March 2021), Https://Www.Dupont.Com/Knowledge/Vespel-Sf-Polyimide-Foam.Html. (n.d.). https://www.dupont.com/knowledge/vespel-sf-polyimide-foam.html.

[257] S. Chen, Y. Jiang, J. Chen, D. Wang, The Effects of Various Additive Components on the Sound Absorption Performances of Polyurethane Foams, Adv. Mater. Sci. Eng. 2015 (2015) 19. https://doi.org/10.1155/2015/317561.

[258] G.G. Karady, M. Argin, B. Shi, F. Rahmatian, A.H. Rose, Electrical properties of rigid pour polyurethane foam applied for high voltage insulation, in: 2003 IEEE PES Transm. Distrib. Conf. Expo. (IEEE Cat. No.03CH37495), IEEE, n.d.: pp. 870-874. https://doi.org/10.1109/TDC.2003.1335051.

[259] X. Liang, Y. Shen, Y. Liu, J. Wang, Y. Gao, S. Li, M. Wang, S. Gao, Investigations on the basic electrical properties of Polyurethane foam material, in: 2015 IEEE 11th Int. Conf. Prop. Appl. Dielectr. Mater., IEEE, 2015: pp. 863-866. https://doi.org/10.1109/ICPADM.2015.7295409.

[260] A. Demharter, Polyurethane rigid foam, a proven thermal insulating material for applications between $+130^{\circ} \mathrm{C}$ and $-196^{\circ} \mathrm{C}$, Cryogenics. 38 (1998) 113-117. https://doi.org/10.1016/S00112275(97)00120-3.

[261] Q. Li, L. Chen, J. Ding, J. Zhang, X. Li, K. Zheng, X. Zhang, X. Tian, Open-cell phenolic carbon foam and electromagnetic interference shielding properties, Carbon N. Y. 104 (2016) 90-105. https://doi.org/10.1016/j.carbon.2016.03.055.

[262] B. Koohbor, A. Kidane, Design optimization of continuously and discretely graded foam materials for efficient energy absorption, Mater. Des. 102 (2016) 151-161. https://doi.org/10.1016/j.matdes.2016.04.031.

[263] S. Yu, X. Li, M. Zou, Z. Li, S. Wang, D. Wang, Tetrafunctional Epoxy Resin-Based Buoyancy Materials: Curing Kinetics and Properties, Polymers. 12 (2020) 1732. https://doi.org/10.3390/polym12081732.

[264] P. Scarfato, L. Di Maio, L. Incarnato, Structure and physical-mechanical properties related to comfort of flexible polyurethane foams for mattress and effects of artificial weathering, Compos. Part B Eng. 109 (2017) 45-52. https://doi.org/10.1016/j.compositesb.2016.10.041.

[265] G.L.A. Sims, J.A. Bennett, Cushioning performance of flexible polyurethane foams, Polym. Eng. Sci. 38 (1998) 134-142. https://doi.org/10.1002/pen.10173.

[266] B.E. Obi, Polymeric Foams Structure-Property-Performance, Elsevier, 2018. https://doi.org/10.1016/C2012-0-06136-4.

[267] M. D’Auria, D. Davino, R. Pantani, L. Sorrentino, Polymeric foam-ferromagnet composites as 
smart lightweight materials, Smart Mater. Struct. 25 (2016) 055014. https://doi.org/10.1088/0964-1726/25/5/055014.

[268] L. Ma, J. Wang, J. Li, Y. Pang, J. He, L. Peng, Y. Li, K. Li, M. Qu, Intelligent composite foam with reversible tunable superwettability for efficient and sustainable oil/water separation and high-concentration organic wastewater purification, Process Saf. Environ. Prot. 149 (2021) 144-157. https://doi.org/10.1016/j.psep.2020.10.043.

[269] A. Baltopoulos, N. Athanasopoulos, I. Fotiou, A. Vavouliotis, V. Kostopoulos, Sensing strain and damage in polyurethane/MWCNT nano-composite foams using electrical measurements, Express Polym. Lett. 7 (2013) 40-54. https://doi.org/10.3144/expresspolymlett.2013.4.

[270] S. Cao, W. Zhu, T. Liu, Bio-inspired self-healing polymer foams with bilayered capsule systems, Compos. Sci. Technol. 195 (2020) 108189. https://doi.org/10.1016/j.compscitech.2020.108189.

[271] X. Yan, H. Li, A.R. Li, H. Zhang, Wearable IMU-based real-time motion warning system for construction workers' musculoskeletal disorders prevention, Autom. Constr. 74 (2017) 2-11. https://doi.org/10.1016/j.autcon.2016.11.007. 